Arrivoc

Free to Authors and Readers
A Platinum Open Access Journal for Organic Chemistry
Review

Arkivoc 2021, part ix, 75-129

\title{
3-Pyrazolines (2,3-dihydro-1H-pyrazoles): synthesis, reactivity, and physical and biological properties
}

\author{
Antonio de la Hoz, ${ }^{a}$ Rosa M. Claramunt, ${ }^{b}$ José Elguero, ${ }^{c}$ and Ibon Alkorta*c
}

a Universidad de Castilla-La Mancha, Facultad de Ciencias y Tecnologías Químicas, Avda. Camilo José Cela, 10, E-13071 Ciudad Real, Spain

${ }^{b}$ Departamento de Química Orgánica y Bio-Orgánica, Facultad de Ciencias, UNED, Senda del Rey 9, E-28040

Madrid, Spain

'Instituto de Química Médica, CSIC, Juan de la Cierva, 3, E-28006 Madrid, Spain

Email: ibon@iqm.csic.es

This paper is intended to honor Professors Alan R. Katritzky (Norwich \& Gainesville), André Maquestiau

(Mons) and Robert Jacquier (Montpellier) for their outstanding contributions to heterocyclic chemistry

Received 03-24-2021

Accepted 05-13-2021

Published on line $07-09-2021$

\section{Abstract}

This account provides a summary of the current knowledge on 3-pyrazolines, an important but rather neglected field of heterocyclic chemistry. The review is divided into sections on the synthesis, reactivity, structure and biological properties and covers the literature from 1937 to 2020. In an effort to clarify some results, theoretical calculations were carried out anew.

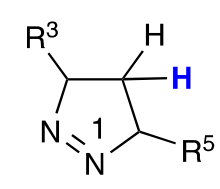

1-Pyrazoline

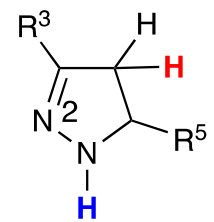

2-Pyrazoline

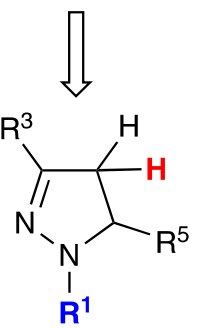

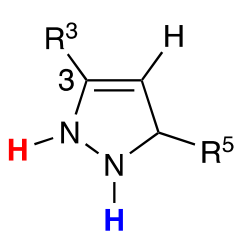

3-Pyrazoline

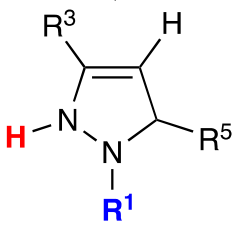

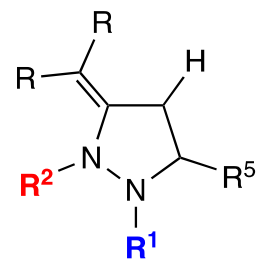

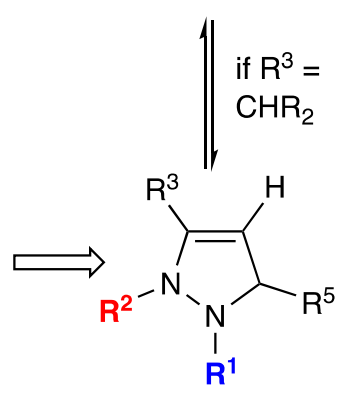

Keywords: Pyrazolines, dihydropyrazoles, tautomerism, protonation, NMR, X-ray structures 


\section{Table of Contents}

1. Introduction

2. Synthesis

2.1. From hydrazines and their derivatives $[(N N)+(C)+(C C)]$ and $[(N N)+(C C C)]$

2.1.1. Simple alkyl and aryl hydrazines

2.1.2. Hydrazides

2.1.2.1. Monosubstituted hydrazides

2.1.2.2. Disubstituted hydrazides. Open ring

2.1.2.3. Disubstituted hydrazides. Cyclic

2.2. By 1,3-dipolar cycloaddition [(NNC) + (CC)]

2.2.1. Diaziridines as azomethine imine precursors

2.2.2. 2-(Propan-2-ylidene)pyrazolidin-2-ium-1-ides

2.2.3. Diethyl azodicarboxylate and the Morrison-Brunn-Huisgen betaine

2.2.4. From sydnones and other 1,3-dipoles

2.2.5. 1,5-Electrocyclic reactions

2.3. Other methods

2.3.1. By reduction of pyrazoles, pyrazolones and pyrazolidinones

2.3.2. By reduction of pyrazolium salts

2.3.3. From other pyrazole derivatives

2.3.4. Non-conventional methods

3. Chemical Properties

3.1. Conformational analysis

3.2. Tautomerism and prototropy

3.3. Basicity, protonation and quaternization

3.4. Reactions on the nitrogen atoms

3.5. Reactions of the C-substituents

3.6. Reactions on the CC double bond

3.7. Oxidation

3.8. Reduction

3.9. Rearrangement

4. Structure, spectra, and physical properties

4.1. UV spectra

4.2. IR spectra

4.3. ${ }^{1} \mathrm{H}$ NMR spectra

4.4. ${ }^{13} \mathrm{C}$ NMR spectra

4.5. ${ }^{15} \mathrm{~N}$ and ${ }^{19} \mathrm{~F}$ NMR spectra

4.6. X-ray molecular structures

4.7. Computational results

5. Biological Properties

6. Conclusions 


\section{Introduction}

The compounds that are the subject of this review are called 3-pyrazolines, although they were previously known as $\Delta^{3}$-pyrazolines - similarly 2-pyrazolines were known as $\Delta^{2}$-pyrazolines. The IUPAC prefers the use of the Hantzsch-Widman nomenclature, in which these compounds are called dihydropyrazoles (Scheme 1).

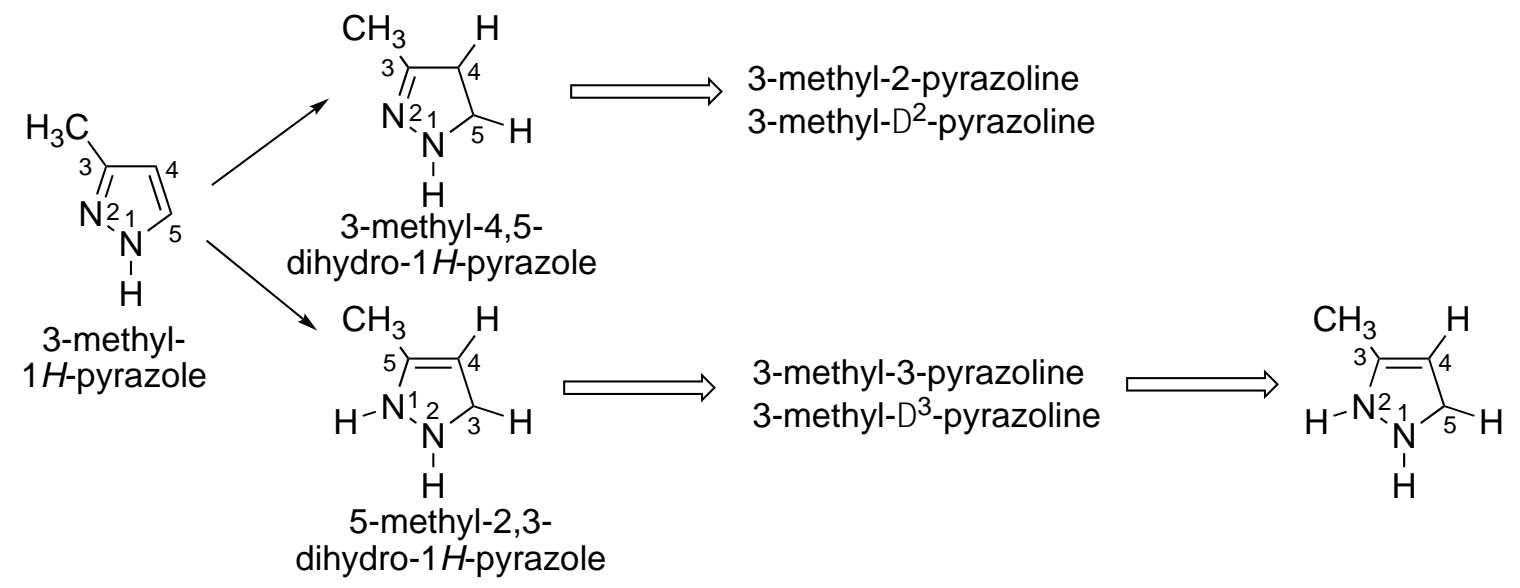

Scheme 1. Nomenclature and atom numbering.

The two nomenclature systems coexisted but finally the IUPAC abandoned the pyrazoline names and accepted the dihydropyrazole ones. However, pyrazoline continues to be used (for instance by the NIST), probably because it is shorter and more intuitive. The main advantage of the old names is that the numbering of the atoms is the same for 2-pyrazolines, for instance a 3-methyl substituent in a 2-pyrazoline maintains the numbering in a 2,3-dihydro- $1 \mathrm{H}$-pyrazole but not for 3-pyrazolines, e.g., 3-methyl-3-pyrazoline corresponds to 5 methyl-2,3-dihydro-1H-pyrazole. A search of the literature affords compounds that are named 3- or 4pyrazolines but are actually 2-pyrazolines, ${ }^{1-6}$ or 1-pyrazolines ${ }^{1,7-11}$ and 2,3-dihydro-1H-pyrazoles when they are 4,5-dihydro- $1 \mathrm{H}$-pyrazoles. This discrepancy in nomenclature made it difficult to search databases. ${ }^{12}$ Even in the Cambridge Structural Database ${ }^{13}$ there is at least one product (Refcode YAKYAK, no hydrogen atoms, Figure 1) that it is represented as a 3-pyrazoline $\mathbf{1}$ with an NH on N2 when the structure is that of a 2-pyrazoline $\mathbf{2}$ (with characteristic distances for the N1-N2-C-C fragment). It is worth noting that the authors reported this compound as the 2-pyrazoline $2 .{ }^{10}$ The structure of YAKYAK will be discussed again in Section 3.2.

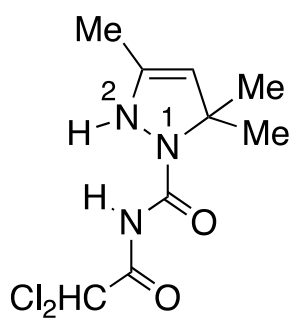

1

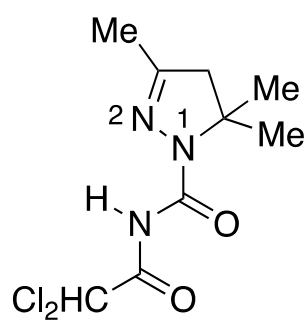

2

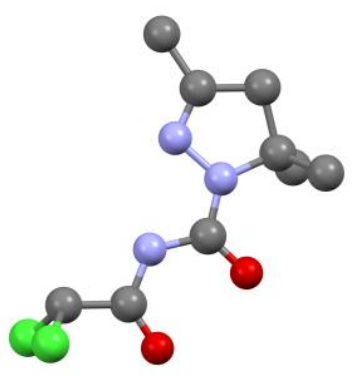

YAKYAK

Figure 1. The structures of YAKYAK. 
In the present review we decided to use the names 2-pyrazolines and 3-pyrazolines. Furthermore, the 2,3dihydro- $1 H$-indazoles (3), i.e., compounds in which the CC double bond is part of an aromatic ring (Figure 2), are excluded due to the loss of the enamine (or ene-hydrazine) reactivity of 3-pyrazolines as well as their character as a dipolarophile.

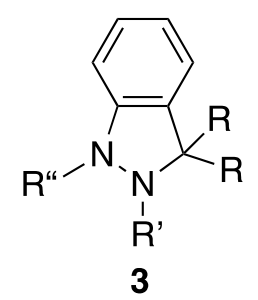

Figure 2. 2,3-Dihydro- $1 \mathrm{H}$-indazoles.

Pyrazoles, their oxidized derivatives, pyrazolones, and their reduced ones, pyrazolines and pyrazolidines, all form part of classical heterocyclic chemistry. Pyrazoles and pyrazolones are stable but pyrazolidines and, in particular, pyrazolines are easily oxidized. In addition to the sensitivity to oxidation, 3-pyrazolines 5 could isomerize to 2-pyrazolines $\mathbf{4}$ or $\mathbf{6}$ if substituents do not prevent this process, as in structures $\mathbf{7}$ and $\mathbf{8}$ (Scheme 2). This aspect will be discussed in detail in Section 3.2.

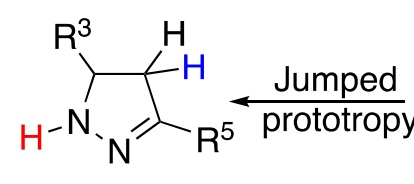

2-pyrazolines (4)

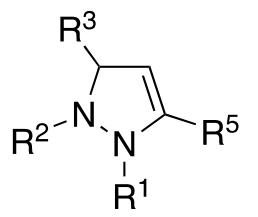

stable 1,2-disubstituted 3-pyrazolines (7)<smiles>[R3]C1=CC([R5])N([Hg])N1</smiles>

3-pyrazolines (5)<smiles>[R]C1=CC([R5])([Pb])N([R2])N1</smiles>

stable 2,5,5trisubstituted

3-pyrazolines (8)

Scheme 2. Prototropy and stability.

One final - but important - aspect of the chemistry of 3-pyrazolines is the acid-base relationship with 2pyrazolinium salts (Scheme 3). Several mechanisms to obtain 3-pyrazolines 9 proceed via 2-pyrazolinium salts, either directly from 10 or, after prototropy, from 11. 


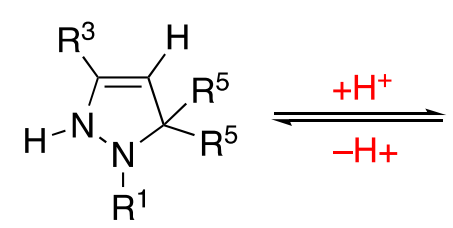

3-pyrazolines (9)

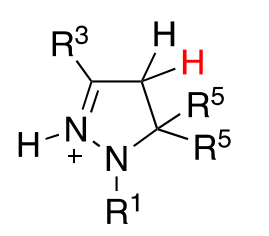

$1 \mathrm{R}^{1}, 2 \mathrm{H}$ -

2-pyrazolinium

salts (10)

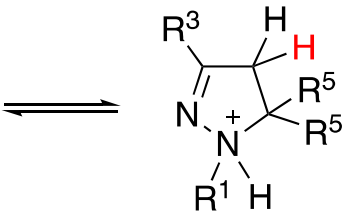

$1 \mathrm{R}^{1}, 1 \mathrm{H}^{-}$

2-pyrazolinium salts (11)

Scheme 3. Relationship between 3- and 2-pyrazolines through their pyrazolinium salts.

\section{Synthesis}

\subsection{From hydrazines and their derivatives $[(N N)+(C)+(C C)]$ and $[(N N)+(C C C)]$}

2.1.1. Simple alkyl and aryl hydrazines. Curiously, the first reported synthesis of a 3-pyrazoline was a threecomponent reaction although it was not recognized as such; ${ }^{14}$ this process is related to the Mannich reaction (replacing a secondary amine by a hydrazine) and it was reported by Hinman and subsequently became known as the Hinman reaction (Scheme 4). ${ }^{15}$ In this synthesis a carbonyl compound, like benzophenone, reacts with paraformaldehyde and 1,2-dimethylhydrazine dihydrochloride to afford pyrazoline $\mathbf{1 2}$. On using cyclanones, formaldehyde and 1,2-dimethylhydrazine the corresponding 1,2-dimethyl-3,4-polymethylene-3-pyrazolines were obtained. ${ }^{16}$

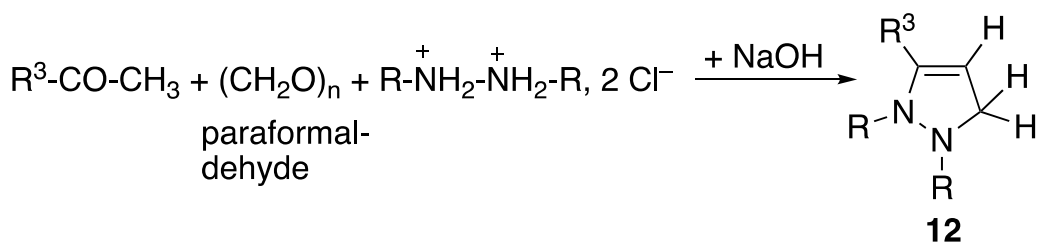

Scheme 4. Hinman reaction $[(N N)+(C)+(C C)]$.

The mechanism (Scheme 5) was elucidated by Aubagnac et al. ${ }^{17}$ through a series of experiments and using literature results on the synthesis of 2-pyrazolines. The conclusion was that the reaction follows pathway $\mathbf{c}$ in Scheme 5. The pyrazolinium salt $\mathbf{1 3}$ is the common intermediate in all of the hypothetical mechanisms.

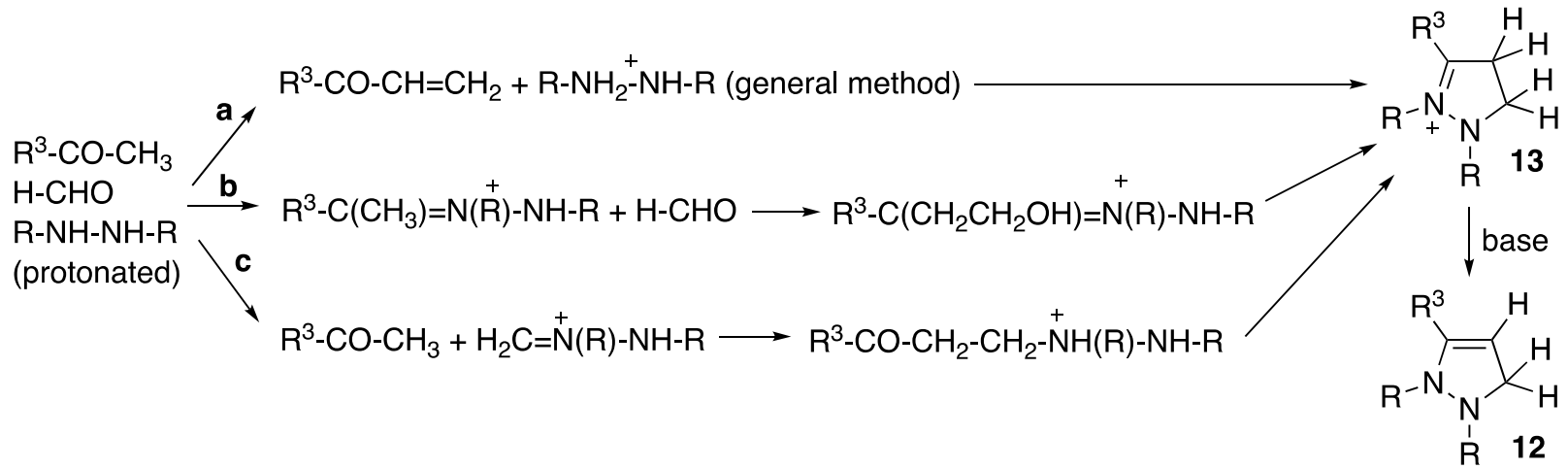

Scheme 5. The three possible mechanisms of the Hinman reaction. 
The Hinman method was widely used ${ }^{18-20}$ but it was soon superseded by the general method in which unsaturated carbonyl compounds (often $\alpha, \beta$-unsaturated ketones) react with 1,2-substituted hydrazines with a stoichiometric amount of a protic acid or an acid catalyst to afford 3-pyrazolines 12; In some cases the intermediate 1,2-disubstituted-2-pyrazolinium salts 13 were isolated. In the case of the Hinman reaction, formaldehyde can be replaced by another molecule of the same ketone to give 1,2,3,5,5-trisubstituted 3pyrazolines (pyrroles are also formed). ${ }^{21-23}$ One of the steps in the preparation of 3-pyrazolinium cations 13 took place by a disrotatory process. ${ }^{23}$ The transformation of 13 into 12 by the action of $\mathrm{NaOH}$ involves a 3-hydroxypyrazolidine 14 (Figure 3). ${ }^{24,25}$

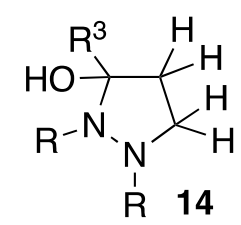

Figure 3. Structure of the 3-hydroxy-pyrazolidine 14.

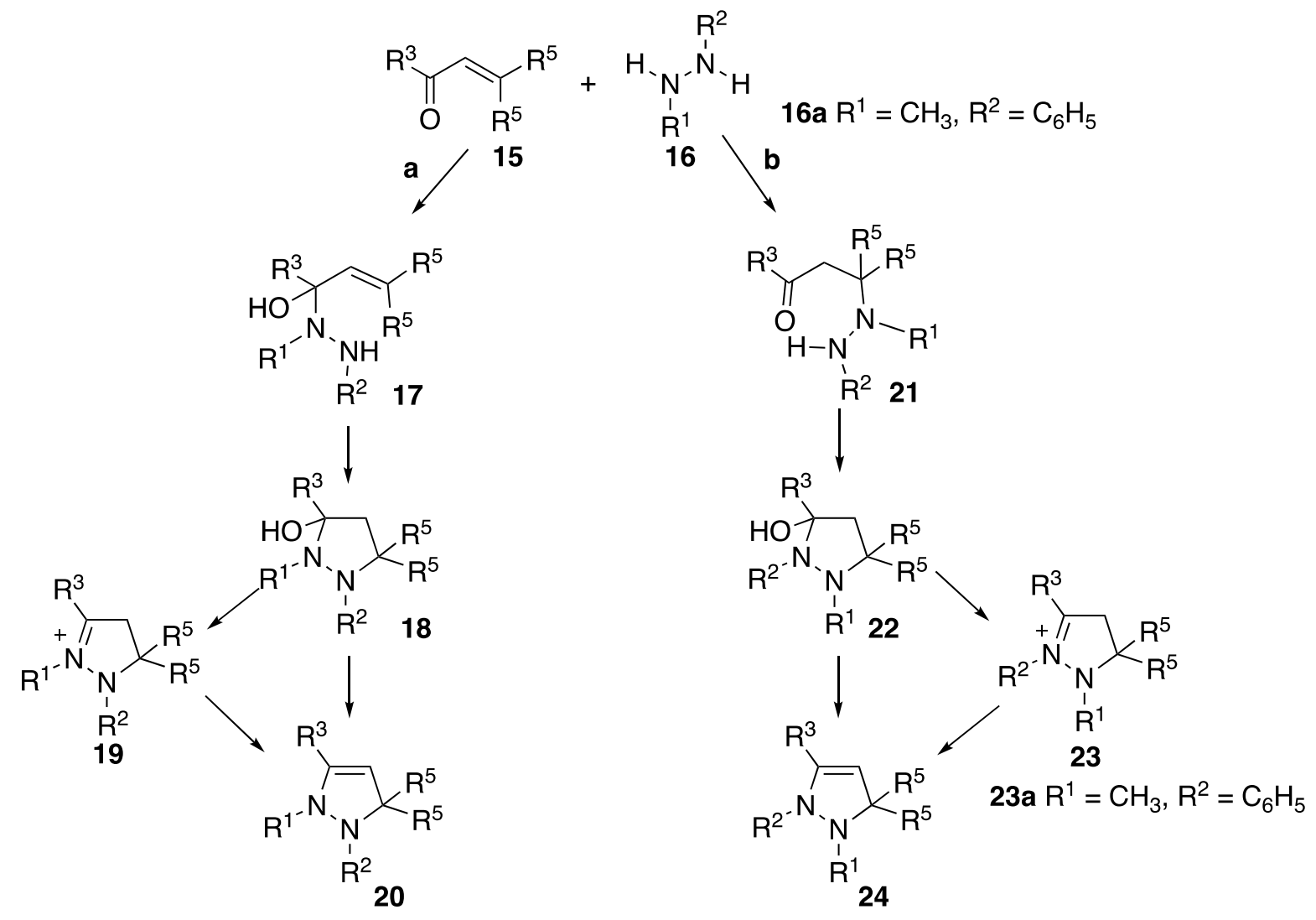

Scheme 6. Mechanism for the formation of 3-pyrazolines from $\alpha, \beta$-unsaturated carbonyl compounds [(NN) + $(\mathrm{CCC})]$.

The mechanism for the formation of $\mathbf{1 3}$ is the same as that for 2-pyrazolines. For a long time ${ }^{26}$ it was not clear which of the two NC bonds was formed first, i.e., $\mathbf{1 7}$ or $\mathbf{2 1}$ (Scheme 6). However, in 1970 it was established, using 1-methyl-2-phenylhydrazine (16a), that the initial step in the mechanism is a 1,4-addition of the more nucleophilic NHMe on the double bond of $\mathbf{1 5}$ (Scheme 6, pathway b). This was confirmed by Kenny and 
Robinson ${ }^{27,28}$ in the reaction between chalcone and phenylhydrazine to give 1,3,5-triphenyl-2-pyrazoline using Baldwin's rules (5-exo-trig is a favored ring closure while 5-endo-trig is not favored) ${ }^{29}$ and a very elegant labeling with ${ }^{13} \mathrm{C}$ on the chalcone and ${ }^{15} \mathrm{~N}$ on the phenylhydrazine. It should be noted that in Scheme 6 both pathways lead to the same compounds (pairs $\mathbf{1 8} / \mathbf{2 2}, \mathbf{1 9} / \mathbf{2 3}$, and $\mathbf{2 0 / 2 4}$ ) when $\mathrm{R}^{1}=\mathrm{R}^{2}$. Although Kenny and Robinson were not cited, ${ }^{27,28}$ other authors employed Baldwin's rules to explain the results obtained with methylhydrazine (21, $\left.\mathrm{R}^{1}=\mathrm{CH}_{3}, \mathrm{R}^{2}=\mathrm{H}\right) .^{30}$

The use of Baldwin's rules by Kenny and Robinson ${ }^{27,28}$ was questioned by List in 2010; he suggested that a more plausible mechanism would involve a pericyclic $6 \pi$-electrocyclization. ${ }^{31}$ Although both mechanisms will lead to different stereoisomers, the $N$-phenyl inversion will make them indistinguishable (Figure 4). We proposed the List electrocyclic mechanism for the synthesis of 2- and 3-pyrazolines in 1971 in a review entitled 'Synthesis and reactivity of pentagonal heterocycles: electrocyclic reactions and sigmatropic rearrangements". ${ }^{32}$
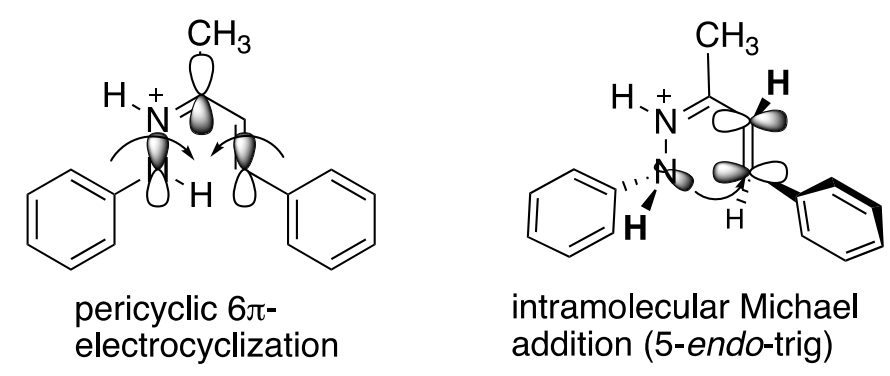

intramolecular Michael addition (5-endo-trig)

Figure 4. Two possible mechanistic scenarios.

Both the Hinman $[(N N)+(C)+(C C)]$ and Aubagnac $[(N N)+(C C C)]$ methods were used by Kostyanovsky et al. to prepare the sterically hindered 3-pyrazolines that were required to study their nitrogen inversion. ${ }^{33,34}$

1,3-Difunctional compounds ( $\beta$-dicarbonyls, $\beta$-ketoesters, and similar compounds) react with hydrazine to afford different types of pyrazoles. Amongst them are malononitriles that yield 3,5-diamino-1H-pyrazoles. ${ }^{26,35}$ Starting from a special derivative 25, 3-amino-2-phenyl-5,5-bis(trifluoromethyl)-3-pyrazoline-4-carbonitrile 26 was obtained (Scheme 7). ${ }^{36}$ Compound 26 belongs to class $\mathbf{8}$ (Scheme 2) and was found to be stable.

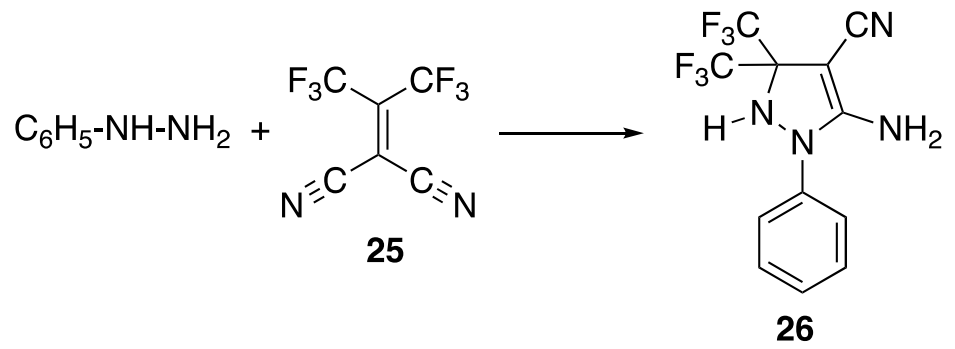

Scheme 7. Reaction of phenylhydrazine with malononitrile 25.

Müller and List reported chiral 3-pyrazolines as intermediates in the synthesis of chiral 2-pyrazolines (Scheme 8). ${ }^{37,31}$ A 6r-electrocyclization of protonated $\alpha, \beta$-unsaturated hydrazones 27 led to 1-protonated 3pyrazolines 28, which isomerized to 2-pyrazolines, with the chirality arising from the use of a chiral Brønsted acid used as catalyst. 
<smiles></smiles>

27<smiles>[R3]C1=C[C@@H](P)[NH+]([R7])N1</smiles>

28

Scheme 8. Müller and List mechanism.

Swarnkar et al. reacted chalcones with different hydrazines under microwave irradiation and obtained 3pyrazolines 29-33 (Figure 5). ${ }^{38}$ This result is very unexpected and the compounds were characterized by an $\mathrm{NH}$ band in the IR spectra and by two (30-33) or three (29) signals in the ${ }^{1} \mathrm{H}$ NMR spectra due to the $\mathrm{NH}$ and the saturated $\mathrm{CH}$ at position 5 . We have tried to repeat this work without success.<smiles>C/C=C\C</smiles><smiles>[R]CN1C(c2ccc(F)cc2)C=CN1c1ccccc1</smiles>

29<smiles>[R]c1ccc([C@H]2C=C(c3ccccc3)NN2C(=O)c2ccncc2)cc1</smiles>

31<smiles>[R]N1C(c2ccccc2)=CC(c2ccc(F)cc2)[C@H]1c1cccnc1</smiles>

32<smiles>[R]c1ccc([C@H]2C=C(c3ccccc3)NN2C(N)=S)cc1</smiles>

33

Figure 5. Swarnkar's 3-pyrazolines.

Jetti et al. followed an approach related to previous work but isolated the intermediate $\mathrm{NH}-3$-pyrazolines in the form of 2-formyl derivatives prior to obtaining 1-formyl-2H-3-pyrazolines 34 and 35 and 1-formyl-2R-3pyrazolines 36, 37, 38 and $\mathbf{3 9}$ (Figure 6). ${ }^{39}$ These structures warrant further exploration.<smiles>O=CN1NC(c2ccccc2)C=C1c1ccccc1</smiles>

34<smiles>O=CN1NC(c2ccccc2)C=C1c1cccnc1</smiles>

35

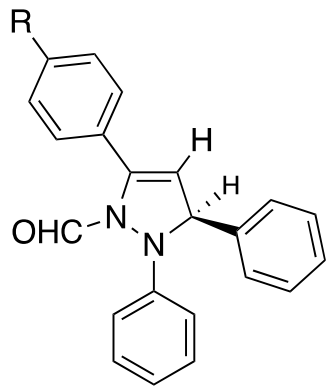

36, $\mathrm{R}=\mathrm{H}$

37, $\mathrm{R}=\mathrm{CH}_{3}$

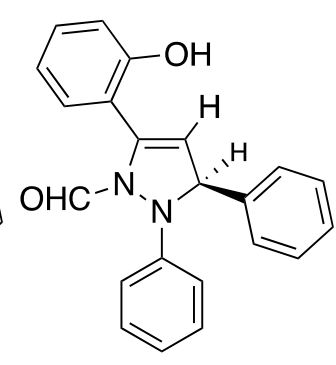

38<smiles>O=CN1C(c2cccnc2)=CC(c2ccccc2)N1c1ccccc1</smiles>

39

Figure 6. Jetti's 3-pyrazolines.

Kasabe et al. reacted thiosemicarbazide with rather unusual $\beta$-unsaturated ketones $\mathbf{4 0}$ (Scheme 9)..$^{40}$ The resulting pyrazolines $\mathbf{4 1}$ were characterized by IR and ${ }^{1} \mathrm{H}$ NMR spectroscopy but the position of the double bond remained ambiguous. 


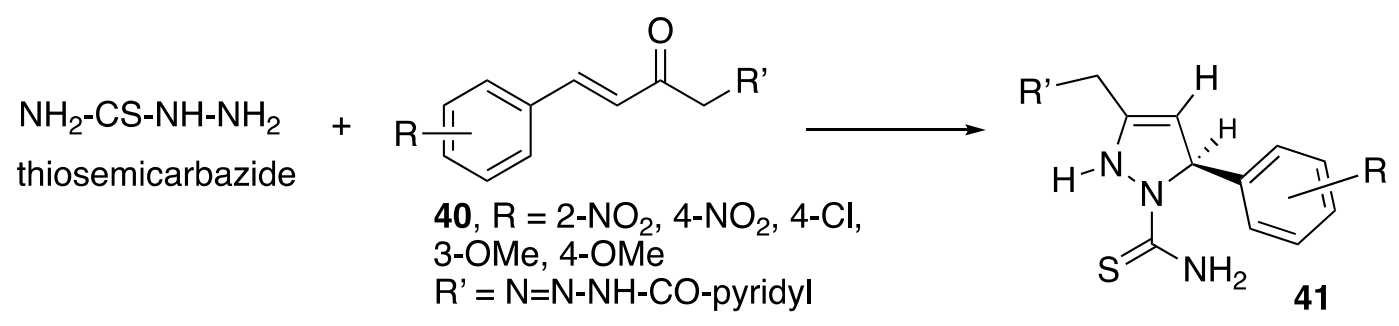

Scheme 9. Kasabe's 3-pyrazolines.

Burger et al. obtained 3-pyrazolines $\mathbf{4 3}$ by a criss-cross cycloaddition in which hexafluoroacetone azine $\mathbf{4 2}$ was reacted with acetylenes (Scheme 10). ${ }^{41,42}$ Pyrazolines $\mathbf{4 3}$ provide another example of compounds like $\mathbf{8}$ in Scheme 2. In this work we have included $[(N N C+C C)]$ at this point because hexafluoroacetone azine $\mathbf{4 2}$ is obtained from hexafluoroacetone and hydrazine. We have included this work in the [(NNC + CC)] section because hexafluoroacetone azine $\mathbf{4 2}$ is obtained from hexafluoroacetone and hydrazine.

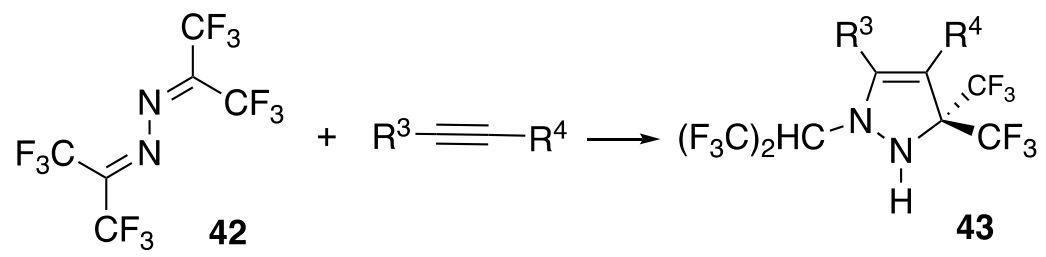

Scheme 10. Burger's 3-pyrazolines.

2.1.2. Hydrazides. The method involving hydrazides has been widely used, especially with phthalazine as the starting material. The presence of acyl substituents leads to a considerable decrease in the basicity of hydrazines and stabilizes 3-pyrazolines.

2.1.2.1. Monosubstituted hydrazides. A four-component reaction involving hydrazides, two acetylenic diesters and isocyanides affords highly substituted 3-pyrazolines 44 (Scheme 11). ${ }^{43}$

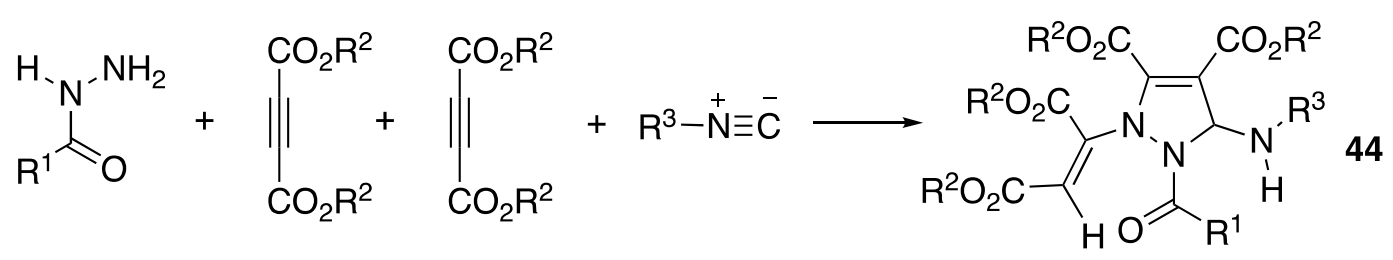

Scheme 11. Synthesis of 3-pyrazolines 44 from hydrazides.

As in other branches of chemistry, the natural evolution of synthetic methods is moving towards catalytic asymmetric synthesis. This approach was successfully applied to the synthesis of 45 starting from a monosubstituted hydrazide, $N^{\prime}$-benzylbenzohydrazide (Scheme 12). ${ }^{44}$ As in other synthetic methods, this reaction involves a reagent that is not isolated, namely an acyclic azomethine imine (Section 2.2). 
<smiles>O=C(NNCc1ccccc1)c1ccccc1</smiles>

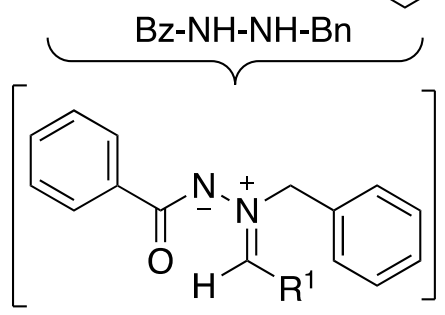

acyclic azomethine imine<smiles></smiles>

Scheme 12. Enantioselective synthesis of 3-pyrazolines 45.

$1 H$-Pyrazolin-5-ones 46 are related to monosubstituted hydrazides in the sense that they behave in a similar way (Scheme 13). The results provided in Scheme 13 represent an interesting way to prepare derivatives of pyrazolo[1,2-a]pyrazole $\mathbf{4 7}$ by a three-component reaction. ${ }^{45-47}$

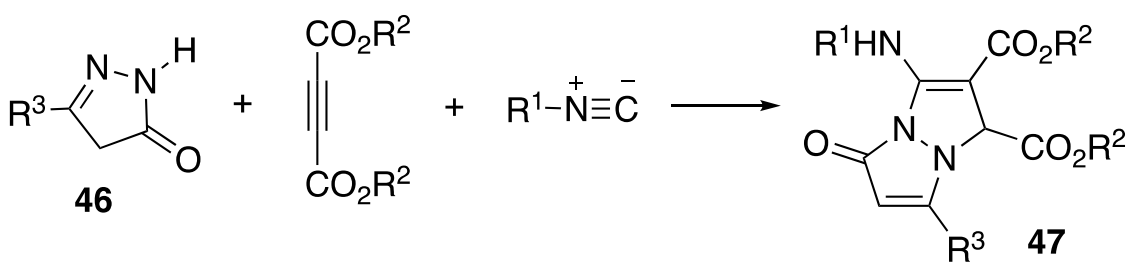

Scheme 13. Multicomponent synthesis of pyrazolo[1,2-a]pyrazoles 47 with a 3-pyrazoline structure.

2.1.2. Disubstituted hydrazides. Open ring. An efficient synthesis of 3 -pyrazolines 48 by a $P d(0)$-catalyzed coupling-cyclization reaction between 2-substituted 2,3-allenylhydrazides and aryl iodides was described by $\mathrm{Ma} ;{ }^{48}$ the reaction product (Scheme 14 ) was accompanied by small amounts of 1,2-diazetidines.<smiles>[R]c1ccc(CC2=CC(C(C)C)N(C(=O)OCC)C2=O)cc1Cc1ccc(I)cc1</smiles>

Scheme 14. Synthesis of 3-pyrazolines 48 from 2-substituted 2,3-allenylhydrazides.

The intramolecular cyclization of 1,2-Boc-substituted hydrazines bearing an alkyne substituent affords 3pyrazolines 49 (Scheme 15); the reaction scope has been extended to include enantioselective synthesis using a chiral phosphoric acid catalyst. ${ }^{49}$ 


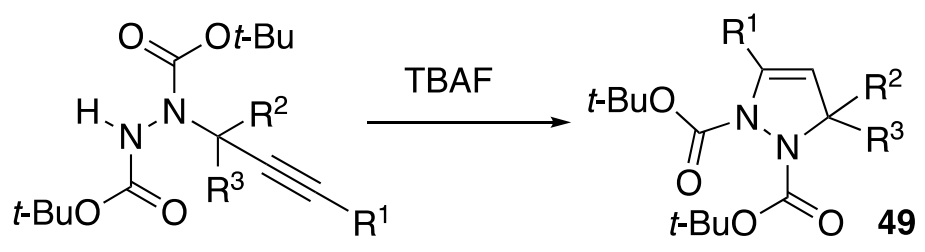

Scheme 15. Intramolecular cyclization of 1,2-Boc-substituted hydrazines.

2.1.2.3. Disubstituted hydrazides. Cyclic. This method is one of the most widely used $[(N N)+(C)+(C C)]$ or $[(N N)$ $+(\mathrm{CCC})$ ] pathways to 3-pyrazolines; the stability of hydrazides, the easy crystallization of aromatic compounds, and the accessibility of 2,3-dihydrophthalazine-1,4-diones all contribute to the success of this method (see Scheme 16). Although dione 50a is clearly the major tautomer (Scheme 16), some authors represent this compound as phthalazine-1,4-diol 50b, but this is irrelevant in terms of the reactivity. There are very few papers in which the use of the simplified derivative $\mathbf{5 1}$ (same problem with their tautomerism) has been reported. ${ }^{50}$

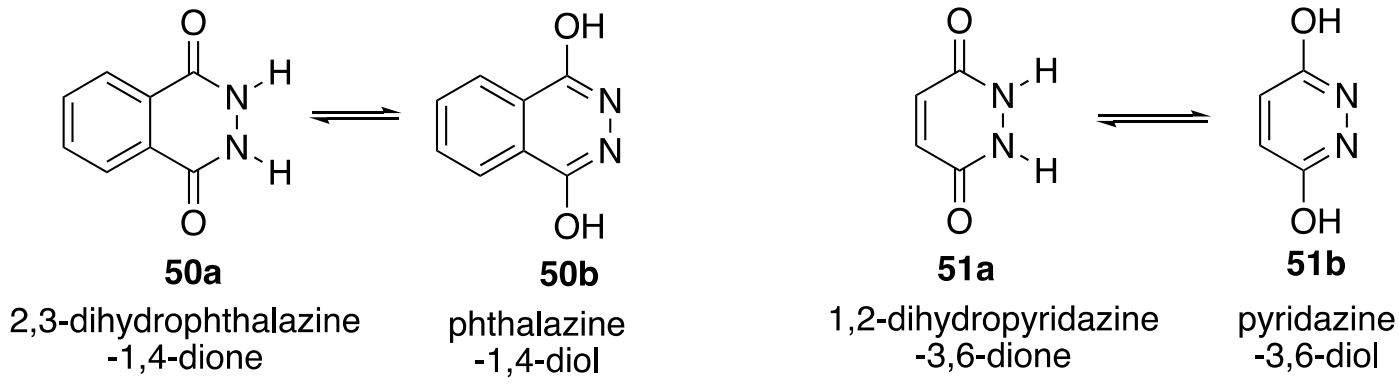

Scheme 16. Cyclic disubstituted hydrazides.

Discovered by Drew and Hatt in $1937(\mathrm{R}=\mathrm{Ph}),{ }^{51}$ this is the oldest method for the synthesis of 3-pyrazolines, although the position of the double bond, 52a or 53a, was not determined (Scheme 17). The correct structures 52a and 52 b were established by Le Berre and Godin. ${ }^{52,53}$ These works were discussed by Tisler and Stanovnik in Chapter III 'Azolo- and Azinopyridazines and Some Oxa and Thia Analogs' in Castle`s book. ${ }^{54}$<smiles></smiles>

$50 a$<smiles>[R]C1C=Cn2c(=O)c3ccccc3c(=O)n21</smiles>

52<smiles></smiles>

53

$$
\mathbf{a}, \mathrm{R}=\mathrm{Ph}, \mathbf{b}, \mathrm{R}=\mathrm{Me}
$$

Scheme 17. Drew and Hatt synthesis.

The most commonly reported example is represented in Scheme $18 .{ }^{55-62}$ The X-ray structures of several 3pyrazolines with structure $\mathbf{5 4}$, prepared by this method, have been determined. ${ }^{63,64}$ 
<smiles>[R]C1([R])CC(=O)CC([R])([18F])C1</smiles>

Scheme 18. Synthesis of 3-pyrazolines 54 from 2,3-dihydrophthalazine-1,4-dione 50a.

Other $\beta$-unsaturated carbonyl compounds such as $\mathbf{5 5}$ and $\mathbf{5 6}$ afford more complex 3-pyrazolines, e.g., $\mathbf{5 7}$ and $\mathbf{5 8}$, respectively, upon reaction with 50a (Scheme 19). ${ }^{65,66}$
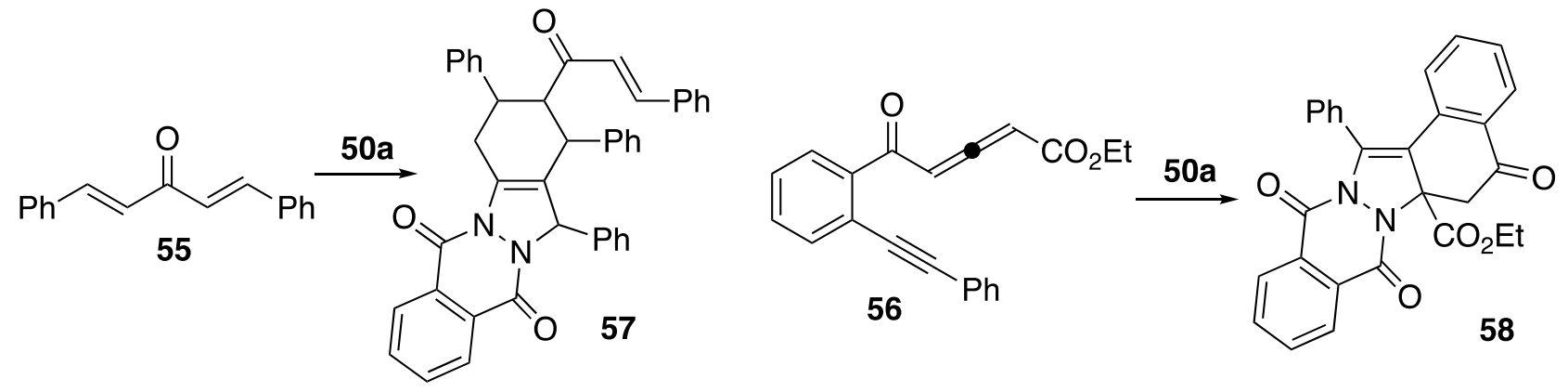

Scheme 19. Polycyclic 3-pyrazolines 57 and 58.

Open-ring $\beta$-diketones such as acetylacetone have rarely been used (Scheme 20) but this compound affords 3-pyrazolines 59 and 60. $\beta$-Ketoesters (ethyl acetoacetate), benzaldehyde and 1,3,5-triazolidine-3,5dione (another cyclic hydrazide) have also been used to prepare 3-pyrazolines. ${ }^{67}$
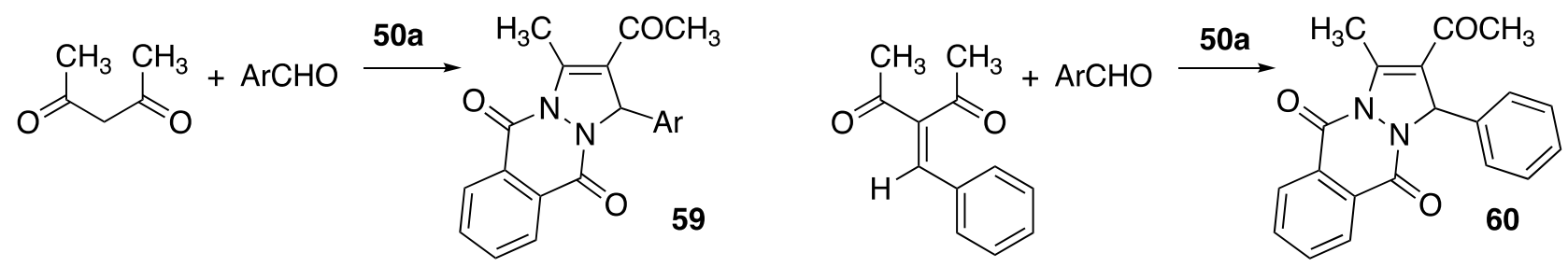

Scheme 20. Reaction of 2,3-dihydrophthalazine-1,4-dione 50a with $\beta$-diketones and aromatic aldehydes.

A less commonly used approach involves the use of malononitrile instead of a $\beta$-dicarbonyl compound and isatin or $N$-alkyl isatins instead of aromatic aldehydes (Scheme 21 ) to form spirooxindoles $61 .{ }^{59,68-70}$<smiles>[R]N1C(=O)C(=O)c2ccccc21</smiles>

Scheme 21. Reaction of 2,3-dihydrophthalazine-1,4-dione 50a with malononitrile and isatins. 


\subsection{By 1,3-dipolar cycloaddition [(NNC) + (CC)]}

For ease of classification we have separated the two main synthetic methods into 'from hydrazines [(NN) $+(\mathrm{C})$ $+(\mathrm{CC})$ and $(\mathrm{NN})+(\mathrm{CCC})]$ ' and 'by 1,3-dipolar cycloadditions $[(\mathrm{NNC})+(\mathrm{CC})]$ ' but these methods are closely related (Scheme 22).

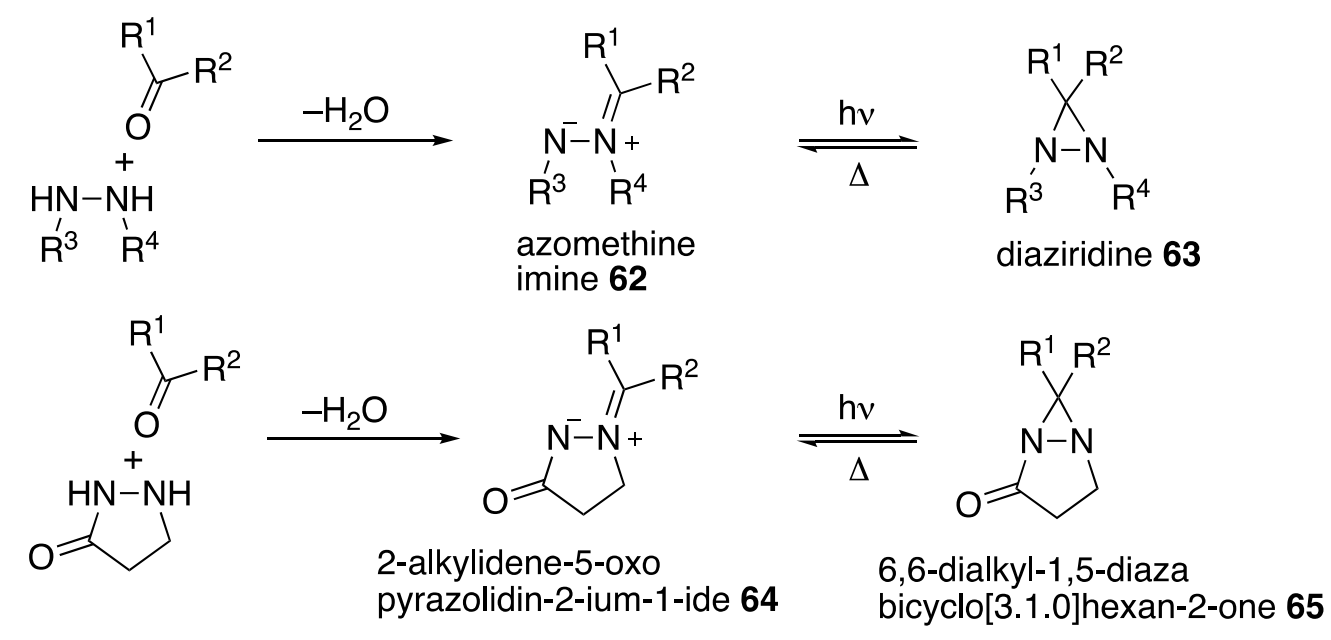

Scheme 22. Relationships between different synthetic methods.

The relationship between azomethine imines, 62 and 64, and diaziridines, 63 and 65, was reported by Huisgen in $1961 ; ;^{71,72}$ since diaziridines open thermally to 1,3-dipoles, they can be used to prepare 3-pyrazolines ${ }^{73}$ (for a review, see references ${ }^{74,75}$ ). Several authors have studied the 64/65 relationship in Scheme 22 between pyrazolidinones and diazabicyclohexanones. ${ }^{76,77}$

2.2.1. Diaziridines as azomethine imine precursors. A remarkable example of a gold(I)-catalyzed synthesis of 3pyrazolines 67 by reaction of diaziridines 66 and alkynes is shown in Scheme $23 .{ }^{78}$

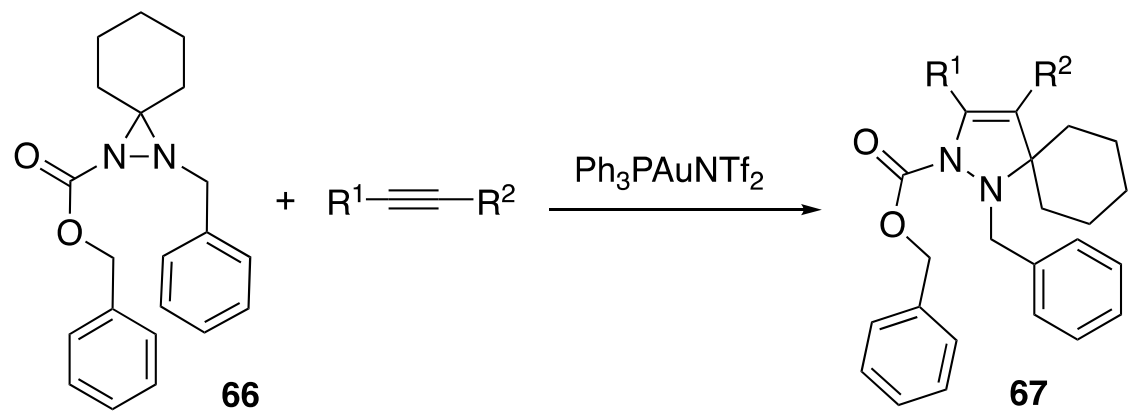

Scheme 23. Synthesis of 3-pyrazolines 67 from diaziridines 66.

2.2.2. 2-(Propan-2-ylidene)pyrazolidin-2-ium-1-ides. The general 1,3-dipolar cycloaddition between 2-(propan2-ylidene)pyrazolidin-2-ium-1-ides and CC triple bonds (or allenes) to afford 3-pyrazolines is represented in Scheme 24. The latter compounds are related to the pyrazolo[1,2-a]pyrazole ring system and two regioisomers can be formed depending on the nature of $R^{6}$ and $R^{7}$. 


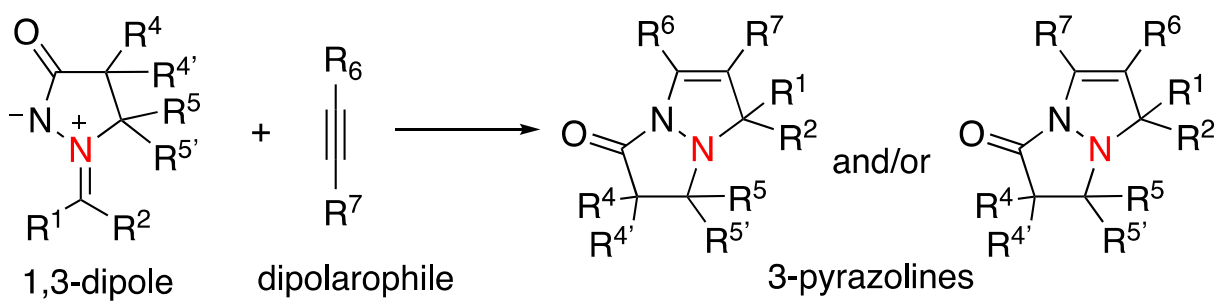

Scheme 24. General synthesis of 3-pyrazolines from 2-(propan-2-ylidene)pyrazolidin-2-ium-1-ides.

The most relevant 1,3-dipoles, 68-78, are summarized in Figure 7 and the most frequently used dipolarophiles, 79-91, are shown in Figure 8.

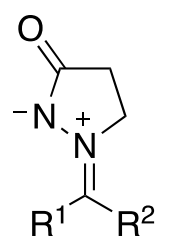

68

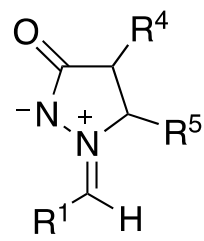

74

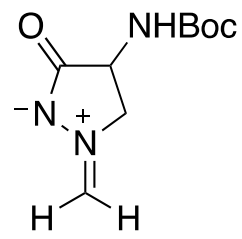

69

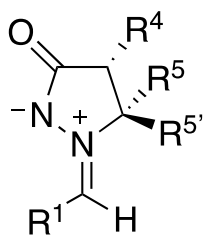

75

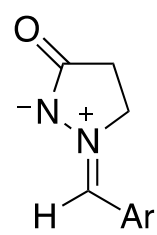

70

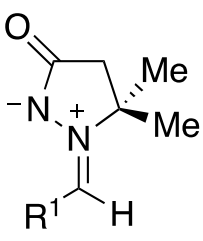

76

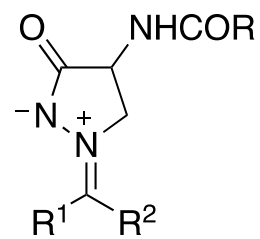

71

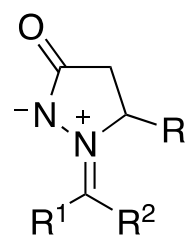

77<smiles>[R7]C=[N+]1CCC(=O)N1C</smiles>

72

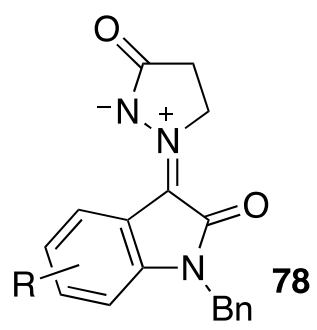

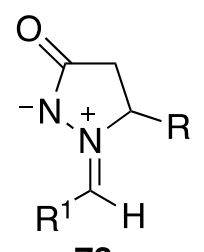

73

Figure 7. 2-(Propan-2-ylidene)pyrazolidin-2-ium-1-ides.

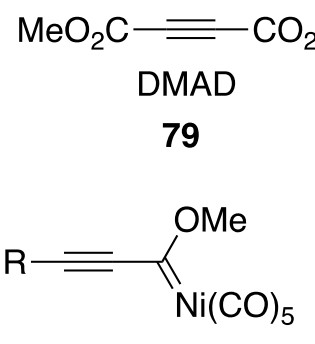

Fischer carbene

83

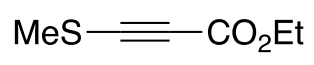

88

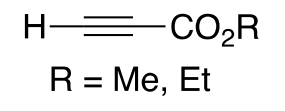

80<smiles>[R]C=C=C([R])[O+]=C</smiles>

allenoates

84

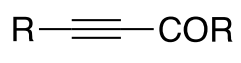

$\mathrm{R}=\mathrm{H}$ or $\neq \mathrm{H} \quad \mathbf{8 9}$
$\mathrm{R}^{1} \mathrm{O}_{2} \mathrm{C}=\mathrm{R}^{2}$

$\mathrm{R}^{1}=\mathrm{Me}$, allyl, $t$-Bu, $\mathbf{8 1}$

$\mathrm{R}^{2}=\mathrm{H}, \mathrm{Ph}, \mathrm{SPh}, \mathrm{COR}, \mathrm{CO}_{2} \mathrm{R}$, CONHPh, $\mathrm{PO}_{3} \mathrm{Me}_{2}, \mathrm{CH}_{2} \mathrm{OH}, \mathrm{CF}_{3}$,<smiles>Cc1cc(C)[nH]n1</smiles><smiles>[R]C#CC(=O)N(C)CC(=O)[Sn]</smiles><smiles>[R]C(C#N)C#N</smiles>

malononitriles $\mathrm{R}=\mathrm{H}, \mathrm{Me} 86$

$\mathrm{H}=\mathrm{CONHR}$

90
$\mathrm{H}-\mathrm{R}$
$\mathrm{R}=\mathrm{COMe}, \mathrm{CO}_{2} \mathrm{Et}, 82$
CONHPh, $\mathrm{Ph}, p-\mathrm{RC}_{6} \mathrm{H}_{4}$,

2-pyridyl, $n$-pentyl

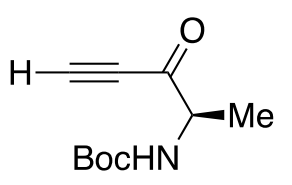

87

Figure 8. Alkene, allene, alkyne and nitrile dipolarophiles.

Table 1 contains the references corresponding to the combinations of the compounds shown in Figures 7 and 8. 
Table 1. 1,3-Dipolar cycloadditions

\begin{tabular}{|c|c|c|c|}
\hline 1,3-Dipole & Dipolarophile & Comments & Reference \\
\hline 68 & 79 & & 79 \\
\hline 68 & $79,82,89,91$ & & 80 \\
\hline 69 & 81 & & 81,82 \\
\hline 70 & 79,80 & & 83 \\
\hline 71 & 79 & & 84 \\
\hline 72 & 82 & & 85 \\
\hline 72 & 82 & Catalyzed by metal amides & 86 \\
\hline 72 & 80,89 & & 87 \\
\hline 72 & 80 & Catalyzed by $\mathrm{Cu}(\mathrm{I})$, asymmetric & 88 \\
\hline 72 & 84 & DMAD & 89 \\
\hline 72 & 85 & & 90 \\
\hline 72 & 86 & & 91 \\
\hline 72 & 89 & Using MW & 92 \\
\hline 73 & 82 & Kinetic resolution & 93 \\
\hline 74 & 83 & Regioselective & 94 \\
\hline 74 & 87 & Absolute configuration & 95 \\
\hline 75 & 87 & Absolute configuration & 96 \\
\hline 75 & 89 & Allenoates & 96 \\
\hline 75 & 89 & Allenoates, catalyzed by $\mathrm{Cu}(0)$ & 97 \\
\hline 75 & 90 & Catalyzed by $\mathrm{Cu}(0)$ & 98 \\
\hline 76 & 89 & & 88 \\
\hline 76 & 91 & Malononitriles & 88 \\
\hline 76 & 80 & Catalyzed by Cu(I) & 98 \\
\hline 76 & 88 & Fischer carbene & 99 \\
\hline 77 & 90 & & 99 \\
\hline 78 & 80 & & 100 \\
\hline
\end{tabular}

An example of a reaction between an azomethine imine 92 and an allene derivative to afford the 3pyrazoline 93 is presented in Scheme $25 .{ }^{97,101}$<smiles>CCOC(=O)C1=C(/C=C/c2ccccc2)N(C(=O)c2ccccc2)N2CCc3ccccc3C12</smiles>

Scheme 25. Synthesis of 3-pyrazoline 93 from azomethine imine 92.

When the reaction of 2-(propan-2-ylidene)pyrazolidin-2-ium-1-ides and triple bonds or allenes was catalyzed by a phosphine, the reaction followed a different mechanism and 3-methylene-pyrazolidines were obtained (Scheme 26). 
<smiles>[Z20]C(C)=[N+]1CCC(=O)[NH+]1C</smiles>

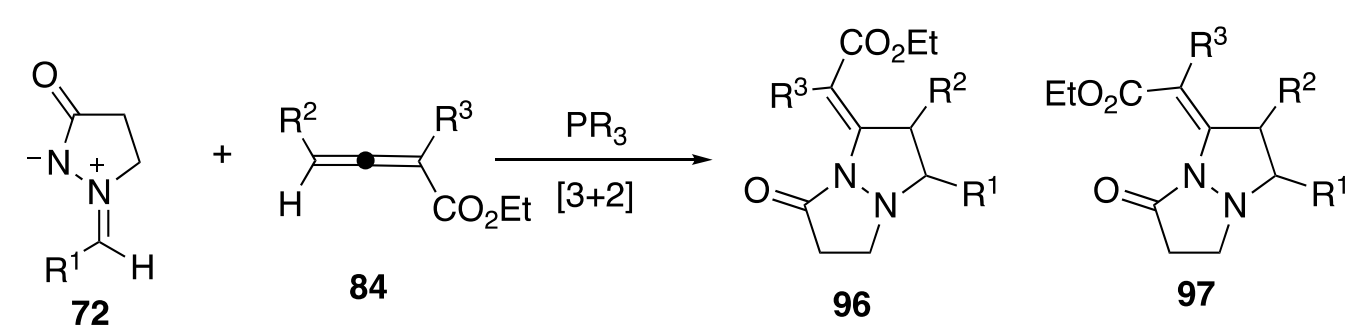

Scheme 26. [3+2] Dipolar cycloadditions catalyzed by phosphines.

Compound 94 was obtained from the acetylenic ester 81 (structure 95 was proposed as an intermediate), ${ }^{102}$ while a mixture of $E$ and $Z$ isomers, 96 and $\mathbf{9 7}$, was obtained from allenoate $84 .^{103}$ If the allenoate has $\mathrm{R}^{2}=\mathrm{H}$, then the reaction only gives the $E$ isomer $\mathbf{9 6}$ (in this paper the mechanism was analyzed in detail). ${ }^{104}$ The structure of $97\left(\mathrm{R}^{1}=p-\mathrm{NO}_{2}-\mathrm{C}_{6} \mathrm{H}_{4}, \mathrm{R}^{2}=\mathrm{R}^{3}=\mathrm{H}\right.$, Refcode UZIRUR) was determined by $\mathrm{X}$-ray crystallography (Figure 9).

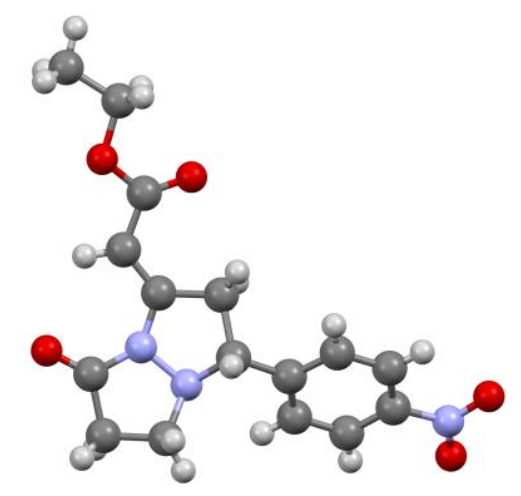

Figure 9. The structure of UZIRUR.

Compounds 96 and 97 present tautomerism of the endo/exo class (Section 3.2) with two exo-isomers that we calculated (Table 2) at the B3LYP/6-311++G(d,p) level. The calculations reproduce the experimental evidence. 
Table 2. Position of the CC double bond in compounds 96 and $\mathbf{9 7}$. Relative energies in $\mathrm{kJ} \cdot \mathrm{mol}^{-1}$

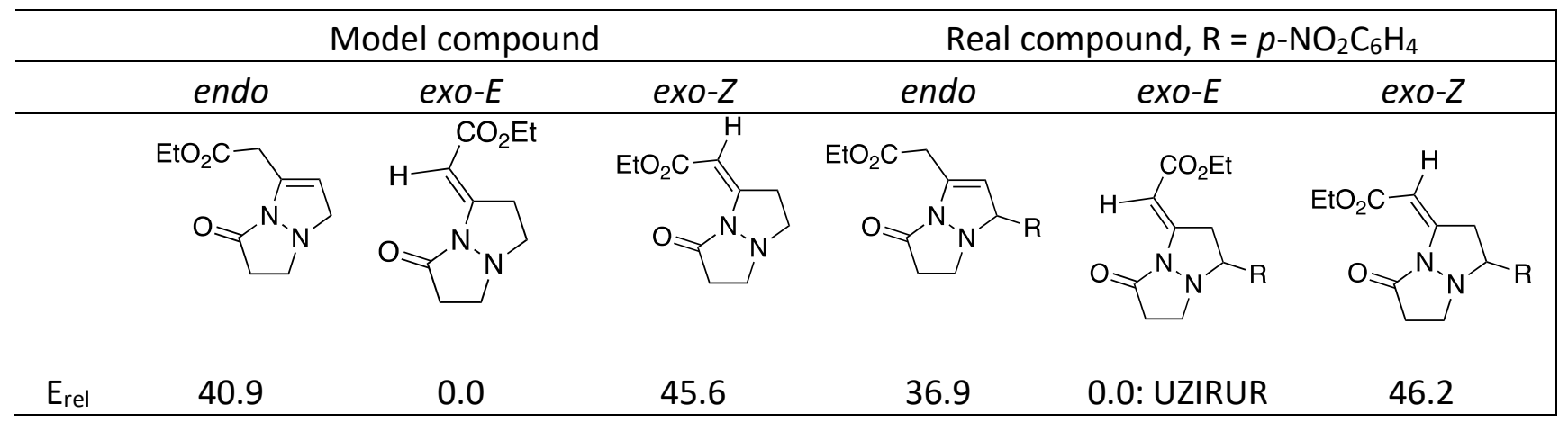

2.2.3. Diethyl azodicarboxylate and the Morrison-Brunn-Huisgen betaine. Diethyl azodicarboxylate reacts with phosphines to afford the Morrison-Brunn-Huisgen betaines (98), 105,106 a 1,3-dipole that constitutes the first step of the Mitsunobu reaction. ${ }^{107}$ The synthesis of a diisopropyl 3-pyrazoline-1,2-dicarboxylate 99 was carried out by this method from a halogenated chalcone and DIAD (Scheme 27). Compound 98a was not isolated. ${ }^{108}$ The difficult problem of assigning the bromo- and fluorophenyl groups of compound 99 at the 3- and 5-positions, respectively, was solved by X-ray crystallography (Section 4.6). Two more examples are represented in Scheme 27, one involving the same betaine $98 \mathrm{a}$ and chromone 100 to prepare $101^{109}$ and the other a chiral betaine related to 103 and a vinyl ester 102 to prepare the chiral 3-pyrazoline $104 .^{110}$

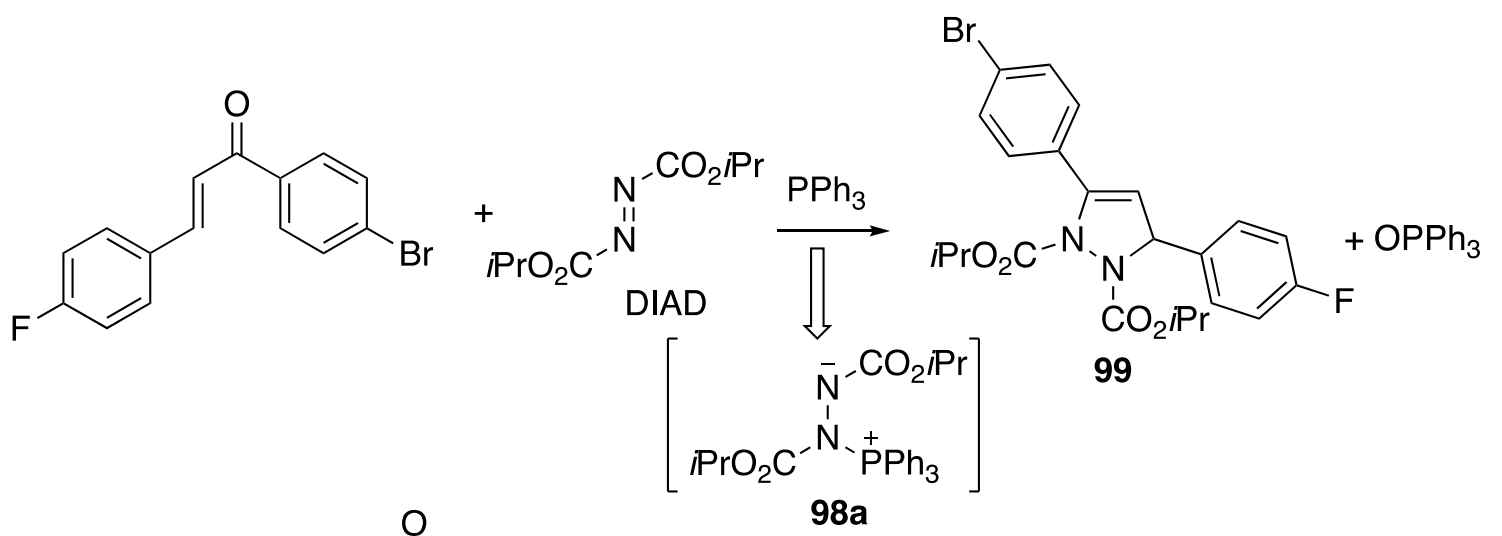<smiles>O=C(O)C(=O)C(=Cc1coc2ccccc2c1=O)C(=O)O</smiles>

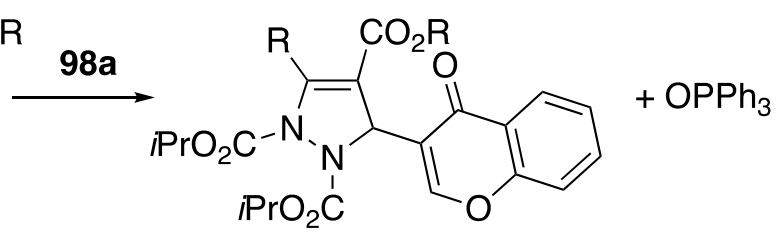<smiles>[R6]OC([R])C(=C)C(=O)OCC</smiles><smiles>COC(C)=NN=[V]</smiles><smiles>[R10]C1C(C(=O)OCc2ccccc2)=CN(C(C)=O)N1[R]</smiles>

Scheme 27. The use of Morrison-Brunn-Huisgen betaines.

Another example is presented in Scheme 28 and in this case 3-pyrazoline 105 was postulated as an intermediate to pyrazole $106 .^{111}$ 


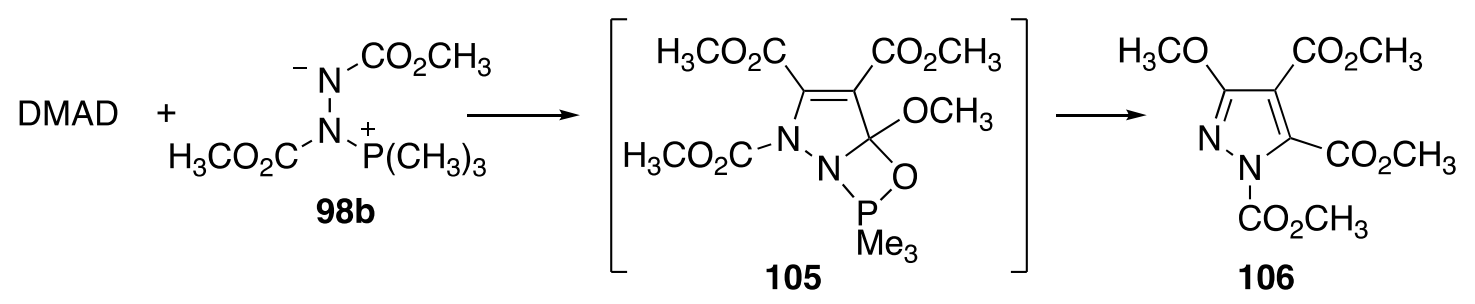

Scheme 28. Another use of the Morrison-Brunn-Huisgen betaines.

2.2.4. From sydnones and other 1,3 -dipoles. In the synthesis of pyrazoles from sydnones and olefins, $1 \mathrm{H}-2-$ phenyl-3-pyrazolines 107 and 108 have been postulated as intermediates in the synthesis of pyrazoles 109 and 110 (Scheme 29)..$^{112}$<smiles>c1ccc(-c2cn(-c3ccccc3)nc2-c2ccccc2)cc1</smiles>

107
109<smiles>[R]C1=C(c2ccccc2)C(C)(CC)C(C)C1c1ccccc1</smiles>

110

Scheme 29. Synthesis of pyrazoles 110 from sydnones.

A very complex mechanism was proposed to explain the formation of 3-pyrazoline 113, the structure of which was determined by X-ray crystallography in $1985 .{ }^{113} \mathrm{~A}$ further fifteen years passed before the mechanism was published for the transformation of pyrazolidine 112, obtained from the dipole 111 and dimethyl maleate, into the 3-pyrazoline 113 with an unexpected supplementary $\mathrm{CH}_{2} \mathrm{CO}_{2} \mathrm{CH}_{3}$ arm (Scheme 30). ${ }^{114,115}$

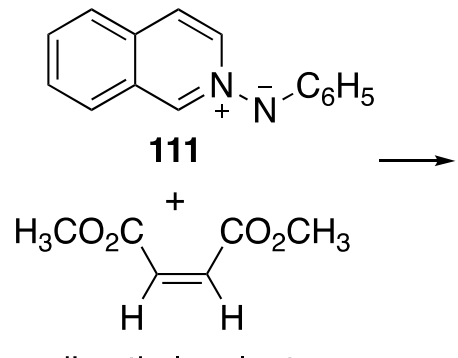

dimethyl maleate

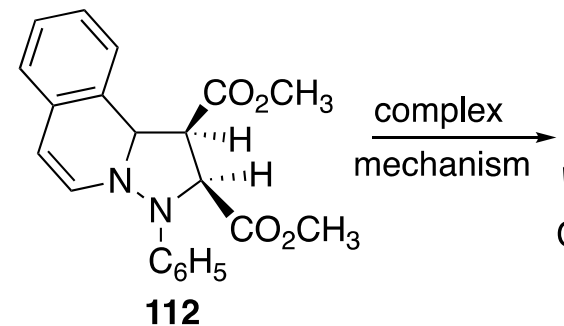

112

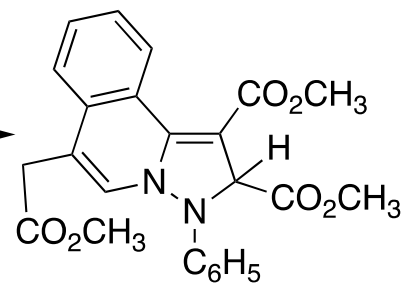

113

Scheme 30. Synthesis of 3-pyrazoline 113.

One of the most curious 3-pyrazolines synthesized was part of a 1-aza-6,7-dehydrotropane skeleton 114. The synthesis, a one pot three-component reaction, starts from monosubstituted hydrazine 115, 5chloropentan-2-one 116 and a terminal alkyne $\mathbf{1 1 7}$ in the presence of $\mathrm{Cu}_{2} \mathrm{O}$ (Scheme 31). The azomethine imine intermediate 118 was not isolated. ${ }^{116}$ 


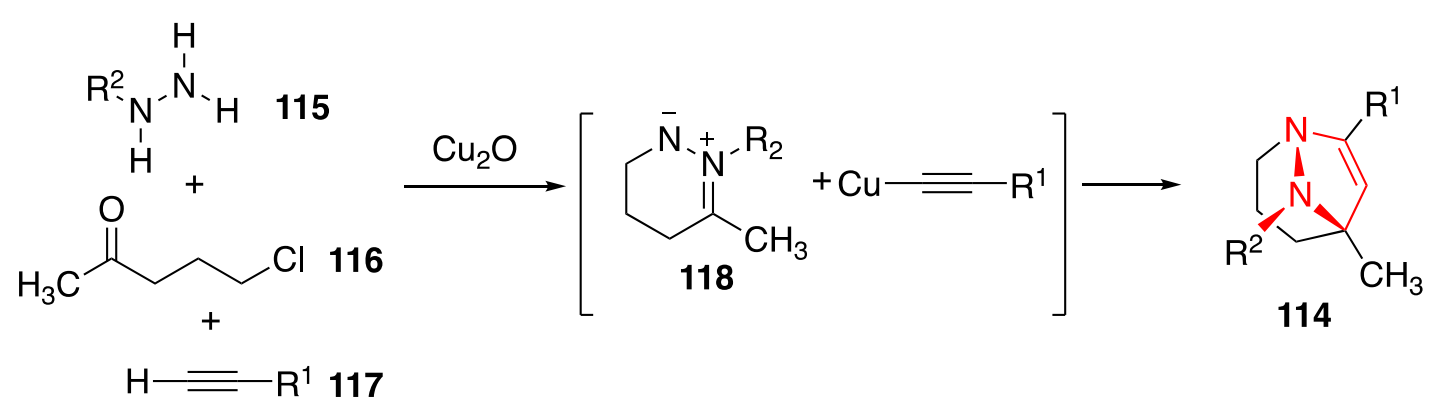

Scheme 31. A 3-pyrazoline with an azadehydrotropane structure.

Another way to prepare 3-pyrazolines by an $[(N N)+(C C C)]$ approach that it is very different from the methods based on hydrazines (Section 2.1) is to use a [3+2] cycloaddition but with the dipole on the (CCC) fragment, which is related to the Baylis-Hillman bromide, and the dipolarophile is an azo derivative such as diethyl azodicarboxylate (Scheme 32, R = Et). The synthesis of 3-pyrazoline 119 from the dipole 120 was described in reference ${ }^{117}$ and the more complex case in which $\mathbf{1 2 1}$ is obtained from $\mathbf{1 2 2}$ (Morita-Baylis-Hillman adducts) in reference. ${ }^{118}$<smiles>[R]OC(=O)COC(=O)N1C=C(C(=O)OCc2ccccc2)C(Br)N1C(=O)O</smiles>

120<smiles>[R]c1ccc2c(c1)/C(=C(/C[18OH])C[PH3+])C(=O)N2[R7]</smiles>

122

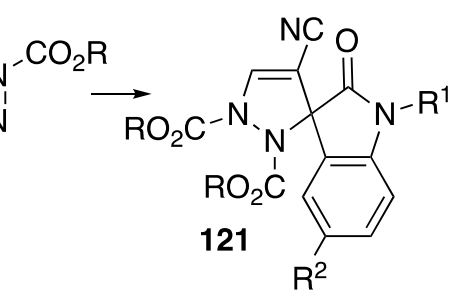

Scheme 32. The use of (CCC) 1,3-dipoles.

2.2.5. 1,5-Electrocyclic reactions. A rare and beautiful example of a 1,5-electrocyclic reaction was reported by Dürr et al. (Scheme 33). ${ }^{119}$ Starting with a thermal reaction of cyclopropene $\mathbf{1 2 3}$ or photochemical reaction of pyrazolenine 124 and benzo[c]cinnoline 125, the azomethine imine 126 and the 3-pyrazoline 127 were isolated and rearranged. The photochemical ring opening of $\mathbf{1 2 7}$ to $\mathbf{1 2 6}$ is a property that will be discussed in Section 3.9.

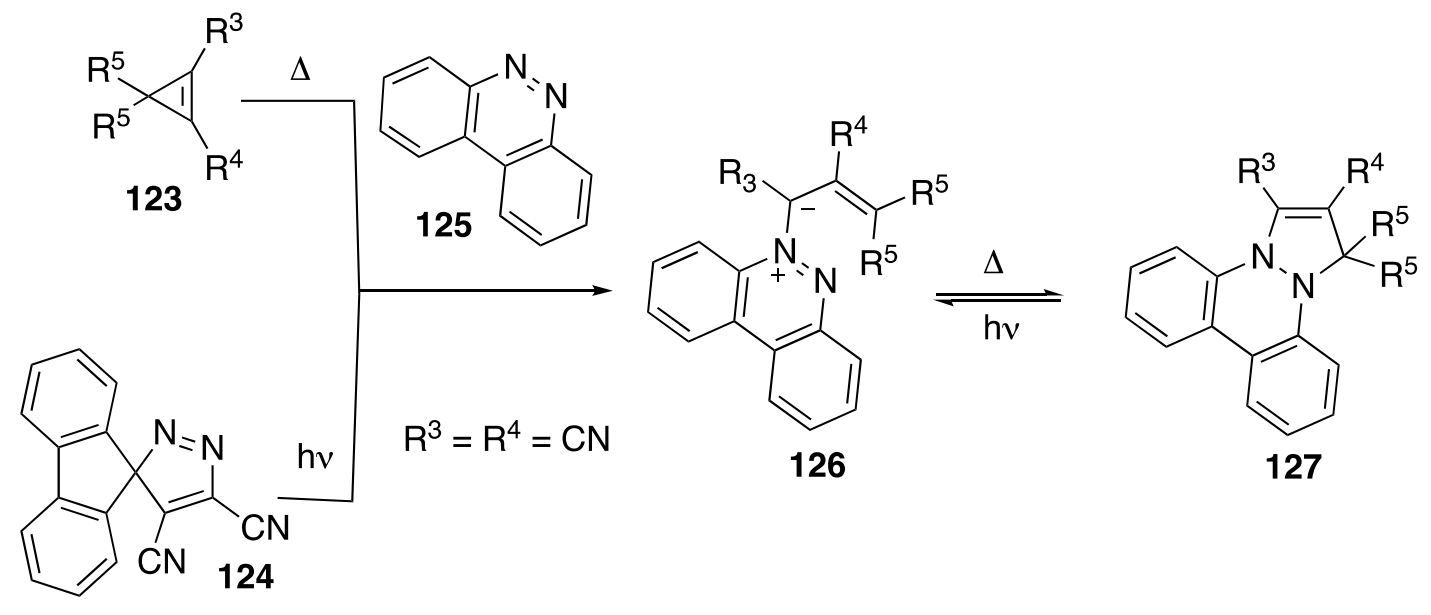

Scheme 33. Synthesis of $1 H$-benzo[c]pyrazolo[1,2-a]cinnolines 127. 


\subsection{Other methods}

2.3.1. By reduction of pyrazoles, pyrazolones and pyrazolidinones. Reduction of pyrazoles to 3-pyrazolines is not expected to work well because this will lead to 1-R-2H-3-pyrazolines, which would usually isomerize to 2pyrazolines (see Section 3.2). Moreover, pyrazoles are resistant to reduction, in particular by lithium aluminium hydride. ${ }^{120}$ The only example of this process was reported by Wittig and Hutchison (Scheme 34), who claimed to have isolated 3-pyrazoline 130 by reduction of pyrazole $129 .{ }^{121}$ This claim was later proved to be incorrect ${ }^{122}$ due to an indirect error that affects the structure of pyrazole 129 . When the reaction was repeated, the rearrangement of the pyrazolenine 128 did not afford pyrazole 129 but isopyrazole 131; the reduction of 131 afforded two isomeric 2-pyrazolines, the major cis isomer 132a with identical properties to those reported for 130 and the minor isomer trans $\mathbf{1 3 2 b .}$

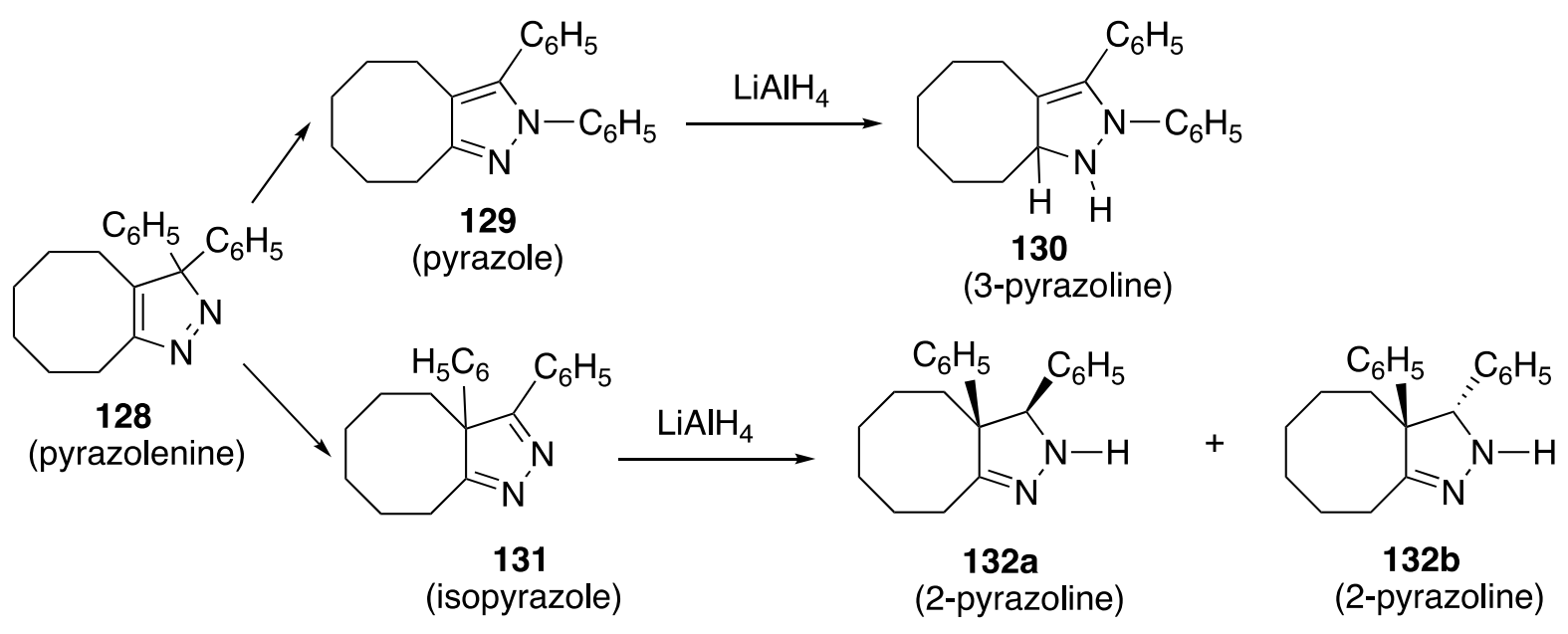

Scheme 34. The Wittig and Hutchison synthesis. ${ }^{122}$

Concerning pyrazolones (Scheme 35), in 1957 Bowman and Franklin reported the reduction of antipyrine (133) to the 3-pyrazoline $134^{123}$ and in 1963 Wagner-Jauregg and Zirngibl described the reduction of pyrazolidinone 135 to 4-pyrazoline $136 .{ }^{124}$ The instability of these tautomers and their easy transformation into 2-pyrazolines (Section 3.2) prompted us to study this reaction in 1966 using $N$-phenyl 137 instead of $N$ - $p$ chlorophenyl 135 and it was discovered that the reduction product was the 1-phenyl-2-pyrazoline $138 .{ }^{125}$ The original authors acknowledged their error in a subsequent paper. ${ }^{126}$

We also reported the reductions of 139 to 140 and 141 to $143 .{ }^{126}$ Bird reported that compound 141 cannot be reduced by $\mathrm{LiAlH}_{4}{ }^{; 27}$ in fact treatment with $\mathrm{LiAlH}_{4}$ affords 1-phenyl-3-methyl-1H-pyrazole 143 by a mechanism that involves a 4-pyrazoline $142 .{ }^{126}$

An obvious extension of reductions was the use of Grignard reagents (Scheme 36). This approach enabled us to obtain 3-pyrazolines 145 and 146 from pyrazolidinone 144 and 3-pyrazoline 148 from $147 .{ }^{128}$ 
<smiles>Cc1cc(=O)n(-c2ccccc2)n1C</smiles>

133 (antipyrine)

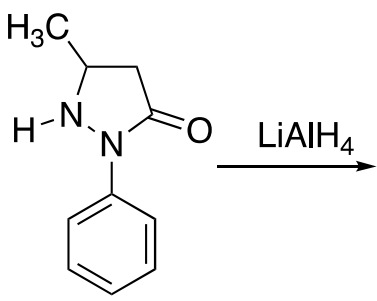

137

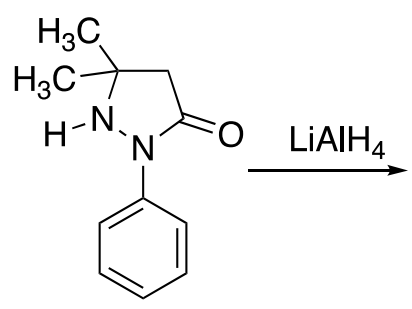

141<smiles>CC1=CCN(c2ccccc2)N1C</smiles>

134<smiles>CC1=NN(c2ccccc2)CC1</smiles>

138
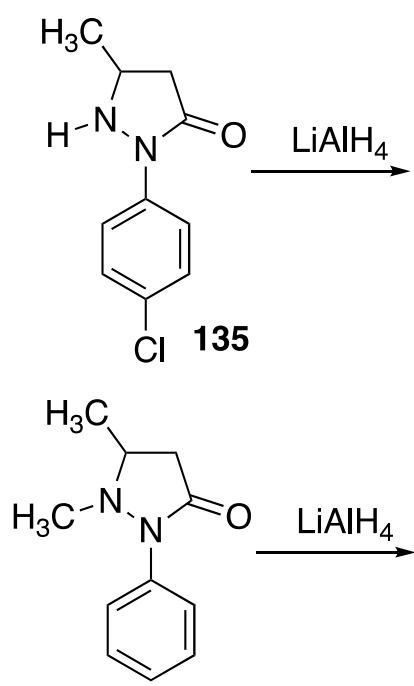

139<smiles>CC1C=CN(c2ccc(Cl)cc2)N1</smiles><smiles>CC1C=CN(c2ccccc2)N1C</smiles>

140<smiles>Cc1ccn(-c2ccccc2)n1</smiles>

142

Scheme 35. Reduction of pyrazolones and pyrazolinones.<smiles>CC1CC(=O)N(C)C1c1ccccc1</smiles><smiles>[R]C1=CC(C)N(c2ccccc2)N1</smiles>

145, $\mathrm{R}=\mathrm{CH}_{3}, \mathrm{X}=\mathrm{I}$ 146, $\mathrm{R}=\mathrm{C}_{6} \mathrm{H}_{5}, \mathrm{X}=\mathrm{Br}$<smiles>CC1CC(=O)N(c2ccccc2)N1C</smiles>

147<smiles>CC1=CC(C)N(C)N1c1ccccc1</smiles>

148

Scheme 36. The action of Grignard reagents on pyrazolidinones.

2.3.2. By reduction of pyrazolium salts. Discovered in Montpellier (France) and St. Petersburg (Russia) between 1967 and 1973 and developed in Valladolid (Spain) between 1989 and 2009, this is a general and versatile synthetic method, although pyrazolidines are often accompanied by 3-pyrazolines. El'tsov et al. reported the same reaction in $1968^{129}$ and they extended it to polarographic reduction. ${ }^{130}$ The main problem with this method is that in some cases it yields mixtures of 3-pyrazolines 150 and 4-pyrazolines 151 if the substituents at N1/N2 or $\mathrm{C} 3 / \mathrm{C} 5$ of the pyrazolium salt $\mathbf{1 4 9}$ are not sufficiently different (Scheme 37 ). ${ }^{131}$ The first study, in which the substituents were $\mathrm{H}, \mathrm{CH}_{3}$ and $\mathrm{C}_{6} \mathrm{H}_{5}$, was extended to include many other substituents in a subsequent paper that included kinetic studies and deuterium labeling experiments. ${ }^{121}$ In this paper the Grignard reaction was also studied. The attack at positions 3 and 5 depends on the nature of $R^{3}$ and $R^{5}$. For example, when $R^{3}=P h$ and $R^{5}$ 
$=$ Me the attack occurs on the C5 (>95\%, < 5\%) but a primary isotope effect lowered the percentages to $90 \%$ and $10 \%$ when LiAlD $_{4}$ was used. ${ }^{132}$
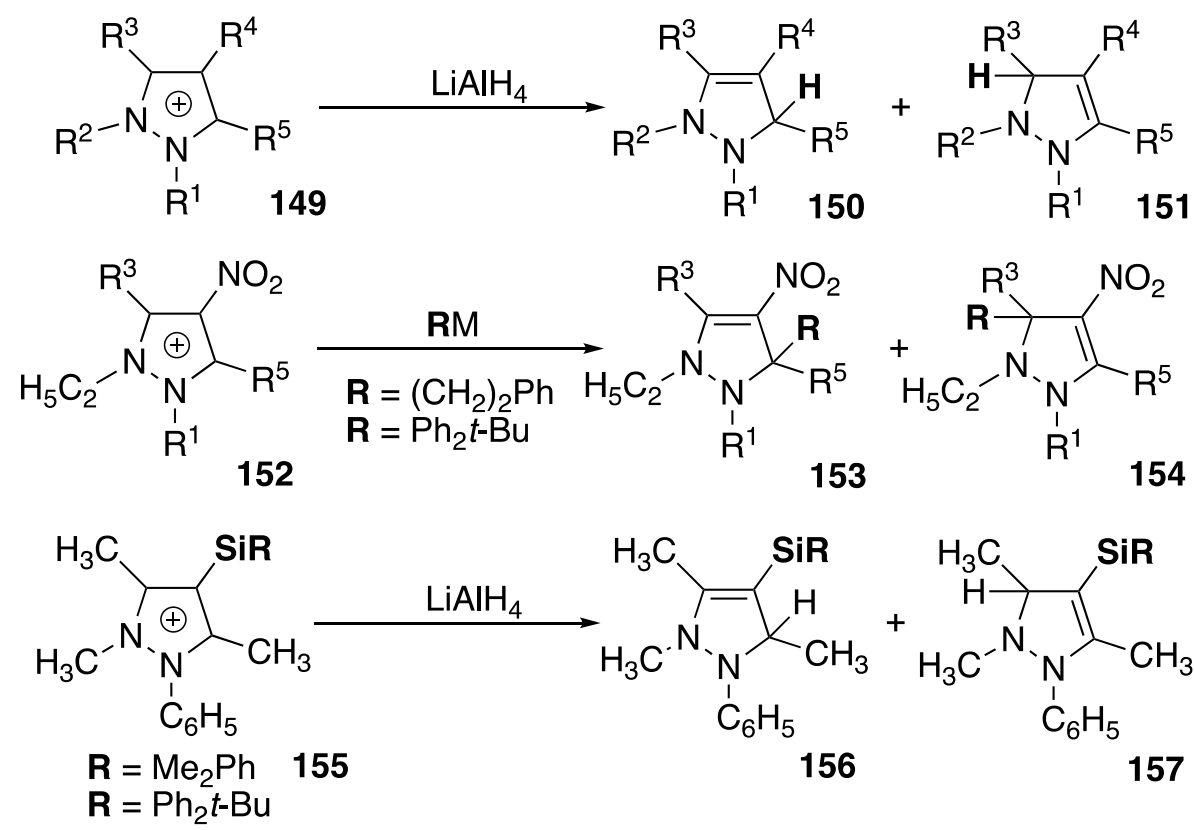

Scheme 37. Reduction of pyrazolium salts.

The series of Valladolid papers started with a brief communication concerning simple pyrazolium salts, ${ }^{133}$ followed by a paper on the treatment of 4-nitropyrazolium salts 152 with organometallic reagents $\left(\mathrm{CH}_{3} \mathrm{Li}, \mathrm{C}_{6} \mathrm{H}_{5} \mathrm{Li}\right.$, $\mathrm{CH}_{3} \mathrm{Mgl}, \mathrm{C}_{6} \mathrm{H}_{5} \mathrm{MgBr}$ ) to afford 3-pyrazolines 153 and 154 (Scheme 37). ${ }^{134}$ A subsequent study was performed on the reactivity of pyrazolium salts 155 towards complex metal hydrides to obtain mixtures of 3-pyrazolines 156 and 157. ${ }^{135,136}$ Compounds 156 and 157 are in equilibrium, with 157 being the most stable because, according to the authors, the C4C5 double bond is conjugated with the $N$-phenyl group (see Scheme 43 in Section 3.2). ${ }^{137}$ The case where the SiR groups are at position 5 instead of 4 was also studied. ${ }^{138}$

2.3.3. From other pyrazole derivatives. Jursic theoretically calculated hypothetical reactions (Scheme 38) that transform pyrazole 158 into 3-pyrazolines 159 and $160 .^{138}$

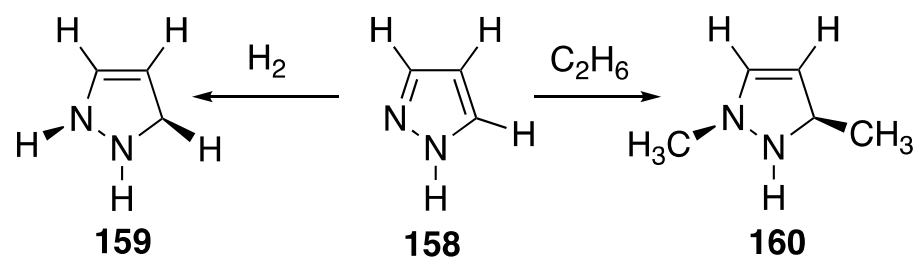

Scheme 38. Theoretical study of relationships between pyrazoles and 3-pyrazolines.

Pyrazolenines (3H-pyrazoles) are cyclic azo compounds. Thus, 1-(3,3-dimethyl-3H-pyrazol-5-yl)ethan-1one (161) reacts with 2,4-dimethylpenta-1,3-dien-1-one (162, a vinylketene) to yield the pyrazolo[1,2a]pyridazinone 163 by a [4+2] cycloaddition (Scheme 39). ${ }^{139}$ 
<smiles>CC(=O)C1=CC(C)(C)N=N1</smiles>

161<smiles>CC=C(C)C=O</smiles>

162<smiles>CC(=O)C1=CC(C)(C)N2C(=O)C(C)=CC(C)(C)N12</smiles>

Scheme 39. 3-Pyrazoline 163 from pyrazolenines.

There is a rare example (Scheme 40) of a 3-pyrazoline (165) that was obtained by acylation of a 2pyrazoline $164 .^{140}$

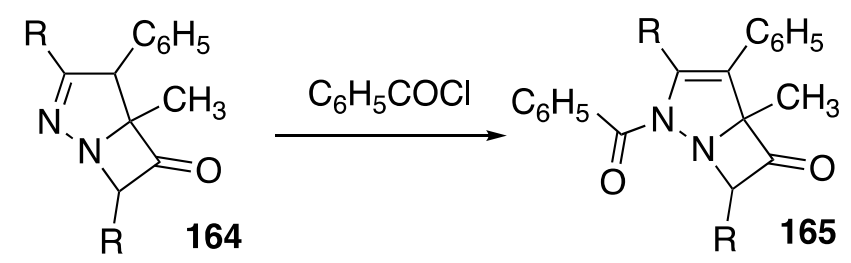

Scheme 40. Benzoylation of 2-pyrazoline 164.

2.3.4. Non-conventional methods. Some methods are difficult to classify and these include the reaction represented in Scheme 41, where a disubstituted open hydrazide 166 reacts with DEAD in the presence of triphenylphosphine to afford the polycyclic 1,2-diacyl-3-pyrazoline $167 .^{141}$

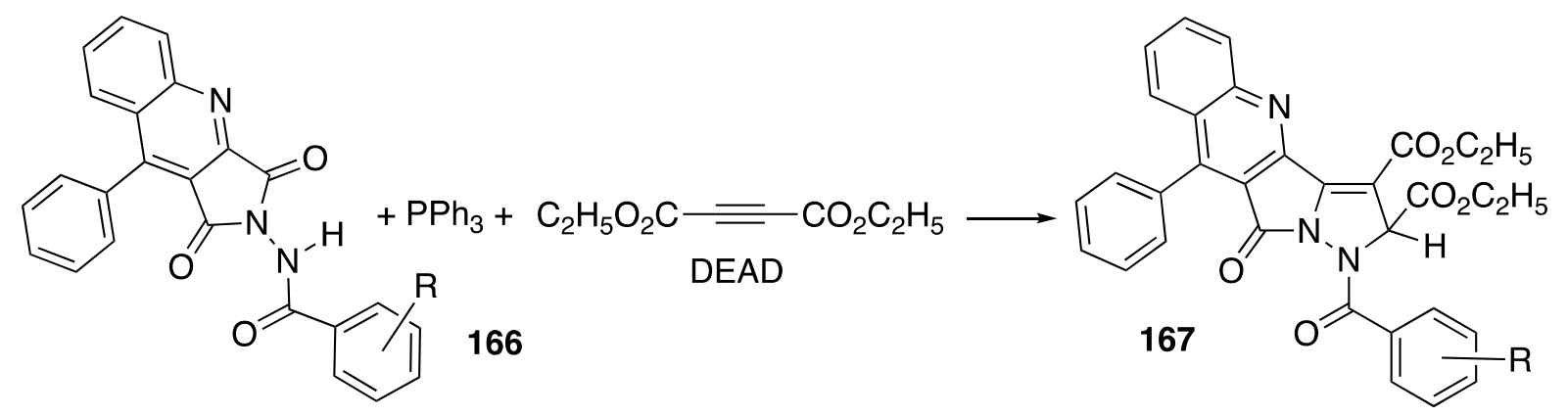

Scheme 41. Synthesis of the polycyclic 3-pyrazoline 167.

The position of the double bond in $167(\mathrm{R}=p-\mathrm{Cl})$ was established by X-ray crystallography (Figure 10, Refcode: ZEWBAH). ${ }^{141}$ 


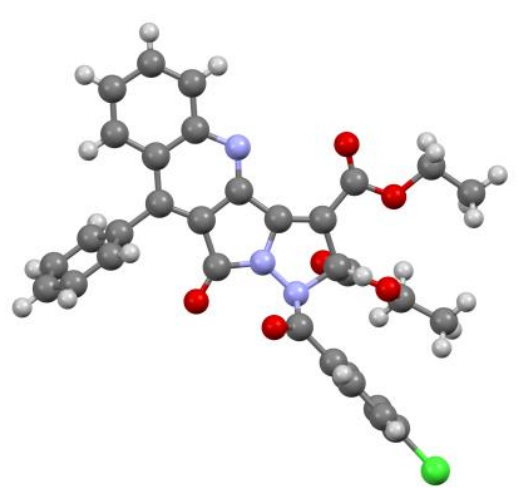

Figure 10. The structure of ZEWBAH.

\section{Chemical Properties}

\subsection{Conformational analysis}

In 3-pyrazolines the substituents on the nitrogen atoms adopt a trans disposition; the cis isomer is much less stable to the point that in some cases it is not stable and corresponds to a transition state. ${ }^{142}$ When a substituent is present at position 5 (the other being an $\mathrm{H}$ atom) the minimum energy conformation corresponds to the transtrans isomer. The experimental barriers to the double nitrogen inversion were measured by Kostyanovsky et al. in two cases. ${ }^{34,35}$ The results are provided in Table 3 together with those of the theoretical calculations.

Table 3. Barriers to the $\mathrm{N}-\mathrm{R}$ inversion $\left(\mathrm{kJ} \cdot \mathrm{mol}^{-1}\right)$ for pyrazolines $\mathbf{1 6 8 - 1 7 0}$

\begin{tabular}{cccc}
\hline 3-Pyrazoline & 168 & 169 & 170 \\
Calculated & $42.7^{143}$ & $71.2^{143}$ & $125.2^{143}$ \\
Experimental & Not measured & $67.7^{34,35}$ & Blocked $^{34,35}$ \\
\hline
\end{tabular}

The five-membered ring, as in cyclopentene, has an envelope conformation but the potential curve is very flat.

\subsection{Tautomerism and prototropy}

Although there are only three classes of pyrazolines, there are five tautomers when $R^{3} \neq R^{5}$ (Scheme 42). When one of the nitrogen atoms is substituted (replace $H$ by $R^{1}$ ) the number of tautomers is reduced to two 3pyrazolines (replace $H$ with $R^{2}$ ). Finally, if $R^{3}$ is an alkyl derivative $\left(\mathrm{CH}_{3}, \mathrm{CH}_{2} \mathrm{R}, \mathrm{CHRR}\right.$ ) there exists the possibility of an exo-methylene tautomer; ${ }^{15}$ the presence of this tautomer, which is always minor, and its dependence on the solvent and the temperature were studied. ${ }^{23}$ 


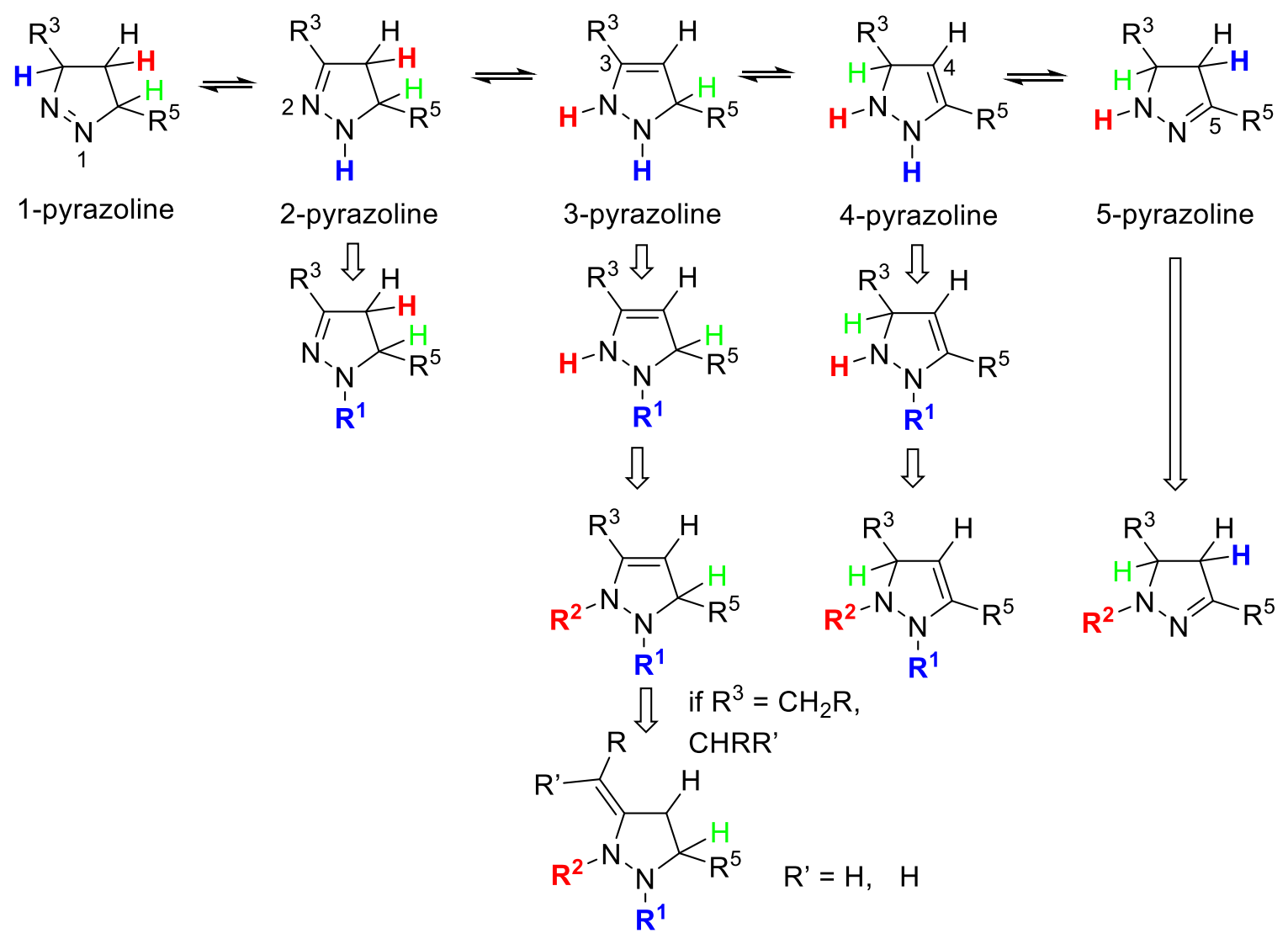

Scheme 42. The complex problem of the tautomerism of pyrazolines.

This phenomenon is important as far as the cyclic structures are concerned because there are numerous possible open-ring structures that in general are not very probable isomers. In the case of 2-pyrazolines the most stable is the hydrazone. ${ }^{144}$

In the Introduction we discussed the structure of $\mathrm{N}$-(2,2-dichloroacetyl)-3,5,5-trimethyl-pyrazoline-1carboxamide (YAKYAK) as either 3- (1) or 2- (2). ${ }^{10}$ The energies and optimized geometries of these species were calculated at the B3LYP/6-311++G(d,p) level (Figure 11). The 2-pyrazoline $\mathbf{2}$ is more stable than the 3-pyrazoline 1 by $75.8 \mathrm{~kJ} \cdot \mathrm{mol}^{-1}$. Some geometrical data are reported in Figure 11 and, since there are two independent molecules in the unit cell, the distances of the N1-N2-C3-C4 fragment have been averaged: there is no doubt that the structure of YAKYAK is that of a 2-pyrazoline 2. It is also worth noting that the conformation of the 2,2dichloroacetamide group is consistent with the presence of an $\mathrm{N}-\mathrm{H} \cdots \mathrm{N} 2$ hydrogen bond in structure 2.
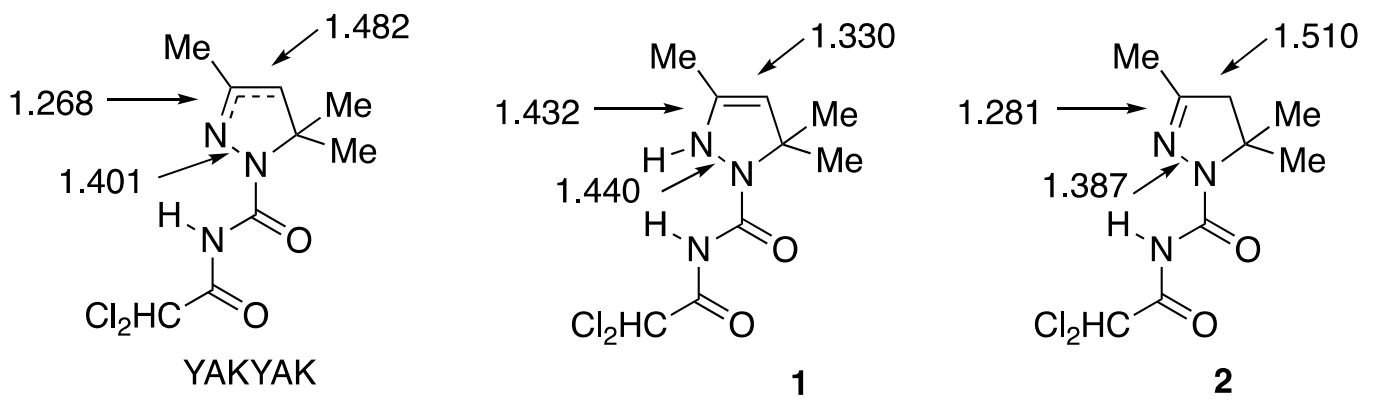

Figure 11. The structure of YAKYAK. 
We have already discussed how the isolation of a $2 \mathrm{H}$-3-pyrazoline 130 (Scheme 37) ${ }^{122}$ was incorrect. ${ }^{123}$ Other examples of $2 \mathrm{H}$-3-pyrazolines (Schemes 9 and 11 ) ${ }^{39,41}$ were also in doubt. ${ }^{145}$

By far the most interesting result was that reported by González-Nogal et al. (Scheme 37). ${ }^{137}$ According to these authors, the 3-pyrazoline 156 and the mixture of 156 and 157 were converted to the 3-pyrazoline 157 after several days at room temperature. The 3-pyrazoline $\mathbf{1 5 7}$ is the thermodynamic product because of its greater stability due to the conjugation of the double bond with the $N$-phenyl group. This isomerization was favored by an acidic medium when the experiment was carried out in an aqueous solution of ammonium chloride and probably involved C-protonated cations $\mathbf{H}^{+}$(Scheme 43).
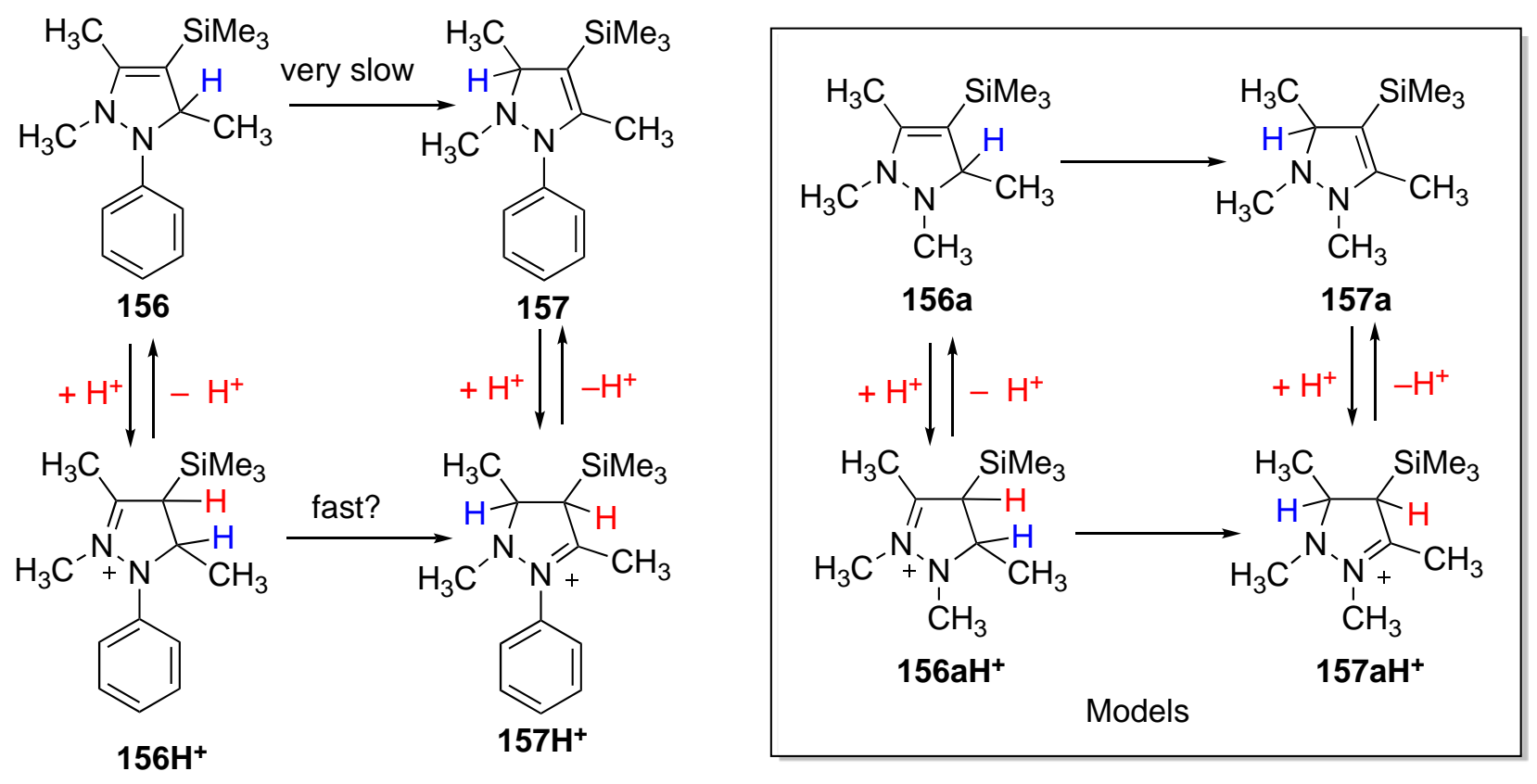

Scheme 43. $\Delta^{3} / \Delta^{4}$-pyrazoline tautomerism.

We carried out B3LYP/6-311++G(d,p) calculations on the compounds in Scheme 43 and these include model compounds (series a) in which the $N$-phenyl ring has been replaced by an $N$-methyl group. According to the calculations 157 is less stable than 156 by $31.0 \mathrm{~kJ} \cdot \mathrm{mol}^{-1}$. The barriers of the $\mathrm{C} 5 \mathrm{H}$ to $\mathrm{C} 3 \mathrm{H}$ proton transfer were calculated on the model compounds. In these compounds the initial and final compounds are the same (autotrope or degenerate tautomerism), i.e., $156 \mathrm{a} \equiv 157 \mathrm{a}$ and $156 \mathrm{aH}^{+} \equiv 157 \mathrm{aH}^{+}$, and this facilitates the location of the transition states (TSs). The calculated barriers are 313 and $236 \mathrm{~kJ} \cdot \mathrm{mol}^{-1}$, respectively, and these very high barriers are expected since they correspond to thermally forbidden [1,3] sigmatropic shifts (Figure 12). ${ }^{145-147}$

The decrease of the barrier, 313 to $236=77 \mathrm{~kJ} \cdot \mathrm{mol}^{-1}$, could be related to a difference in the geometry between a neutral 3-pyrazoline and a 2-pyrazolinium cation; the different pathways are apparent in Figure 12. However, a more important factor is that the difference in stability, which was $-31.0 \mathrm{~kJ} \cdot \mathrm{mol}^{-1}$ for the neutral

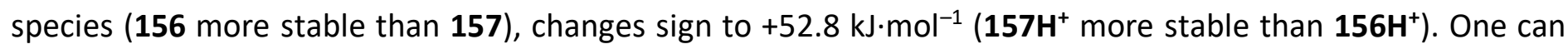

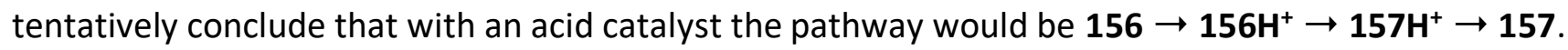

The exo/endo tautomerism of pyrazolines implies that the substituent at position 3 must be an $\mathrm{XH}$ group, $\mathrm{OH}, \mathrm{SH}, \mathrm{NHR}, \mathrm{CHRR}$ ', that is, groups such as $\mathrm{H}, \mathrm{C}_{6} \mathrm{H}_{5}, \mathrm{CRR}^{\prime} \mathrm{R}^{\prime}, \mathrm{COR}, \mathrm{CO}_{2} \mathrm{R}$, etc., cannot have exo tautomers. It is well known, for general tautomerism, that for $\mathrm{CH}_{2} \mathrm{R}$ and $\mathrm{CHRR}$ ' substituents to be stable as exo tautomers, the $\mathrm{R}$ groups should be $\mathrm{COR}, \mathrm{CO}_{2} \mathrm{R}$ or $\mathrm{CN} .{ }^{148}$ For this reason compounds $\mathbf{9 4 ,} 96$ and 97 (Scheme 26) exist as exomethylene-pyrazolidines. ${ }^{103,104}$ 

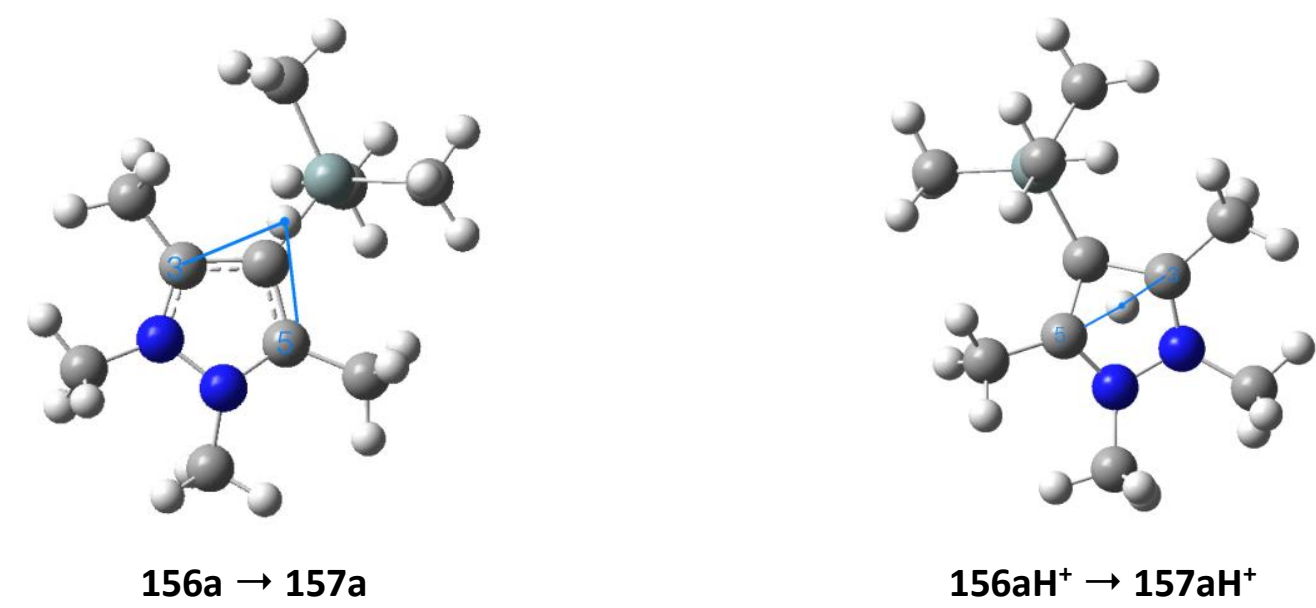

Figure 12. Transition states of 1,3-proton shifts.

The most important result was the determination of the tautomeric equilibrium constant $K_{\mathrm{T}}$ (endo/exo= $0.37,0.32$ and 1.0 ) and the dependence of $K_{T}$ on the nature of the solvent for compound 171 (Scheme 44). ${ }^{23}$

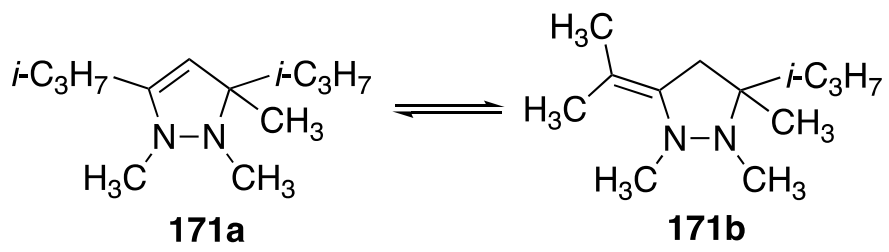

$\begin{array}{lll}\mathrm{CHCl}_{3} & 27 \% & 73 \% \\ \text { Chlorobenzene } & 27 \% & 73 \% \\ \text { Nitrobenzene } & 24 \% & 76 \% \\ \text { Pyridine } & 50 \% & 50 \%\end{array}$

Scheme 44. Presence of both endo/exo tautomers.

The equilibria between 171a and 171b were calculated at the [B3LYP/6-311++G(d,p)] level (Table 4).

Table 4. The endo/exo tautomerism of $\mathbf{1 7 1}$

\begin{tabular}{ccccccc}
\hline & \multicolumn{3}{c}{ \% endo population } & \multicolumn{3}{c}{$\mathrm{E}_{\mathrm{rel}}\left(\mathrm{kJ} \cdot \mathrm{mol}^{-1}\right)$} \\
\hline Endo & gas & nitrobenzene & pyridine & gas & nitrobenzene & pyridine \\
\hline Experimental & --- & 24 & 50 & --- & 2.7 & 0.0 \\
Calculated & 37.1 & 50.0 & 48.9 & 1.3 & 0.0 & 0.1 \\
\hline
\end{tabular}

The calculation does not reproduce the solvent effects but the energy differences are very small, i.e., less than $3 \mathrm{~kJ} \cdot \mathrm{mol}^{-1}$.

The Petrus group published a paper that contained some examples of endo/exo tautomerism (Scheme 45) where only one tautomer, $\mathbf{1 7 2 a}$ and $\mathbf{1 7 3 b}$, was observed. ${ }^{149}$ 


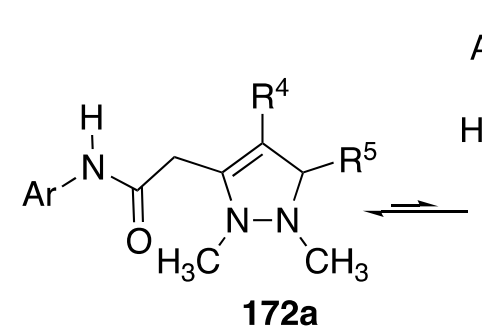<smiles>[R7]C1/C(=C\C(=O)N[Al])N(C)N(C)C1P</smiles><smiles>[R7]C1=C(C(C(=O)N[Al])C(=O)N[Al])N(C)N(C)C1PC=C</smiles><smiles>[Z7]C1C(=C(C(=O)N[Al])C(=O)N[Al])N(C)N(C)C1P</smiles>

Scheme 45. The effect of amide substituents on endo/exo tautomerism.

\subsection{Basicity, protonation and quaternization}

In a way similar to enamines, 150,151 3-pyrazolines have a kinetic (on N1) and a thermodynamic (on C4) site of protonation, as partly illustrated in Scheme 43. We will now explain how that conclusion was reached; UV and ${ }^{1} \mathrm{H}$ NMR spectroscopies and quaternary ammonium salts (Section 3.4) were used as techniques and models. ${ }^{92,152}$ The NMR approach will be illustrated using the oldest example, i.e., 1,2,4-trimethyl-3-phenyl-3-pyrazoline (176) obtained by reduction of the pyrazolium cation 175 (Section 2.3.2) and using the quaternary salt 179 as a model (Scheme 46). ${ }^{153}$ The identification of both methyl groups was carried out using deuteromethyl iodide instead of methyl iodide to quaternize pyrazole $\mathbf{1 7 4}$ - this labels the methyl group at position 2 of 175 resulting in the disappearance of the signals at 2.93 and $3.83 \mathrm{ppm}$ (Figure 13). ${ }^{133,153}$ The rate of the 1,4-proton transfer was determined and it has a first-order kinetic with a rate of $4^{*} 10^{-3} \mathrm{~s}^{1} .153$<smiles>Cc1cn(C)nc1-c1ccccc1</smiles><smiles>Cc1cn(C)[n+](C)c1-c1ccccc1</smiles>

175<smiles>CC1=C(c2ccccc2)[N+](C)(C)C[N+]1(C)C</smiles>

model compound
179

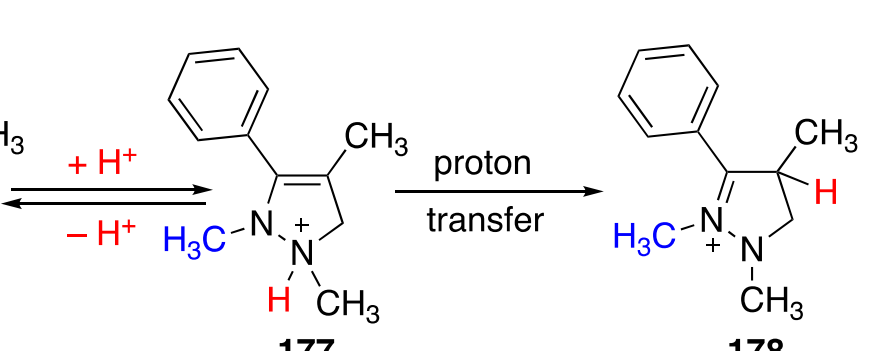

Scheme 46. 1,4-Proton transfer in 3-pyrazolines. 


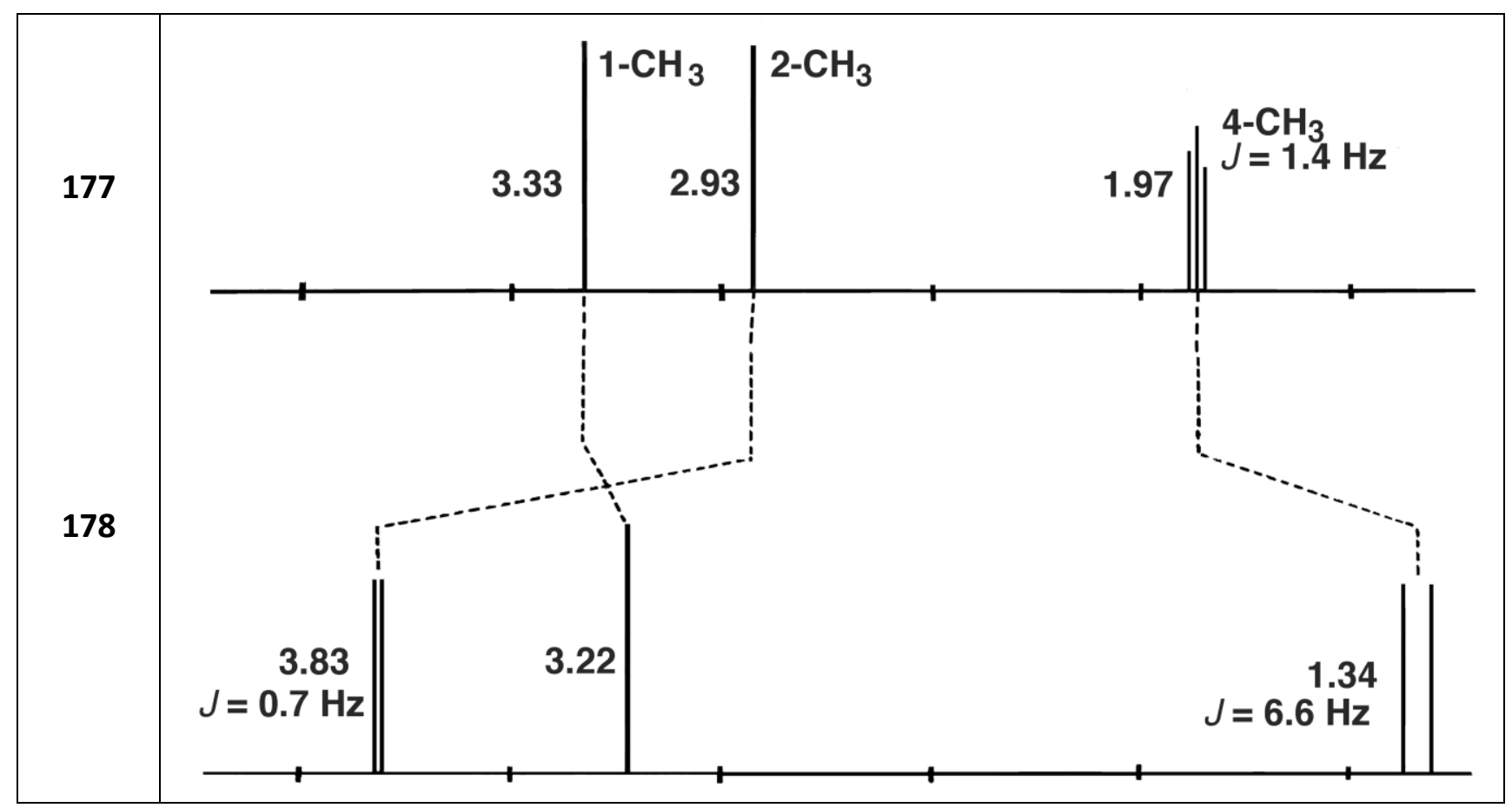

Figure 13. ${ }^{1} \mathrm{H}$ NMR spectra of compounds 177 and 178.

In two subsequent papers the model in Scheme 46 was refined. In the first paper it was proposed that the origin of 178, in addition to the isomerization of 177, could be the result of a direct protonation of 176 or a second protonation of $\mathbf{1 7 7}$ on C4 followed by loss of the proton on N1.154 In the second paper the stereochemistry of the C-protonation was discussed (Scheme 47). ${ }^{1} \mathrm{H}$ NMR experiments led to the conclusion that the protonation of 3-pyrazolines 180 affords the trans structure, i.e., the thermodynamic one 182; the kinetic one 181, corresponding to an attack at the less hindered face, was not observed (Scheme 47). ${ }^{155}$

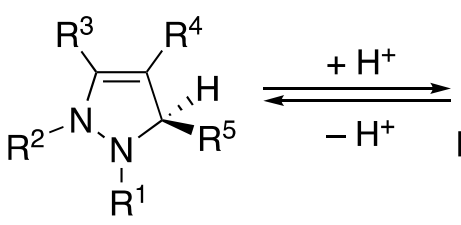

180<smiles>[R]C1=[N+]([R7])N([R7])C([R8])C1[R7]</smiles>

181<smiles>[R]C1=[N+]([O])N([R7])[C@@H]([R7])[C@H]1[Z17]</smiles>

182

Scheme 47. Stereochemistry of the C-protonation of 3-pyrazolines.

The kinetic (on N1) and thermodynamic (on C4) protonation of 3-pyrazolines can be hampered by the Bredt rule. ${ }^{156,157}$ In the case of 3-pyrazolines 114 (Scheme 48$)^{117}$ the $C$-protonation would lead to the unstable cation 184 (Scheme 48), which is similar to bicyclo[3.2.1] oct-5-ene, and for this reason the $N$-protonated cation 183 would be stable. 


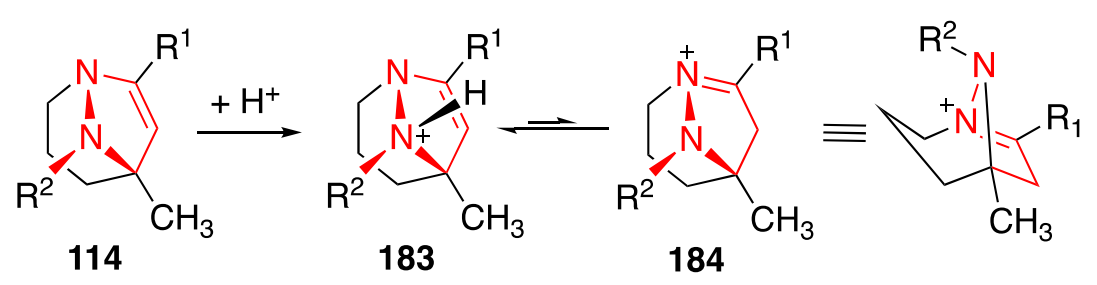

Scheme 48. Possible result of the protonation of 3-pyrazoline 114.

\subsection{Reactions on the nitrogen atoms}

In previous sections we have discussed quaternary structures $\left(13,19,23,156 \mathrm{Hb}^{+}, 157 \mathrm{Hb}^{+}, 178,179,181,182\right)$. All of the possibilities starting from 2-pyrazolines 185 and from 3-pyrazolines 186 are shown in Scheme 49. Quaternization of 2-pyrazolines only produces 187 but 188 can be obtained by protonation of 3-pyrazolines 186.

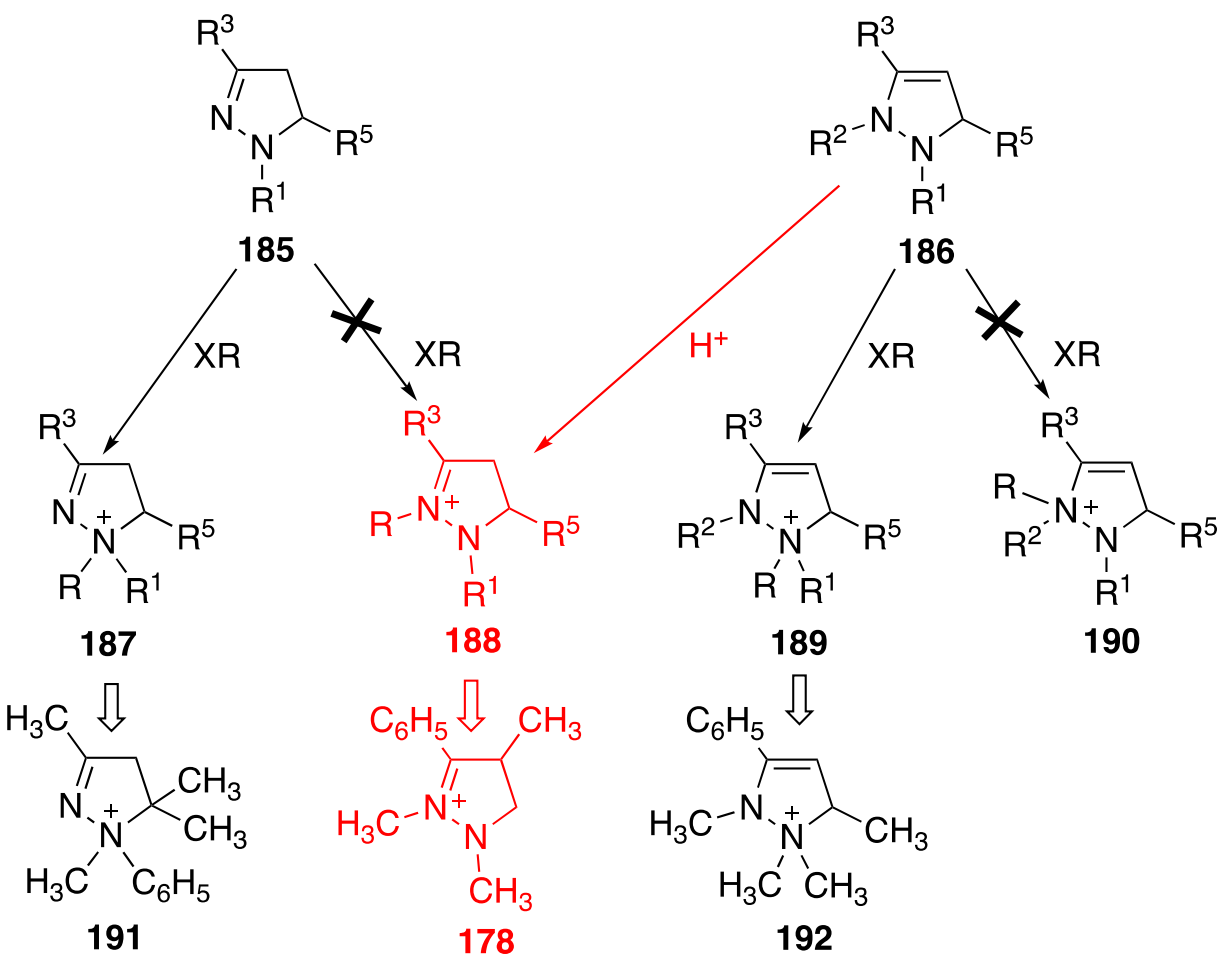

Scheme 49. Quaternization of 2-and 3-pyrazolines.

The only unknown quaternary salt is 190; Hinman methylated compound 12 but the position of the new methyl group was not determined, ${ }^{15}$ although the product most certainly has the structure 189. Several examples of compounds 187-189 with different substituents are shown in Scheme 49; compound 178 has already been discussed (Scheme 46) and compounds $191^{158}$ and $192^{153}$ were described in old publications. Evidence that the methylation of 185 occurs at position 1 , structure 187, was provided by a ${ }^{1} \mathrm{H}$ NMR study of 191 as only this structure explains why the methyl groups at position 5 give two different signals, with one being cis to the methyl and the other cis to the phenyl group. ${ }^{158}$ 


\subsection{Reactions of the C-substituents}

There is only one publication in which the reactivity of a $\mathrm{C}$-substituent of a 3-pyrazoline is discussed. The $\mathrm{Si}\left(\mathrm{CH}_{3}\right)_{2} \mathrm{Ph}$ and $\mathrm{Si}\left(\mathrm{C}_{6} \mathrm{H}_{5}\right)_{2}$ tBu groups of compounds 153-157 (Scheme 37) react with $\mathrm{BF}_{3}, \mathrm{I}_{2}$ and $\mathrm{CH}_{3} \mathrm{COCl}$ to afford different 3-pyrazolines 193, 194 and 195, with elimination of the corresponding silanes (Figure 14). Compound 194 was not isolated since it is oxidized by iodine to a pyrazolium salt. ${ }^{136}$

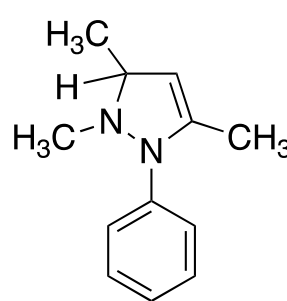

193
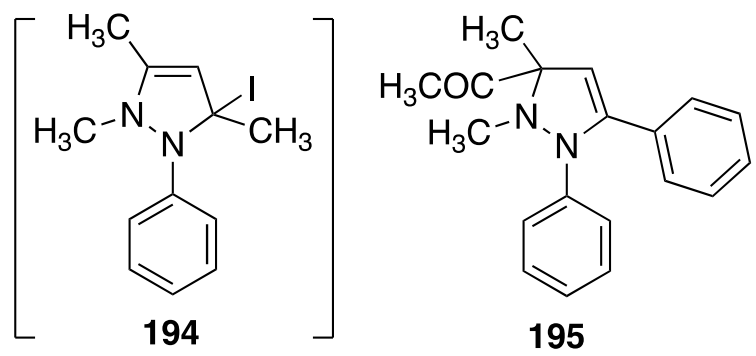

Figure 14. Pyrazolines prepared by elimination of silanes.

\subsection{Reactions on the CC double bond}

Petrus et al. published four important papers on a series of reactions of 3-pyrazolines with 1,3-dipoles that, depending on the dipole, lead to cycloadducts (Scheme 50) or to substitution reactions (enamine behavior, Scheme 51). Although several aryl groups were explored, only the phenyl groups are represented in Scheme 50.<smiles>[R9]C1=CC([PH3])C([PH3])N(C)N1C</smiles>

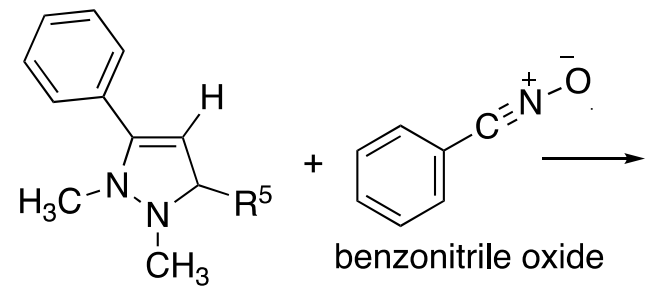

199<smiles>CN1C([PH])C2C(c3ccccc3)=NOC2(c2ccccc2)N1C</smiles>

200<smiles>[R]c1onc(-c2ccccc2)c1C([R])([2H])N(C)NC</smiles>

201

Scheme 50. Reactivity of 3-pyrazolines as dipolarophiles.

The reaction of 196 with phenyl azide led to a pyrazolidino-1,2,3-triazoline 197, which opened in an acidic medium to give 1,2,3-triazole $198 .{ }^{150}$ Similarly, but on using benzonitrile oxide, 199 was transformed to 200, which ring-opened to 201 in an acidic medium. ${ }^{159}$

Different behavior was observed in the reaction with phenyl isocyanate, where $\mathbf{2 0 3}$ was obtained from 202 (Scheme 51). ${ }^{160}$ The related case of compound 204 is more interesting; this compound exists in two tautomeric forms in rapid equilibrium, namely the endo 204a and the exo 204b, with the endo form being 
predominant; however, in the reaction with phenyl isocyanate $\mathbf{2 0 5}$ is the minor isomer and 206 the major one. ${ }^{161}$ The fact that the minor tautomer is the most reactive is known as the Gustafson paradox. ${ }^{149,161}$
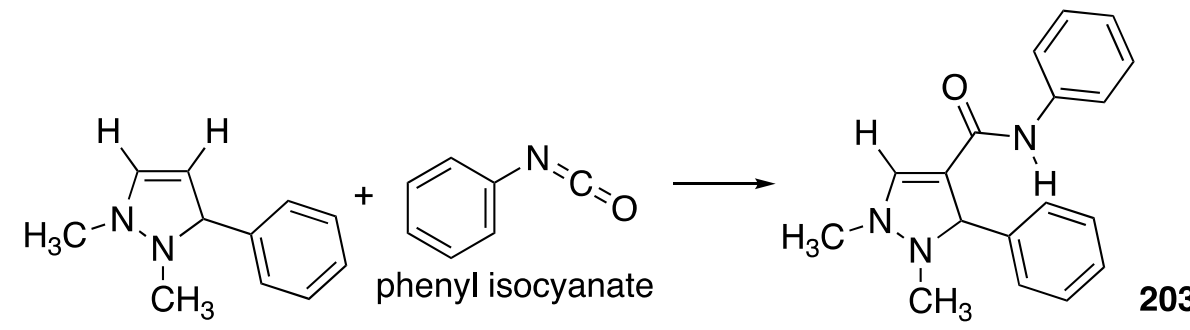

202

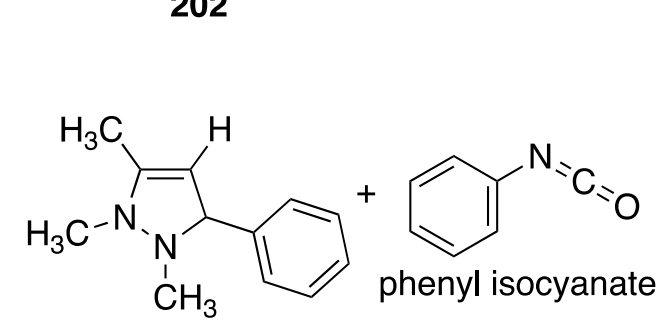<smiles>CC1=C(C(=O)N(C)c2ccccc2)C(c2ccccc2)N(C)N1C</smiles>

203
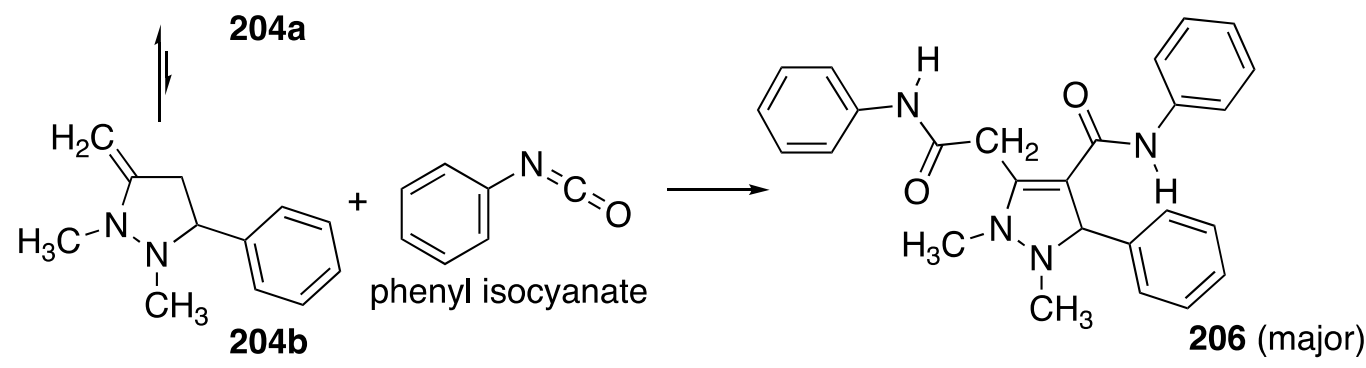

Scheme 51. Reactivity of 3-pyrazolines as enamines.

The last paper of this group studied (Scheme 52) the stereochemistry of [3+2] cycloaddition of benzonitrile oxide on a 3-pyrazoline 207, related to 199, to give pyrazolidino[4,3-d]2-isoxazoline 208 (Scheme 52). ${ }^{162}$ Two $R^{3} R^{5}$ cis products (Scheme 52) stereoisomers result on using a 3-pyrazoline disubstituted at positions 3 and 5, namely the $R^{3} R^{5}$ trans and the $R^{3} R^{5}$ cis. Epimerization of carbon $C 5$ by treatment with $12 \mathrm{~N} \mathrm{HCl}$ partly transforms 208 into 209 by a mechanism that involves ring opening of the pyrazolidine.<smiles>[R5]Oc1cccc(C#[N+][O-])c1</smiles>

207, $\mathrm{R}^{3}=\mathrm{C}_{6} \mathrm{H}_{5}$

$\mathrm{R}^{5}=\mathrm{CH}_{3}(\mathbf{a}), \mathrm{C}_{6} \mathrm{H}_{5}(\mathbf{b})$

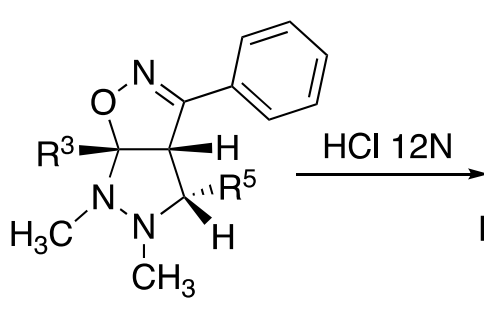

208<smiles></smiles>

209

Scheme 52. Cycloaddition of $\mathbf{2 0 7}$ with benzonitrile oxide and epimerization of 208 into 209.

We calculated the energies of $\mathbf{2 0 8}$ and $\mathbf{2 0 9}$ in both the $\mathbf{a}$ and $\mathbf{b}$ series (Table 5). 
Table 5. Relative energies $\left(\mathrm{kJ} \cdot \mathrm{mol}^{-1}\right)$ of the isomers 208 and 209 (Scheme 58).

\begin{tabular}{ccccc}
\hline & $\mathbf{2 0 8 a}$ & $\mathbf{2 0 9 a}$ & $\mathbf{2 0 8 b}$ & $\mathbf{2 0 9 b}$ \\
\hline $\mathrm{E}_{\mathrm{rel}}$ & 0.6 & 0.0 & 0.0 & 5.3 \\
\hline
\end{tabular}

In series a the result of the calculation is consistent with the epimerization of 208a to 209a but the value of $E_{\text {rel }}$ is very weak. In series $\mathbf{b}$ the calculation yields the opposite effect. We also calculated the two approaches of benzonitrile oxide to pyrazoline 207a; in this case the approach that yields 208a is favored, with a barrier of $50.1 \mathrm{~kJ} \cdot \mathrm{mol}^{-1}$ compared to $86.2 \mathrm{~kJ} \cdot \mathrm{mol}^{-1}$, which is consistent with the enamine behavior proposed by Jacquier et al. ${ }^{150}$

\subsection{Oxidation}

The formation of pyrazoles 109 and 110 from 3-pyrazolines 107 and 108, which were not isolated, was shown in (Section 2.2.4). ${ }^{113}$ 1,2-Dimethyl-3-phenyl-3-pyrazoline $\left(150, R^{1}=R^{2}=M e, R^{3}=P h, R^{4}=R^{5}=H\right)$ was oxidized to 1,2-dimethyl-3-phenyl-3-pyrazolium chloride 149 by trityl chloride (Section 2.3.2); other 1,2-dimethyl-3,4polymethylene-3-pyrazolines (Section 2.1.1) react with oxidizing agents to give the corresponding pyrazolium ions. ${ }^{16}$

\subsection{Reduction}

Several reducing agents have been used to reduce 3-pyrazolines to pyrazolidines: $\mathrm{H}_{2} / \mathrm{Pd}-\mathrm{C}^{15,126} \mathrm{NaBH}_{4}{ }^{130}$ $\mathrm{B}_{2} \mathrm{H}_{6}{ }^{155}$ and $\mathrm{I}_{2}+\mathrm{LiAlH}_{4}{ }^{121}$ In latter case the mechanism was studied by using all combinations of $\mathrm{LiAlH}_{4}$ and $\mathrm{LiAlD}_{4}$ followed by treatment with $\mathrm{H}_{2} \mathrm{O}$ and $\mathrm{D}_{2} \mathrm{O}$.

\subsection{Rearrangement}

The ring opening of 127 to afford 126 (Section 2.2.5) by irradiation was the first example of a rearrangement in these compounds. ${ }^{120}$ Compound 127 undergoes a conrotatory 1,5-electrocyclic ring-opening reaction to give 126 photochemically. Although 5-silyl-3-pyrazolines are stable at room temperature, when compound 210 is heated at $150{ }^{\circ} \mathrm{C}$, the ring opens by cleavage of the $\mathrm{N}-\mathrm{N}$ bond with silicon rearrangement to give an $\alpha$-silyl- $\beta$ diimine 211 (Scheme 53). ${ }^{136}$

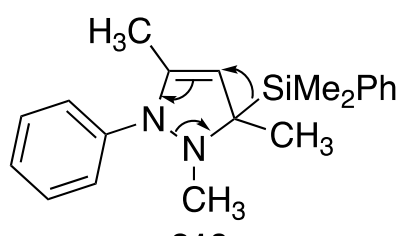

210

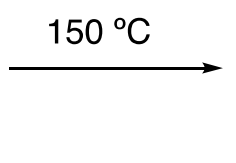<smiles>CNc1ccccc1</smiles>

Scheme 53. Rearrangement of 5-silyl-3-pyrazolines.

Huisgen et al. commented that examples of the rearrangement of 3-pyrazolines into 4-imidazolines were, and still are, lacking. ${ }^{116}$ 


\section{Structure, Spectra, and Physical Properties}

In this section we will highlight publications that contain specific discussions of the structure, spectra and physical properties of 3-pyrazolines. Publications that contain spectroscopic data in the experimental part only will not discussed. Note that older papers cite UV and IR results and, progressively, ${ }^{1} \mathrm{H}$ NMR data at low field, while more recent papers cite ${ }^{1} \mathrm{H}$ NMR and ${ }^{13} \mathrm{C}$ NMR data at high field and mass spectrometry data.

\subsection{UV spectra}

After two previous studies on the absorption of 3-pyrazolines, ${ }^{132,163}$ a complete discussion was published in the years 1969-1970, ${ }^{155}$ when a large number of 3-pyrazolines 212 were studied (Figure 15). The alkyl groups do not have any effect $\left(\lambda_{\max }=235-245 \mathrm{~nm}, \varepsilon \sim 3000\right)$, the effect of the phenyl groups on the $C$ atoms depend on the position, i.e., 3-phenyl, cross-conjugation ( $\left.\lambda_{\max }=270 \mathrm{~nm}, \varepsilon \sim 3000-6000\right)$, 4-phenyl, normal conjugation ( $\lambda_{\max }$ $=300 \mathrm{~nm}, \varepsilon \sim 8000)$. The case of $N$-phenyl derivatives is more complex due to the presence of two maxima. Note that $212 \mathrm{~m}$ is $207 \mathrm{a}$.
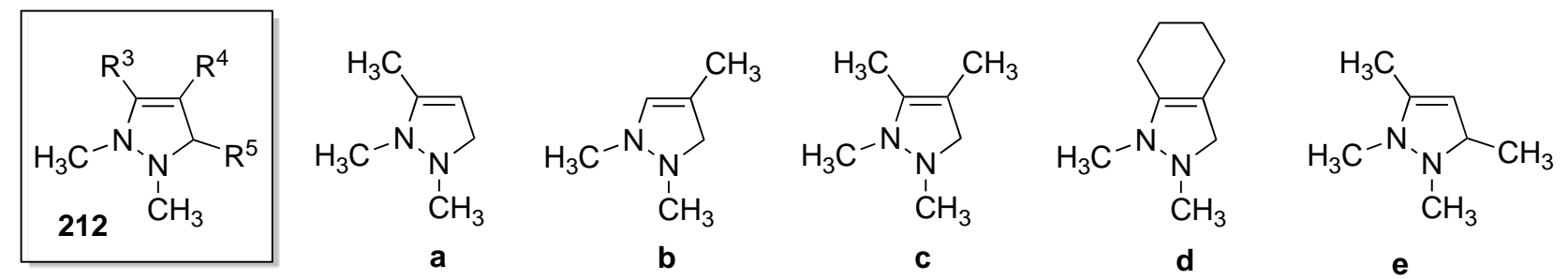<smiles>CC1=C(C)N(C)C(C)N1C</smiles>

f<smiles>CCC1=C(C)N(C)C(C)C1C</smiles>

g

h

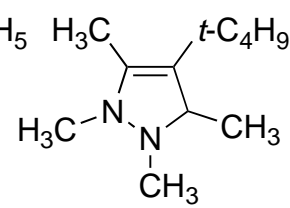

i<smiles>CN1CC=C([AsH2+])N1C</smiles>

j<smiles>CC1=C([18F])N(C)N(C)C1</smiles>

k<smiles>CC1=C([15CH3])N(C)N(C)C1</smiles>

I<smiles>CC1=CCN(C)N1CCCCCCCC1C(C)=C([15CH2])N(C)N1C</smiles>

$r$

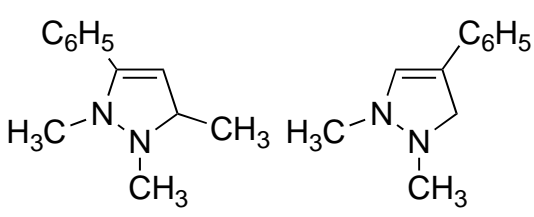

m<smiles>CCCCCCCCCCCCC</smiles>

o<smiles>CCCCCCC1=CN(C)N(C)C1C</smiles>

p<smiles>CC1=CC(c2ccccc2)N(C)N1C</smiles>

q<smiles>CC1=CN(c2ccccc2)N(C)C1</smiles>

$\mathbf{t}$<smiles>CC1=C(C)N(N2C=CC(C)N2C)N(C)C1</smiles>

u<smiles>[X]CN1C(C)C=C(C)N1Cc1ccccc1</smiles>

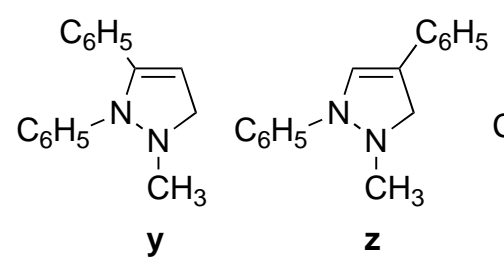<smiles>CN1C(S)=CC(Cc2ccccc2)N1C</smiles>

aa

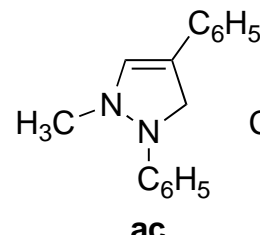

ac

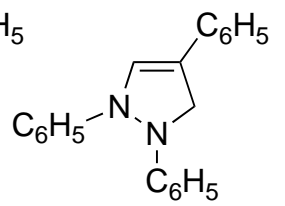

ad

Figure 15. 3-Pyrazolines studied by UV/visible spectroscopy in 95\% EtOH. 
Electronic spectra are no longer routinely used to characterize a compound and the main points of interest are the photophysics and photochemistry of these compounds as well the theoretical calculations of these properties.

\subsection{IR spectra}

Hinman et al. indicated that 1,2-dimethyl-3-phenyl-3-pyrazoline 212j (Figure 15) exhibits two characteristic bands in the IR spectrum (pure liquid): one at $1642 \mathrm{~cm}^{-1}$ attributed to the $\mathrm{C}=\mathrm{C}$ double bond and the other at $1580 \mathrm{~cm}^{-1}$ attributed to the phenyl conjugated to the double bond. ${ }^{15}$ Wagner-Jauregg and Zirngibl, with reference to the previous authors, assigned the reduction product of a pyrazolone as having a 3-pyrazoline structure because it exhibited a band at $1600 \mathrm{~cm}^{-1} .{ }^{125}$ We have shown that it is in fact a 2-pyrazoline, with the band at $1600 \mathrm{~cm}^{-1}$ being assignable to the phenyl at position $1 .^{126}$

The 1,2-dimethyl-3-pyrazolines that we prepared (Figure 15) were studied by IR spectroscopy (solvent $\mathrm{CHCl}_{3}$ ). The first UV group of Figure 15 (only alkyl substituents) showed a band at $1665-1675 \mathrm{~cm}^{-1}$ attributable to the $\mathrm{C}=\mathrm{C}$ double bond (in enamines it is found at $1650-1660 \mathrm{~cm}^{-1}$ ), ${ }^{164}$ whereas the second UV group ( $N$-phenyl substituents) showed two styryl bands (whether the phenyl is in position 3 or 4) at 1595-1600 and 1640-1650 $\mathrm{cm}^{-1}$.

\section{3. ${ }^{1} \mathrm{H}$ NMR spectra}

At a time when NMR spectroscopy was limited to ${ }^{1} \mathrm{H}$ spectra recorded on low-field instruments, problems were solved 'chemically' with deuterium-labeled compounds and by analogy with model compounds. This was the era before Fourier Transformation, ${ }^{13} \mathrm{C}$ and ${ }^{15} \mathrm{~N}$ NMR spectroscopies, and 2D experiments and it covers most of the publications from 1965 to 1973, during which $56.4 \mathrm{MHz}$, then $60 \mathrm{MHz}$ and finally $100 \mathrm{MHz}$ spectrometers were employed.

Our 1965 paper concerned the use of ${ }^{1} \mathrm{H}$ NMR spectroscopy to determine the structure of 3-pyrazolines 212j and 2120, including the exo/endo tautomerism in the latter case. ${ }^{164}$

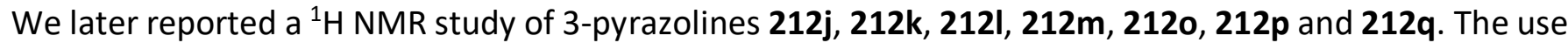
of $H / D$ exchange in 2-pyrazolinium salt $\mathbf{2 1 3}$ to afford 213- $d_{5}$ enabled the preparation of the deuterated analog of $\mathbf{2 1 2 q}, \mathbf{2 1 2 q}-d_{4}$, which proved useful to identify some long-range ${ }^{1} \mathrm{H}-{ }^{1} \mathrm{H}$ spin-spin coupling constants (SSCC) (Scheme 54). ${ }^{132,153}$
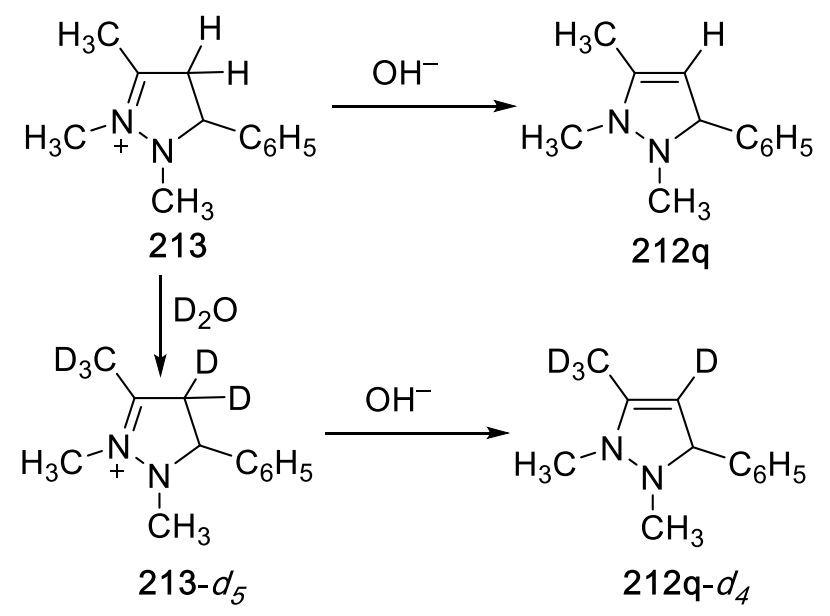

Scheme 54. Deuteration at positions 3 and 4 of pyrazoline 212q. 
A similar study on pyrazolines 212a, 212b, 212c, 212d, 212e, 212j, 212k, 212l, 212m, 212q and 2120 also involved $\mathrm{H} / \mathrm{D}$ exchanges but the major emphasis was on ${ }^{1} \mathrm{H}-{ }^{1} \mathrm{H}$ SSCC, for instance in compounds $\mathbf{2 1 2 a}$ and $\mathbf{2 1 2 k}$ (Figure 16). ${ }^{155}$
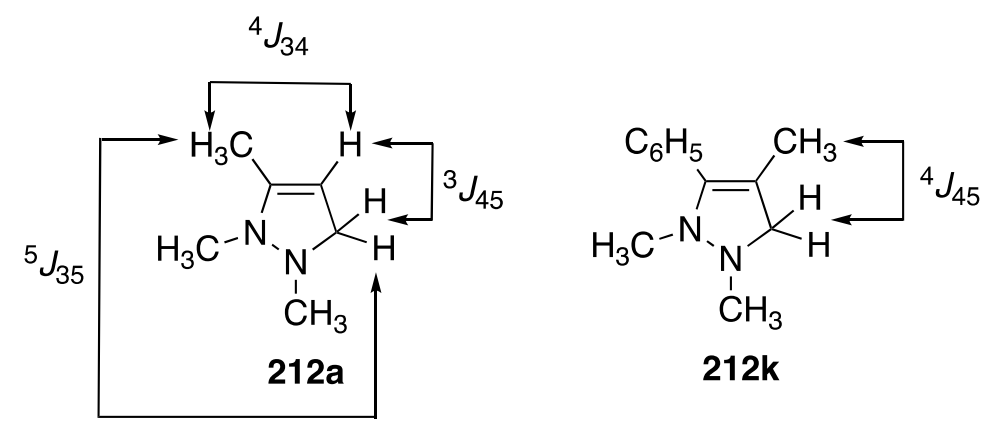

Figure 16. Long-range SSCC.

A classical example of diastereotopic protons was observed in the isopropyl groups of pyrazoline 214 (1.00 and $1.03 \mathrm{ppm}$ ) but not in 169 (1.02 ppm), possibly because the $i$-Pr group is further from the stereocenter at position 5 and because the ${ }^{1} \mathrm{H}$ NMR spectra were recorded at $60 \mathrm{MHz}$ (Figure 17). ${ }^{165}$<smiles>C[C]1C=C(C)N(c2ccccc2)N1C(C)C</smiles>

214<smiles>Cc1ccc(C)n1-c1ccccc1</smiles>

169

Figure 17. Chiral consequences of the methyl substituent at C5.

A major paper was published in $1970^{154}$ on the NMR spectra of a large series of 3-pyrazolines recorded in $\mathrm{CDCl}_{3}$. Amongst others, compounds 212f, 212g, 212h, 212i, 212j, 212k, 212m, 212n, 212o, 212p, 212r, 212s, 212t, 212u, 212v, 212x, 212y, 212z, 212aa, 212ab, 212ac and 212ad are represented in Figure 15. Besides the results reported in Figure 17, the $\mathrm{CH}_{2}$ part of the 1-ethyl substituent of compound $212 \mathrm{x}$ also presented diastereotopicity (2.84 and $2.00 \mathrm{ppm}$ ). Another aspect discussed in this paper is the successful application of the Matter, Pascual, Pretsch, Pross, Simon and Sternhell rules for olefins ${ }^{166}$ to the C3C4 double bond of 3pyrazolines. 
Table 6. Torsion angles and ${ }^{1} \mathrm{H}$ chemical shifts of the phenyl groups of $\mathbf{2 1 2} \mathbf{j}$ and $\mathbf{2 1 2} \mathbf{y}$.

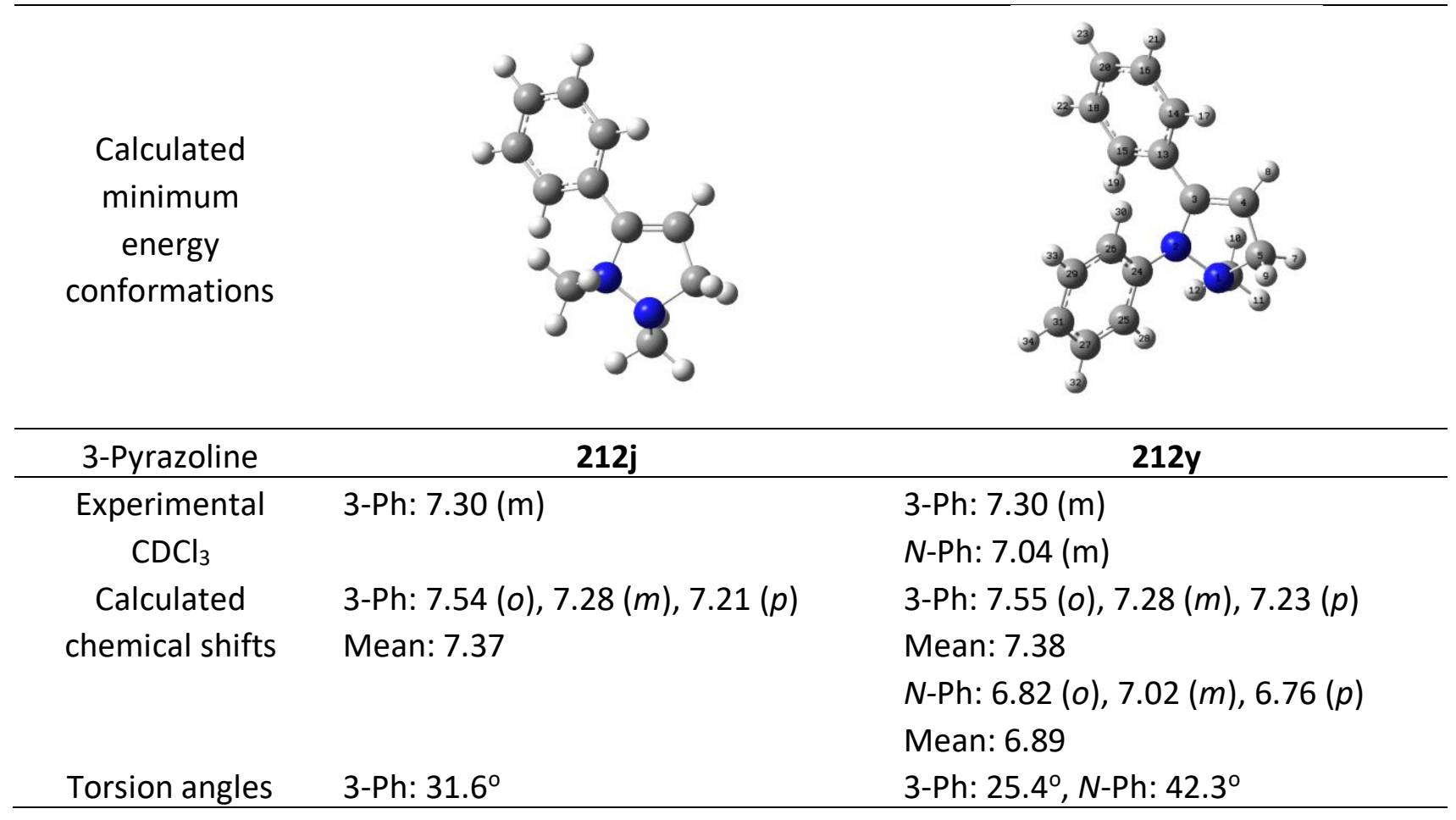

Based on the ${ }^{1} \mathrm{H}$ chemical shifts in the NMR spectra at $60 \mathrm{MHz}$, the assignment of the C-and $N$-phenyl groups of 3-pyrazolines $\mathbf{2 1 2 j}$ and $\mathbf{2 1 2 y}$ was achieved (Table 6). ${ }^{154}$ Calculations at the GIAO/B3LYP/6-311+G(d,p) level reproduced adequately these findings and provided information about the conformation of the phenyl groups.

In $1973{ }^{1} \mathrm{H}$ NMR spectra were recorded at $100 \mathrm{MHz}$ and experiments such as decoupling of $N$-methyl protons were carried out. ${ }^{133}$ The increased precision allowed the creation of a model for the $N$-methyl groups that included the effects of the phenyl groups at positions 3, 4 and 5 on 1-methyl and 2-methyl chemical shifts.

In much more recent studies NMR was used to determine the inversion barrier of the $\mathrm{N}-\mathrm{R}$ groups (Section 3.1, Table 3, compounds 169 and 170) using 300, 400 and $500 \mathrm{MHz}$ spectrometers to record the ${ }^{1} \mathrm{H}$ NMR spectra at different temperatures. ${ }^{34,35} \mathrm{~A}$ paper dealing with theoretical calculations of 3-pyrazolines will be discussed in Section 4.7. ${ }^{143}$

\section{4. ${ }^{13} \mathrm{C}$ NMR spectra}

Kostyanovsky et al. reported the chemical shifts in $\mathrm{CDCl}_{3}$ at $100.61 \mathrm{MHz}$ of the methyl groups of the $\mathrm{N}$-isopropyl substituents of compound 215 at $17.73\left(\mathrm{Me}_{\mathrm{A}}\right)$ and $19.34 \mathrm{ppm}\left(\mathrm{Me}_{\mathrm{B}}\right)$ for the 1-iPr group and $19.60\left(\mathrm{Me}_{\mathrm{A}}\right)$ and $19.77 \mathrm{ppm}\left(\mathrm{Me}_{\mathrm{B}}\right)$ for the 2-iPr group (Figure 18). For the 1-iPr group the anisochronism amounts to $160 \mathrm{~Hz} .^{34} \mathrm{In}$ the case of compound 170, the methyl signals of the methyl groups at positions 1 and 2 are, as expected, different with shifts of 27.63 and 28.23 ppm. ${ }^{35}$

${ }^{13} \mathrm{C}$ NMR data for 3-pyrazolines have been reported in several recent papers, albeit without a detailed discussion ${ }^{40,117}$ until an experimental and theoretical paper was published in $2021 .{ }^{143}$ 


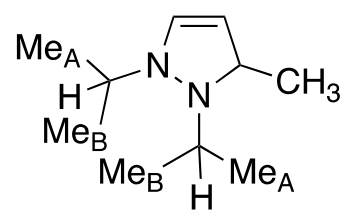

215

Figure 18. The structure of pyrazoline 215.

\section{5. ${ }^{15} \mathrm{~N}$ and ${ }^{19} \mathrm{~F}$ NMR spectra}

Experimental data have not been published for ${ }^{15} \mathrm{~N}$ NMR spectroscopy of 3-pyrazolines and only calculated values are available. ${ }^{143}$ For compound $\mathbf{4 3}$ (Scheme 10) the ${ }^{19} \mathrm{~F}$ chemical and ${ }^{19} \mathrm{~F}-{ }^{19} \mathrm{~F}$ SSCC were reported. ${ }^{42,43}$

\subsection{X-ray molecular structures}

Exploration of the Cambridge Structural Database (CSD uses six capital letters called Refcodes) ${ }^{167}$ yielded numerous 3-pyrazoline structures although some of them are not 3-pyrazolines but 2,3-dihydro-1H-indazoles 3. We have already discussed some structures such as YAKYAK (Figure 1), UZIRUR (Figure 9) and ZEWBAH (Figure 10).

In Section 2.2.3 it was outlined how the difficult problem of assigning the bromo- and fluorophenyl groups of compound 99 was solved by X-ray crystallography (CEZDIV, Figure 19). ${ }^{109}$

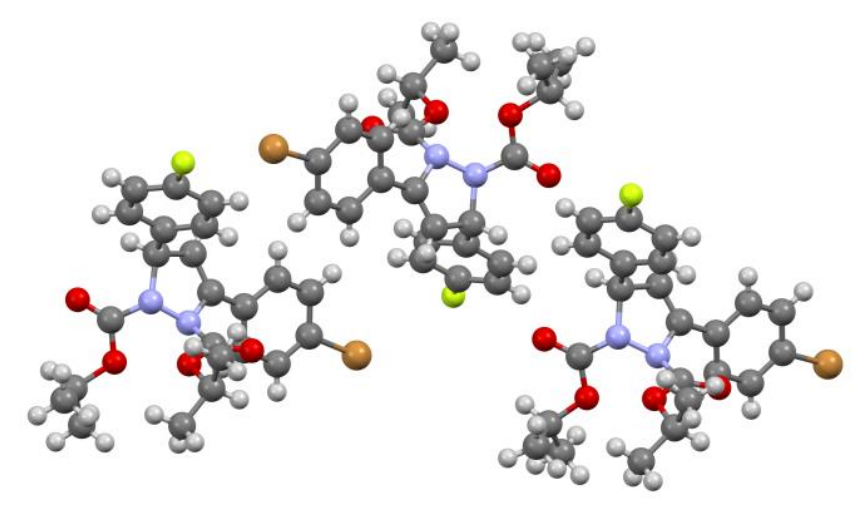

Figure 19. The three independent molecules of CEZDIV.

Many other structures of compounds cited previously have been determined, either as represented or with specific substituents instead of generic R groups: 26, VEYBUW; ${ }^{37}$ 48, KULNOV; ${ }^{47}$ 54, AHEFEA, ${ }^{64}$ and JADSOZ; ${ }^{65}$ 57, NECSEW; ${ }^{66}$ 58, YOHRIZ; ${ }^{67}$ 61, BEZTAD, BEZTASD01, OZEGUW; ${ }^{69,70}$ 67, UDAJIU; ${ }^{79}$ 101, UVUZUH; ${ }^{110}$ 104 (PORLUG); 111113 (DAHKIG); ;114 121 (NUTRUQ); 119163 (AMZNON10); ; ${ }^{140}$ and 165 (DAPZOJ). ${ }^{141}$

\subsection{Computational results}

As an essential component of structural studies, computational studies have been carried out on 3-pyrazolines by several authors, including ourselves. In one paper, the 3-pyrazoline fragment was included in a list of possible effects of pentagonal fragments on aromaticity. ${ }^{168}$ Kraka, Cremer et al. studied theoretically the reaction of azomethine imine $\mathbf{2 1 6}$ with acetylene to afford the parent 3-pyrazoline $\mathbf{1 5 9}$ (Scheme 55); the level of the 
calculations was CCSD(T)-F12/aug-cc-pVTZ. ${ }^{169}$ The authors represented the 3-pyrazoline ring as being folded about N1‥C4. ${ }^{143}$

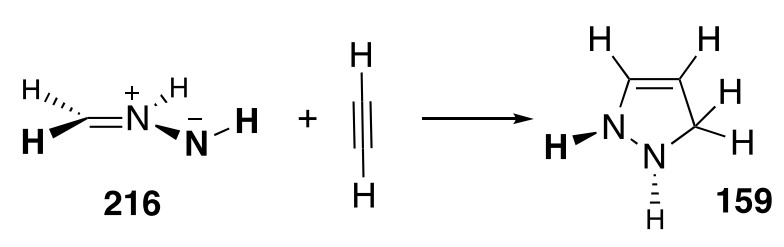

Scheme 55. A theoretical study of a [3+2] cycloaddition.

Our contribution was reported in three papers. ${ }^{143,144,170}$ The first paper ${ }^{143}$ concerns the three pyrazoline isomers (Scheme 42) and the 3-pyrazoline structures, 159 and 168, calculated [B3LYP/6-311++G(d,p)] are shown in Figure 20. For compounds 188 to 190 (Scheme 49), $R=R^{1}=R^{2}=R^{3}=R^{5}=H$.<smiles>CN1CC=CN1</smiles>

159<smiles>CN1C=CCC1N</smiles>

168<smiles>c1c[nH+][nH+][nH]1</smiles>

188<smiles>C1=CN[NH2+]C1</smiles>

189<smiles>C1=CCN[NH+]=C1</smiles>

190

Figure 20. Theoretical calculations of simple 3-pyrazolines.

The study concerns conformational aspects (ring folding and $\mathrm{N}$ inversions of 159 and 168, Section 3.1), tautomerism between 1-, 2- and 3-pyrazolines and between cations (Section 3.2), protonation (compounds 188-190 Section 3.4) and GIAO (Gauge-Independent Atomic Orbital) calculations of chemical shifts of all compounds in Figure 20. ${ }^{144}$

We devoted a paper ${ }^{170}$ to the analysis of two publications by Hamme II et al. and these are summarized in Scheme 56. ${ }^{171,172}$
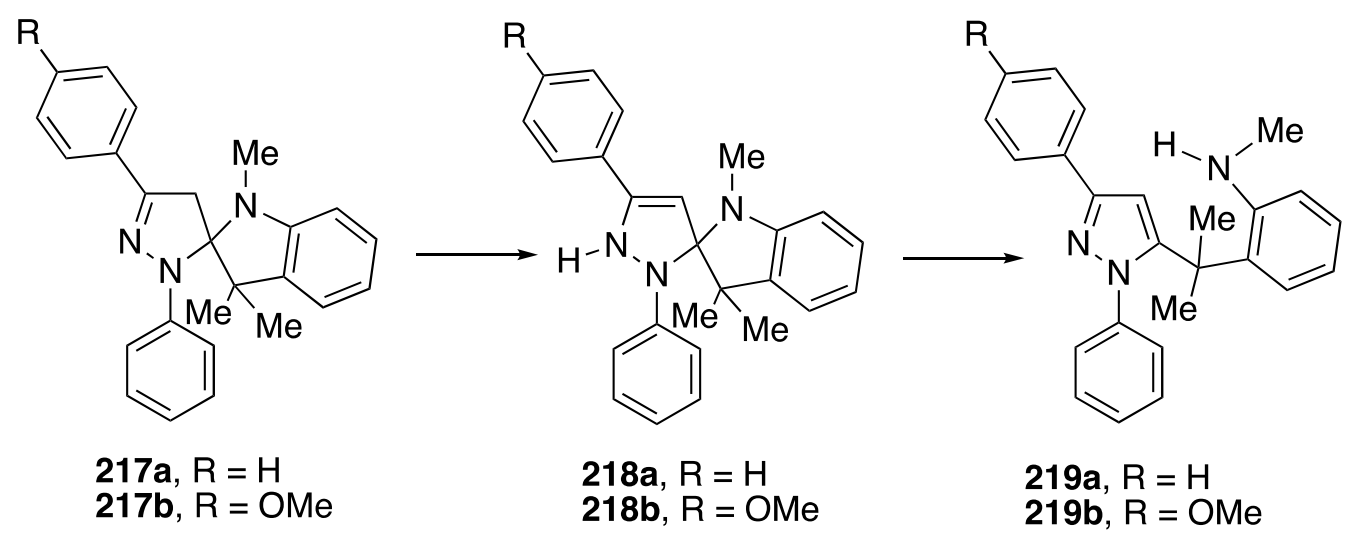

Scheme 56. Structures of the compounds studied by Hamme II.

In the first paper (series $a, R=H$ ) the authors explained that the formation of pyrazole 219a (X-ray structure, refcode CORTEJ) from 2-pyrazoline 217a involves a non-isolated 3-pyrazoline 218a. ${ }^{172}$ Our calculations 
agree with the data reported for the isolated compounds 217 a and $219 a$, including a hydrogen bond between the $\mathrm{N}-\mathrm{H}$ and the $\pi$-system of the pyrazole ring. ${ }^{171}$

The second paper is more contentious and it concerns series $\mathbf{b}(\mathrm{R}=\mathrm{OMe}) .{ }^{173}$ The $\mathrm{X}$-ray structure of $\mathbf{2 1 7 \mathbf { b }}$ was represented but the depository number with CCDC (701051) corresponds to 219a and the structure of 217b was never deposited in the Cambridge Structural Database. The authors studied the dependence of the $\mathbf{2 1 7 b} \mathbf{b} \mathbf{2 1 8} \mathbf{b}$ equilibrium on the solvent $\left(\mathrm{CDCl}_{3}, \mathrm{C}_{6} \mathrm{D}_{6}, \mathrm{CF}_{3} \mathrm{CO}_{2} \mathrm{H}\right)$ but we demonstrated that 3-pyrazoline $\mathbf{2 1 8 b}$ was in fact pyrazole 219b. ${ }^{171}$

One of our two last papers ${ }^{143}$ concerns the structural and spectroscopic properties of the compounds gathered in Figure 21 calculated at the [B3LYP/6-311++G(d,p)] level; some of these compounds have already been discussed and others are new (220 to 225). The aspects covered include the conformation of the fivemembered ring and the inversion of $\mathrm{N}-\mathrm{R}$ substituents (Table 3, Section 3.1.) and the calculation of chemical shifts $\left({ }^{1} \mathrm{H}\right.$-Section $4.3-{ }^{13} \mathrm{C}$-Section 4.4- and ${ }^{15} \mathrm{~N}$-Section 4.5) using the GIAO approximation.<smiles>CN1C=CC2C=CCN21</smiles>

168<smiles>CC(C)CN1C=CC2C=CC21[Y17](=O)[O-]</smiles><smiles>CC1=CC(C)C(N(c2ccccc2)C(C)C)N1C(C)C</smiles>

169<smiles>CN1CCC=C1c1ccccc1</smiles>

212j<smiles>CCCCN(CC(C)C)C1C(C)C=CN1CC(C)C</smiles><smiles>C1=CN(c2ccccc2)N(c2ccccc2)C1</smiles>

224<smiles>CC(C)N1C=CCC1N(C(C)C)C(C)C</smiles>

220<smiles>[Z16]N(CC(C)C)N1C(C)=CC(C)C1C</smiles><smiles>Pc1ccccc1</smiles><smiles>CC1C=CN(C(C)C)N(C(C)C)C1</smiles>

215<smiles></smiles><smiles>[Z10]C([Z10])N1C(C)C=C(C)N1c1ccccc1</smiles>

Figure 21. 3-Pyrazolines studied theoretically.

The calculated profiles of the trans epimerization and cis/trans isomerization of compound 168, the simplest of the 1,2-disubstituted-3-pyrazolines, are provided in Figure 22. Both TSs, namely TS1 and TS2, which correspond to the inversion barriers of N2-Me (low barrier) and N1-Me (high barrier), respectively, were calculated. There are two trans enantiomers and therefore the double nitrogen inversion corresponds to enantiomerization processes (Figure 22). The fact that TS1 < TS2 is a consequence of the stabilization of TS1 by conjugation with the $\mathrm{C} 3 \mathrm{C} 4$ double bond. The two cis-isomers are enantiomers. 


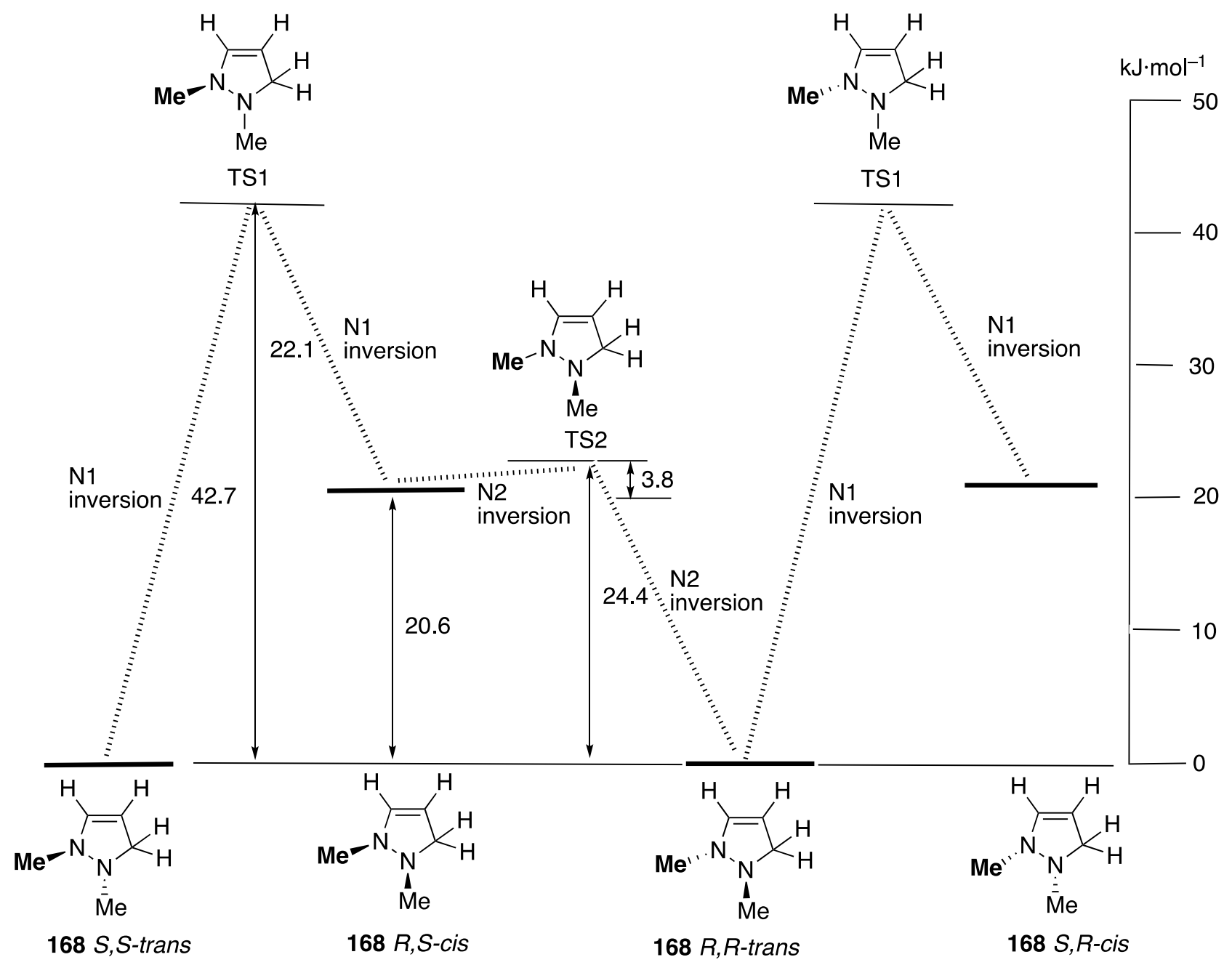

Figure 22. Profile of the inversion processes occurring in 1,2-dimethyl-3-pyrazoline.

The ${ }^{1} \mathrm{H},{ }^{13} \mathrm{C}$ and ${ }^{15} \mathrm{~N}$ NMR chemical shifts were calculated for the most stable conformer (168 trans) using [GIAO/B3LYP/6-311++G(d,p)]. Begtrup reported in 1973 that the conformation about the N1-Cipso bond of the $\mathrm{N}$-phenyl group of azoles is related to the difference in chemical shifts between $\mathrm{Cmeta}$ and Cortho $(\mathrm{Cm}-\mathrm{Co}) .{ }^{173}$ This method, which provides a qualitative assessment of the degree of interannular conjugation, ${ }^{174}$ was based on ${ }^{13} \mathrm{C}$ chemical shifts determined in solution and semi-quantitative considerations about steric effects that must rotate the phenyl group. ${ }^{175,176}$ This method was recently applied to phenyl pyrazoles using experimental chemical shifts and dihedral angles $\vartheta$ calculated by molecular mechanics. ${ }^{177}$ Concerning the 3-pyrazolines of the reported paper, ${ }^{143}$ two equations of medium quality were found:

$\mathrm{Cm}-\mathrm{Co}=(13.8 \pm 1.4)-(0.21 \pm 0.02) \vartheta, \mathrm{n}=17, \mathrm{R}^{2}=0.83, \mathrm{RMS}$ residual $=3.1 \mathrm{ppm}$

$\mathrm{Cm}-\mathrm{Co}=-(3.6 \pm 1.2)+(15.9 \pm 2.0) \cos ^{2} \vartheta, \mathrm{n}=17, \mathrm{R}^{2}=0.82, \mathrm{RMS}$ residual $=3.2 \mathrm{ppm}$

Using the 80 available experimental ${ }^{1} \mathrm{H}$ and ${ }^{13} \mathrm{C}$ NMR data our calculations agree remarkably well:

${ }^{1} \mathrm{H} \&{ }^{13} \mathrm{C}$ : Exp. $=(1.016 \pm 0.004)$ Calc., $\mathrm{R}^{2}=0.999, \mathrm{RMS}$ residual $=1.4 \mathrm{ppm}$,

The second of our last two papers concerned the mechanism of formation of 2-pyrazolines 226 and 227 starting from $p$-methyl-chalcone 228 and four hydrazines 229a, 229b, 229c and 229d. ${ }^{145}$ The mechanism provided in Scheme 57 involves carbinolamines 230 and 233, hydrazones 231 and 232, hydroxypyrazolidines 234 and 239, Michael addition compounds 237 and 238 and 3-pyrazolines 235, 236 and 240 (240a,b,c were reported previously with the numbers 29,30 and 33). A double addition product 241 was also characterized. 


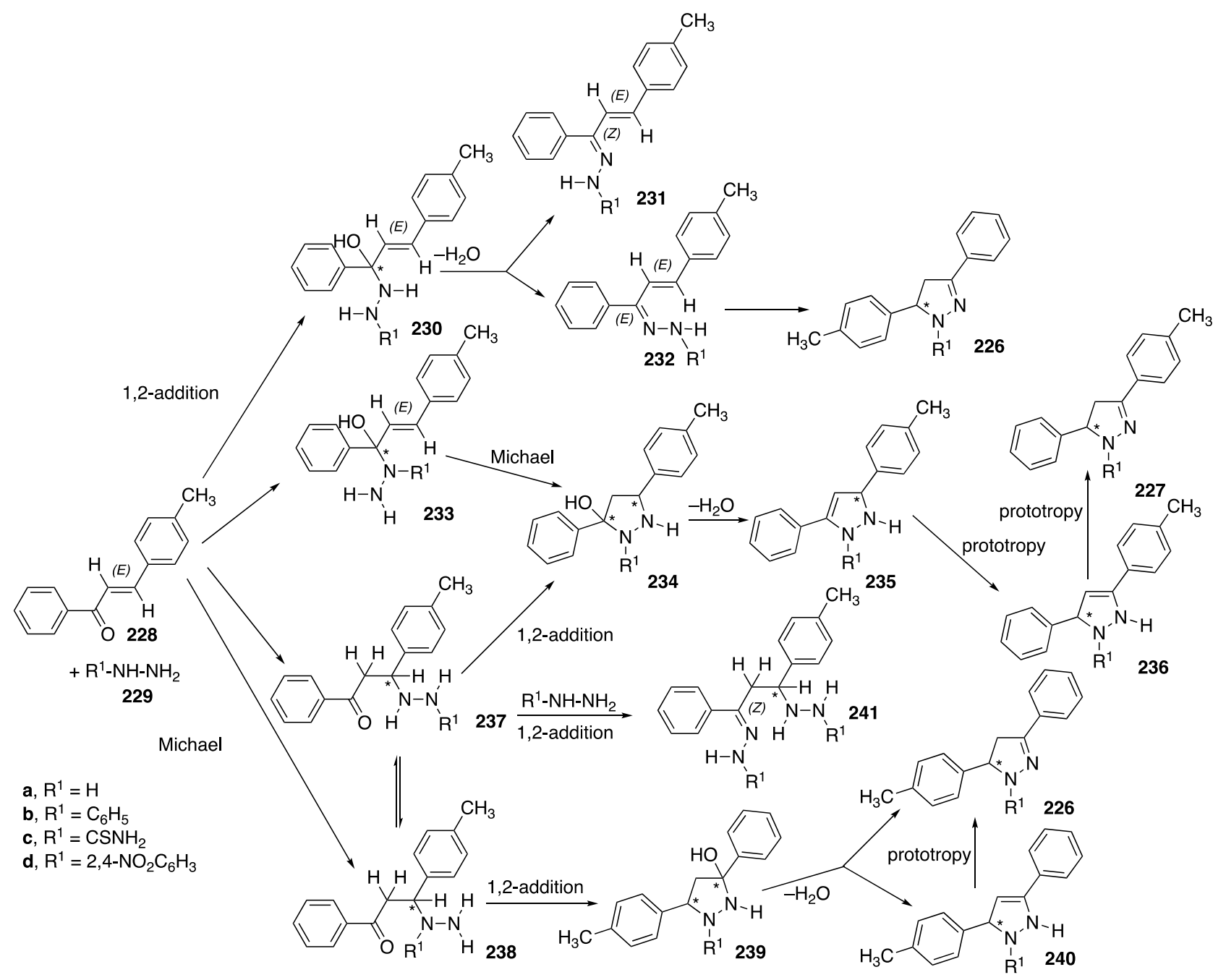

Scheme 57. Different mechanisms for the formation of 2-pyrazolines 226 and 227.

One of the intriguing aspects of Scheme 57 concerns the transformation $\mathbf{2 3 5} \rightarrow \mathbf{2 2 7}$. Compound $\mathbf{2 3 5}$ is a 3-pyrazoline that some authors called a 4-pyrazoline by numbering the ring from the $\mathrm{N}$-substituted atom. The stability, in the sense of the reason why 3-pyrazolines do not isomerize into 2-pyrazolines, is summarized in Scheme 58.
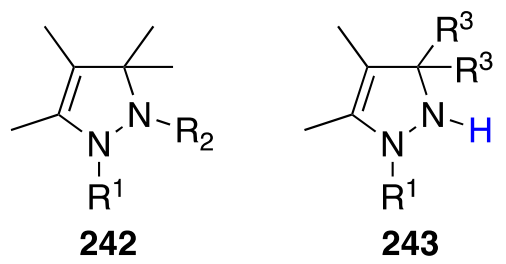

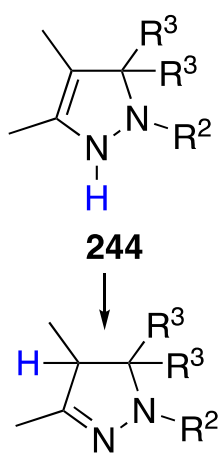

246

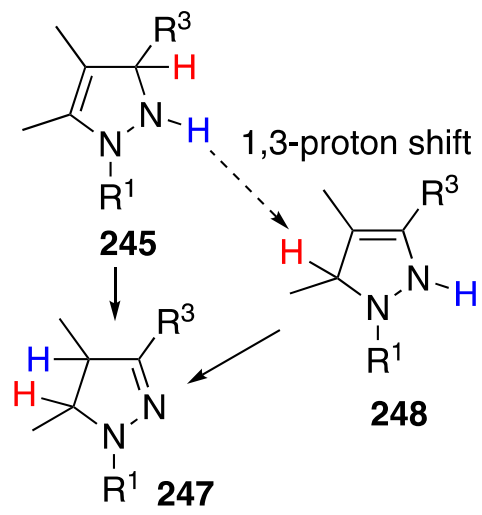

Scheme 58. The 3- to 2-pyrazoline isomerization channels. 
1,2-Disubstituted 3-pyrazolines 242 and 3,3'-disubstituted 3-pyrazolines 243 cannot isomerize into 2pyrazolines; 2,3,3-tribstituted-3-prazolines 244 isomerize to 2-pyrazolines 246, the $\mathrm{R}^{3}$ substituents can be $\mathrm{H}$ or different from $\mathrm{H}$, the process corresponds to an enamine/imine ${ }^{178-181}$ or enehydrazine/hydrazone ${ }^{23,182-185}$ tautomerization. The most important result is the transformation $\mathbf{2 4 5} \rightarrow \mathbf{2 4 7}$, which is equivalent to $\mathbf{2 3 5} \rightarrow \mathbf{2 2 7}$ (Scheme 59); $\mathbf{2 3 5}$ has never been isolated or detected in any of the studies cited previously. Both steps in the processes $\mathbf{2 4 5} \rightarrow \mathbf{2 4 8} \rightarrow \mathbf{2 4 7}$ (model compounds) and $\mathbf{2 3 5} \rightarrow \mathbf{2 3 6} \rightarrow \mathbf{2 2 7}$ (Scheme 58) are 1,3-sigmatropic shifts that are forbidden by symmetry. ${ }^{146-148}$ The difference is that the first step is a classical $\mathrm{CH}$ to $\mathrm{C}$ process while the second step is an $\mathrm{NH}$ to $\mathrm{C}$ process and this can modify the barriers to proton transfer. Both processes were calculated and the results are given in Table 7.

Table 7. Energetics (in $\mathrm{kJ} \cdot \mathrm{mol}^{-1}$ ) of the tautomerization between 3- and 2-pyrazolines

\begin{tabular}{cccccc}
\hline Model & $\mathbf{2 4 9}$ & TS & $\mathbf{2 5 0}$ & TS & $\mathbf{2 5 1}$ \\
\hline \multirow{3}{*}{ Scheme 2 } & 60.8 & $355.1[294.3]$ & 63.1 & $330.4[267.3]$ & 0.0 \\
& $\mathbf{2 3 5 a}$ & TS & $\mathbf{2 3 6 a}$ & TS & $\mathbf{2 2 7 a}$ \\
& 57.7 & $343.2[285.5]$ & 57.1 & $346.3[289.2]$ & 0.0 \\
\hline
\end{tabular}

Both two-step profiles are very similar (actually, proportional, $\mathrm{R}^{2}=0.996$ ). Both 3-pyrazolines, 249 and 250, are very similar in energy because the only difference is the position of the para-methyl group; the 2pyrazolines $\mathbf{2 5 1}$ are much more stable than the 3-pyrazolines. The first step, a 3-pyrazoline $\mathbf{2 4 9}$ to another 3pyrazoline 250, has a barrier of $\sim 290 \mathrm{~kJ} \cdot \mathrm{mol}^{-1}$ and the second step, a 3- to 2-pyrazoline, has a slightly lower barrier of $\sim 280 \mathrm{~kJ} \cdot \mathrm{mol}^{-1}$. Therefore, both steps are forbidden and under neutral conditions the 3-pyrazolines should be stable.

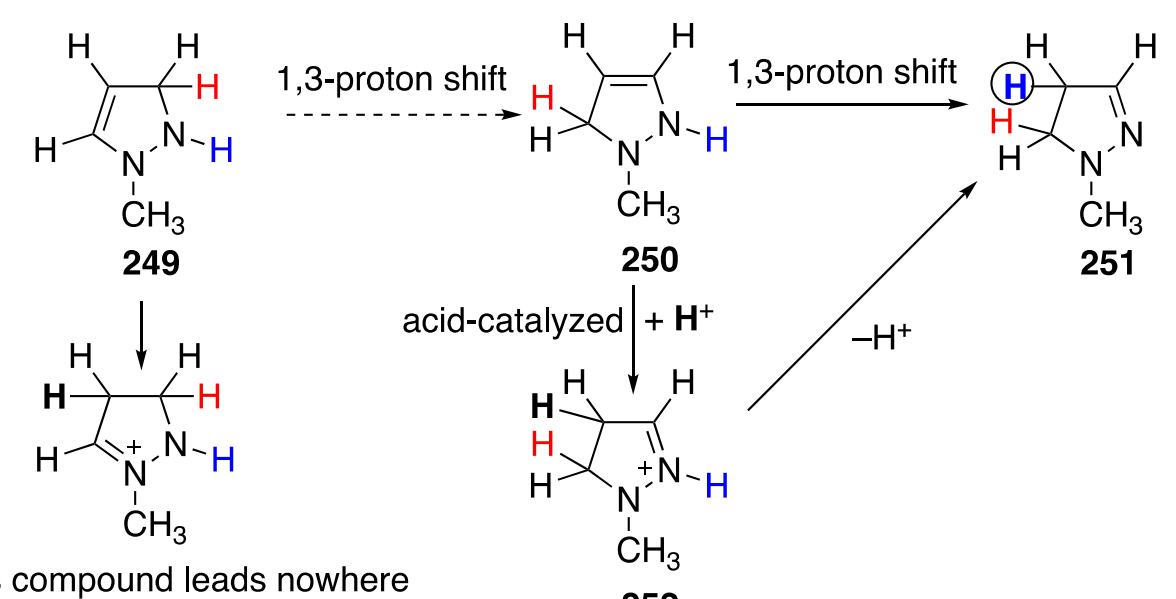

This compound leads nowhere

252

Scheme 59. Isomerization of 3-pyrazolines into 2-pyrazolines (model).

In acid-catalysis conditions, since protonation of 3-pyrazolines affords 2-pyrazolinium cations, ${ }^{153,156,164,186}$ the mechanism through 252 allows the transformation of $\mathbf{2 5 0}$ into 251 (Scheme 59). A series of calculations concerning Swarnkar 3-pyrazolines 29, 30 and $\mathbf{3 3}$ (Scheme 9, $\mathrm{R}=\mathrm{CH}_{3}$ ) ${ }^{39}$ are reported below (Figure 23 and Table 8). 


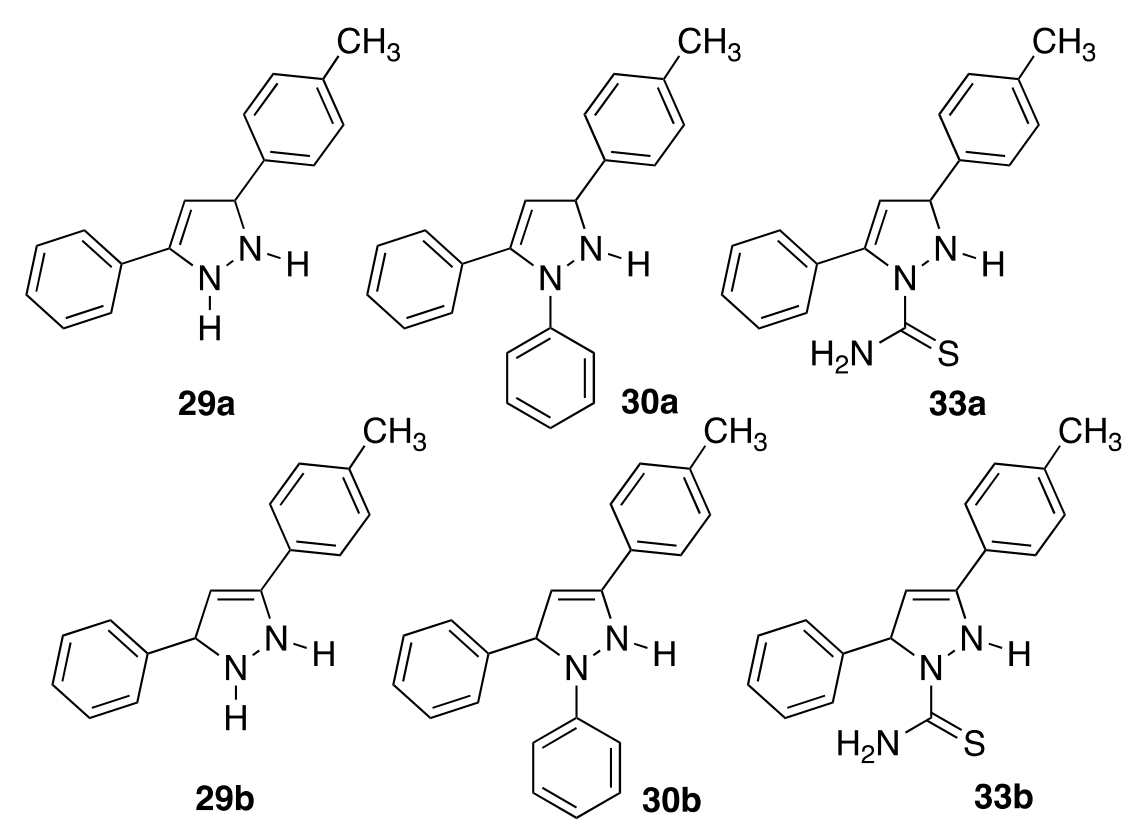

Figure 23. The two kinds of 3-pyrazolines.

Table 8. Energetics (in $\mathrm{kJ} \cdot \mathrm{mol}^{-1}$ ) of the tautomerism between 3-pyrazolines

\begin{tabular}{cccc}
\hline & $\mathbf{a}$ & $\mathbf{b}$ & $\mathbf{c}$ \\
\hline $\mathbf{1 0}$ & 0.6 & 14.6 & 35.8 \\
$\mathbf{1 1}$ & 0.0 & 0.0 & 0.0 \\
\hline
\end{tabular}

The results in Table 8 indicate that - with the exception of the $\mathbf{2 9}$ series, where both isomers have the same energy due to the weak perturbation of the methyl group - in the $\mathbf{3 0}$ and $\mathbf{3 3}$ series tautomer $\mathbf{b}$ is clearly the most stable. However, this does not exclude structure a as a kinetic product in neutral media (see the preceding section)

\section{Biological Properties}

Very few 3-pyrazolines have been reported as having important biological activities, although they have been considered as fragments in protein binding sites. ${ }^{187}$ In the field of anticancer agents (Figure 24) compounds 253 and $\mathbf{2 5 4}$ have received attention in recent years and the most active compound in the $\mathbf{2 5 4}$ series is $\mathbf{2 5 4 a}{ }^{188-190}$

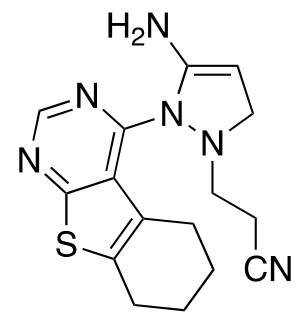

253<smiles>[R]C1=C([R3])N(S(=O)(=O)c2ccccc2)N(Cc2ccccc2)C1c1ccccc1</smiles>

254<smiles>O=S(=O)(c1ccccc1)N1C=C(CO)C(c2ccccc2)N1Cc1ccccc1</smiles>

$254 a$

Figure 24. Anticancer 3-pyrazolines. 
Older but much more widely studied compounds are Lilly's antibiotics (Figure 25). ${ }^{83,191-193}$ The most studied compound is LY $\mathbf{1 8 6 8 2 6}$ and this was prepared by the procedure represented in Scheme 24; the main contributors were Stanovnik, Svete et al. ${ }^{84,194-197}$ Some authors have used the same synthetic procedure and classify these compounds as pyrazolidinones (red part). ${ }^{76}$
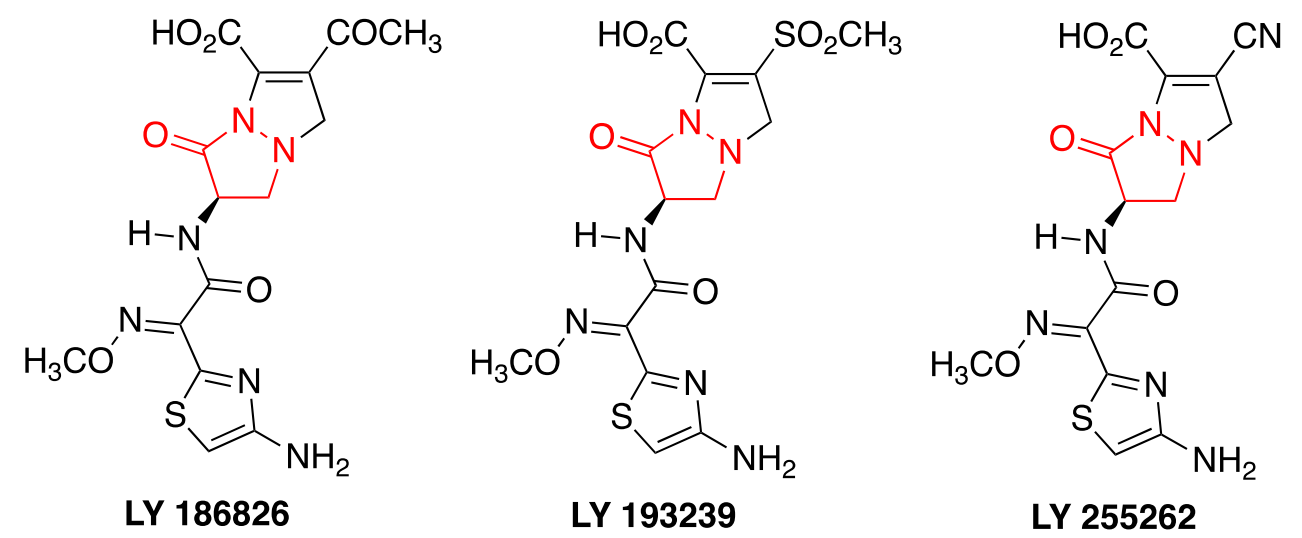

Figure 25. Lilly's antibiotics.

\section{Conclusions}

The main conclusions of the present review are:

1. The synthetic approaches to 3-pyrazolines cover many aspects of heterocyclic chemistry, including hydrazines, hydrazides, [3+2] dipolar cycloadditions, electrocyclic reactions and oxidation-reduction reactions.

2. Structural studies cover the double inversion at nitrogen atoms, tautomerism between different pyrazolines (position of the endo CC double bond) as well as the endo/exo tautomerism. The cations, pyrazolinium salts, resulting from the protonation of 3-pyrazolines also show prototropy.

3. The rich reactivity of 3-pyrazolines covers aspects such as the reactivity of the nitrogen atoms, the CC double bond as a dipolarophile, and rearrangements.

4. UV, IR and NMR results are abundant and have been reported in detail by several groups. Several X-ray structures were used to clarify some structural aspects.

5. Computational results from the literature and those obtained specifically for this review [GIAO/B3LYP/6-311++G(d,p)] proved useful to discuss certain aspects.

6. The scarce but interesting 3-pyrazolines with pharmacological properties are included in this review.

\section{Acknowledgments}

We are grateful to Spanish MICINN for financial support (CTQ2017-84825-R, PGC2018-094644-B-C22) and to Dirección General de Investigación e Innovación de la Comunidad de Madrid (P2018/EMT-4329 AIRTEC-CM).

\section{References}

1. Danion-Bougot, R.; Carrié, R. Compt. Rend. Acad. Sci. 1967, 264, 1141-1143.

2. Fahmy, A. H.; Hassan, K. M.; Khalaf, A. A.; Ahmed, R. A. Indian J. Chem. Sect. B 1987, 26, 884-887.

3. Lepri, L.; Desideri, P. G.; Coas, W. J. Chromatogr. 1985, 322, 163-370. 
https://doi.org/10.1016/S0021-9673(01)97697-6

4. Havrylyuk, D.; Roman, O.; Lesyk, R. Eur. J. Med. Chem. 2016, 113, 145-166.

http://dx.doi.org/10.1016(j.ejmech.2016.02.030

5. Chinnaraja, D.; Rajalakshmi, R.; Latha, V.; Manikandan, H. J. Saudi Chem. Soc. 2016, 20, S599-S605. https://dx.doi.org/10.1016/j.jscs.2013.04.006

6. Bhutani, R.; Pathak, D. P.; Husain, A.; Kapoor, G.; Kant, R. Int. J. Pharm. Sci. Res. 2015, 6, 4113-4128. https://10.13040/IJPSR.0975-8232.6(10).4113-28

7. Hamelin, J.; Carrié, R. Compt. Rend. Acad. Sci. 1965, 261, 5545-5548.

8. Tronchet, J. M. J.; Bourgeois, J. M.; Suard, Y. Helv. Chim. Acta 1972, 55, 2813-2815.

https://doi.org/10.1002/hlca.19720550811

9. Kalsi, P. S.; Gupta, D.; Dhillon, R. S.; Wadia, M. S. Indian J. Chem. Sect. B 1979, 18B, 165-167.

10. Zobova, N. N.; Nazyrova, A. Z.; Litvinov, I. A.; Aganov, A. V.; Naumov, V. A. Zh. Obshch. Khim. 1991, 61, 1453-1461.

11. Tomilov, Y. V.; Shulishov, E. V.; Kostitsyn, A. B.; Nefedov, O. M. Russ. Chem. Bull. 1994, 43, 612-618.

12. López Cara, L. C.; Camacho, M. E.; Carrión, M. D.; Tapias, V.; Gallo, M. A.; Escames, G.; Acuña-Castroviejo, D.; Espinosa, A.; Entrena, A. Eur. J. Med. Chem. 2009, 44, 2655-2666.

https://doi.org/10.1016/j.ejmech.2008.11.013

13. Groom, C. R.; Bruno, I. J.; Lightfoot, M. P.; Ward, S. C. Acta Crystallogr. Sect. B 2016, 72, $171-179$. https://doi.org/10.1107/S2052520616003954

14. Syamala, M. Org. Prep. Proc. Int. 2009, 41, 1-68.

https://doi.org/10.1080/00304940802711218

15. Hinman, R. L.; Ellefson, R. D.; Campbell, R. D. J. Am. Chem. Soc. 1960, 82, 3988-3992. https://doi.org/10.1021/ja01500a048

16. Omar, N. B.; El'tsov, A. V. Zh. Org. Khim. 1968, 4, 726.

17. Aubagnac, J-L.; Elguero, J.; Jacquier, R. Bull. Soc. Chim. Fr. 1969, 3300-3302.

18. Omar, N. B.; El'tsov, A. V. Zh. Org. Khim. 1968, 4, 1294-1299.

19. Elguero, J.; Jacquier, R. Bull. Soc. Chim. Fr. 1969, 2702.

20. Dam, B.; Saha, M.; Jamatia, R.; Pal, A. K. RSC Adv. 2016, 6, 54768.

https://doi.org/10.1039/c6ra06376d

21. Jacquier, R.; Chapelle, J.-P.; Elguero, J.; Tarrago, G. Chem. Commun. 1969, 752.

22. Chapelle, J.-P.; Elguero, J.; Jacquier, R.; Tarrago, G. Bull. Soc. Chim. Fr. 1970, 240-246.

23. Chapelle, J.-P.; Elguero, J.; Jacquier, R.; Tarrago, G. Bull. Soc. Chim. Fr. 1970, 3147-3155.

24. Aubagnac, J. L.; Elguero, J.; Jacquier, R. Bull. Soc. Chim. Fr. 1969, 3306-3316.

25. Jacquier, R.; Pellier, C.; Petrus, C.; Petrus, F. Bull. Soc. Chim. Fr. 1971, 646-650.

26. Coispeau, G.; Elguero, J. Bull. Soc. Chim. Fr. 1970, 2717-2736.

27. Kenny, P. W.; Robinson, M. J. T. Tetrahedron Lett. 1986, 27, 6277-6280.

https://doi.org/10.1016/S0040-4039(00)85452.0

28. Kenny, P. W.; Robinson, M. J. T. Tetrahedron. 1987, 43, 4043-4050.

https://doi.org/10.1016/S0040-4020(01)81687-2

29. Baldwin, J. E. J. Chem. Soc. Chem. Commun. 1976, 734-736. https://doi.org/10.1016/S0040-4020(01)81688-4

30. Gabbutt, C. D.; Hepworth, J. D.; Heron, B. M.; Coles, S. J.; Hurthouse, M. B. J. Chem. Soc. Perkin Trans 1 2000, 2930-2938.

https://doi.org/10.1039/b0041491 
31. Müller, S.; List, B. Synthesis 2010, 13, 2171-2178.

https://doi.org/1055/s-0029-1218792

32. Elguero, J. Bull. Soc. Chim. Fr. 1971, 1925-1932.

33. Usachev, S. V.; Nikiforov, G. A.; Strelenko, Y. A.; Belyakov, P. A.; Chervin, I. I.; Kostyanovsky, R. G. Mendeleev Comm. 2002, 12, 189-192.

http://dx.doi.org/10.1070/MC2002v012n05ABEH0011626

34. Usachev, S. V.; Nikiforov, G. A.; Strelenko, Y. A.; Chervin, I. I.; Lyssenko, K. A.; Kostyanovsky, R. G. Mendeleev Comm. 2003, 13, 136-139.

http://dx.doi.org/10.1070/MC2002v012n05ABEH0011626

35. Al-Mousawi, S. M.; Moustafa, M. S.; Elnagdi, M. H. J. Saudi Chem. Soc. 2011, 15, $309-312$. https://doi.org/10.1016/i.jscs.2011.07.011

36. Komarov, K. V.; Chkanikov, N. D.; Sereda, S. V.; Antipin, M. Yu.; Struchkov, Yu. T.; Kolomiets, A. F.; Fokin, A. V. Proc. USSR Acad. Sci. Chem. Ser. 1988, 2180-2182.

37. Müller, S.; List, B. Angew. Chem. Int. Ed. 2009, 48, 9975-9978.

https://doi.org/10.1002/anie.200905035

38. Swarnkar, D.; Ameta, R.; Vyas, R. Der Pharm. Inno. Int. J. 2014, 3, 5-9.

39. Jetti, S. R.; Kadre, T.; Bjatewara, A.; Jain, S. Pharm. Chem. 2016, 8, 35-45.

40. Kasabe, A. J.; Kasabe, P. J. Int. J. Pharm. Phrmaceutical Sci. 2010, 2, 132-135.

41. Burger, K.; Schikaneder, H.; Hein, F.; Elguero, J. Tetrahedron 1979, 35, 389-395. http://dx.doi.org/10.1016/0040-4020(79)80077-0

42. Burger, K.; Hein, F.; Dengler, O.; Elguero, J. J. Fluor. Chem. 1982, 19, $437-449$. http://dx.doi.org/10.1016/S0022-1139(00)83144-9

43. Anary-Abbasinejad, M.; Shams, N.; Heidari, M. Arkivoc 2012, ix, 13-20.

http://dx.doi.org/10.3998/ark.5550190.0013.902

44. Hashimoto, T.; Takiguchi, Y.; Maruoka, K. J. Am. Chem. Soc. 2013, 135, 11473-11476.

http://dx.doi.org/10.1021/ja405444c

45. Adib, M.; Sayahi, M. H.; Aghaaliakbari, B.; Bijanzadeh, H. R. Tetrahedron 2005, 61, 3963-3966. http://dx.doi.org/10.1016/j.tet.2005.02.050

46. Abbasi, A.; Adib, M.; Erikson, L. Acta Crystallogr. Sect. E 2007, 63, $02115-02116$. http://dx.doi.org/10.1107/S1600536807013773

47. Shaabani, A.; Sepahvand, H.; Nejad, M. K. Tetrahedron Lett. 2016, 57, $1435-1437$. http://dx.doi.org/10.1016/i.tetlet.2016.02.051

48. Cheng, X.; Ma, S. Chem. Commun. 2009, 4263-4265.

http://dx.doi.org/10.1039/b903634b.

49. Nagy, E.; Lepore, S. D. Org. Lett. 2017, 19, 3695-3698.

http://dx.doi.org/10.1021/acs.orglett.7b01401

50. Adib, M.; Koloogani, S. A.; Abbasi, A.; Bijanzadeh, H. R. Synthesis 2007, 3056-3060. http://dx.doi.org/10.1055/s-2007-990775

51. Drew, H. D. K.; Hatt, H. H. J. Chem. Soc. 1937, 16-26.

https://doi.org/10.1039/JR9370000016

52. Le Berre, A.; Godin, J. Comp. Rend. Acad. Sci. 1966, 263C, 297-300.

53. Godin, J.; Le Berre, A. Bull. Soc. Chim. Fr. 1968, 4229-4334.

54. Castle, R. N. Condensed Pyridazines Including Cinnolines and Phthalazines, John Wiley and Sons, New York, 1973. 
55. Sayyafi, M.; Seyyedhamzeh, M.; Khavasi, H. R.; Bazgir, A. Tetrahedron 2008, 64, $2375-2378$. http://dx.doi.org/10.1016/j.tet.2008.01.006

56. Nagarapu, L.; Bantu, R.; Mereyala, H. B. J. Heterocycl. Chem. 2009, 46, $728-731$. http://dx.doi.org/10.1002/jhet.135

57. Khurana, J. M.; Magoo, D. Tetrahedron Lett. 2009, 50, 7300-7303.

http://dx.doi.org/10.1016/j.tetlet.2009.10.032

58. Shanthi, G.; Perumal, P. T. J. Chem. Sci. 2010, 122, 415-421.

59. Lamera, E.; Messaadia, L.; Bouacida, S.; Chibani, A.; Bouchouit, K.; Sahraoui, B.; Bouraiou, A. J. Chem. Sci. 2017, 129, 721-731.

http://dx.doi.org/10.1007/s12039-017-1278-2

60. Lamera, E.; Bouacida, S.; Merazig, H.; Chibani, A.; Le Borgne, M.; Bouaziz, Z.; Bouraiou, A. Z. Naturforsch. 2017, 72b, 361-368.

http://dx.doi.org/10.1515/znb-2016-0262

61. Rego, Y. F.; da Silva, C. M.; da Silva, D. L.; da Silva, J. G.; Ruiz, A. L. T. G.; de Carvalho, J. E.; Fernandes, S. A.; de Fátima, A. Arab. J. Chem. 2019, 12, 4065-4073.

https://doi.org/10.1016/j.arabjc.2016.04.007

62. Martins, F. T.; Maia, L. J. Q.; Gasparotto, G.; Valdo, A. K. S. M.; Neto, J. A. N.; Ribeiro, L.; Rego, Y. F.; da Silva, C. M.; de Fátima, A. New J. Chem. 2019, 43, 1313-1321.

http://dx.doi.org/10.1039/c8nj02976h

63. Bouraiou, A.; Bouacida, S.; Merazig, H.; Chibani, A.; Bouaziz, Z. Acta Crystallogr. Sect. E 2015, 71, 06040605.

http://dx.doi.org/10.1107/S2056989015013894

64. Lamera, E.; Benzerka, S.; Bouraiou, A.; Bouacida, S.; Merazig, H.; Chibani, A.; Le Borgne, M.; Bouaziz, Z. Acta Crystallogr. Sect. E 2015, 71, 01036-01037.

http://dx.doi.org/10.1107/S2056989015023452

65. Xu, Y.-L.; Fu, J.-Y.; Liu, C-H.; Ding, T. RSC Adv. 2017, 7, 38733-38736.

http://dx.doi.org/10.1039/c7ra06856e

66. Tang, B.-Z.; Li, J.-Z-; Zhang, A.-W.; Hao, W.-J.; Tu, S.-J.; Jiang, B. Adv. Synth. Cat. 2019, 361, $3394-3402$. http://dx.doi.org/10.1002/adsc.201900401

67. Gupta, S.; Saluja, P.; Khurana, J. M. Tetrahedron 2019, 72, 3986-3993.

http://dx.doi.org/10.1016/j.tet.2016.05.021

68. Zhang, X.-N.; Li, Y.-X.; Zhang, Z-H. Tetrahedron 2011, 67, 7426-7430.

http://dx.doi.org/10.1016/j.tet.2011.07.002

69. Wang, J.; Bai, X.; Xu, C.; Wang, Y.; Liu, W.; Zou, Y.; Shi, D. Molecules 2012, 17, 8674-8686. http://dx.doi.org/10.3390/molecules17078674

70. Chen, H.; Shi, D.-Q. J. Heterocycl. Chem. 2013, 50, 56-60.

http://dx.doi.org/10.1002/jhet.993

71. Huisgen, R. Proc. Chem. Soc. 1961, 357-369.

72. Huisgen, R.; Fleischmann, R.; Eckell, A. Chem. Ber. 1977, 110, 500-513.

http://dx.doi.org/10.1002/cber.19771100213

73. Khau, V. V.; Martinelli, M. J. Tetrahedron Lett. 1996, 37, 4323-4326.

https://doi.org/10.1016/0040-4039(96)00836-2

74. Nájera, C.; Sansano, J. M.; Yus, M. Org. Biomol. Chem. 2015, 13, 8596-8636. http://dx.doi.org/10.1039/c5ob01086a 
75. Belskaya, N. P.; Bakulev, V. A.; Fan, Z. Chem. Heterocycl. Comp. 2016, 52, $627-636$. http://dx.doi.org/10.1007/s10593-016-1943-2

76. Bren, V. A.; Dubonosov, A. D.; Popova, O. S.; Revinskii, Y. V.; Tikhomirova, K. S.; Minkin, V. I. Int. J. Photoenergy 2018, 9746534.

http://dx.doi.org/10.1155/2018/9746534

77. Hu, H.; Xu, J.; Wang, F.; Dong, S.; Liu, X.; Feng, X. Org. Lett. 2020, 22, 93-97. http://dx.doi.org/10.1021/acs.orglett.9b04007

78. Capretto, D. A.; Brouwer, C.; Poor, C. B.; He, C. Org. Lett. 2011, 13, 5842-5845. http://dx.doi.org/10.1021/ol202452b

79. Dorn, H.; Otto, A. Chem. Ber. 1968, 101, 3287-3301. https://doi.org/10.1002/cber.19681010936

80. Nelina-Nemtseva, J. I.; Gulevskaya, A. V.; Suslonov, V. V.; Misharev, A.D. Tetrahedron 2018, 74, 11011109.

http://dx.doi.org/10.1016/j.tet.2018.01.046

81. Jungheim, L. N.; Sigmund, S. K.; Jones, N. D.; Swartzendruber, J. K. Tetrahedron Lett. 1987, 28, $289-292$. https://doi.org/10.1016/S0040-4039(00)95709-5

82. Jungheim, L. N.; Sigmund, S. K. J. Org. Chem. 1987, 52, 4007-4013. https://doi.org/10.1021/jo00227a013

83. Turk, C.; Svete, J.; Stanovnik, B.; Golič, L.; Golič-Grdadolnik, S.; Golobič, A.; Selič, L. Helv. Chim. Acta 2001, 84, 146-156.

https://doi.org/10.1002/1522-2675(20010131) 84:1<146.aid-hlca146>3.0co2-7

84. Panfil, I.; Urbańczyk-Lipkowska, Z.; Suwińska, K.; Solecka, J.; Chmielewski, M. Tetrahedron 2002, 58, 11991212.

https://doi.org/10.1016/S0040-4020(01)01195-4

85. Shintani, R.; Fu, G. C. J. Am. Chem. Soc. 2003, 125, 10778-10779.

https://doi.org/10.1021/ja036922u

86. Imaizumi, T.; Yamashita, Y.; Kobayashi, S. J. Am. Chem. Soc. 2012, 134, $20049-20052$. https://doi.org/10.1021/ja311150n

87. Yoshimura, K.; Oishi, T.; Yamaguchi, K.; Mizuno, N. Chem. Eur. J. 2011, 17, $3827-3831$. https://doi.org/10.1002/chem.201002793

88. Pozgan, F.; Al Mamari, H.; Groselj, U.; Svete, J.; Stefane, B. Molecules 2018, $23,3$. https://doi.org/10.3390/molecules23010003

89. Naa, R.; Liu, H.; Li, Zh.; Wang, B.; Liu, J.; Wang, M-A.; Wang, M.; Zhong, J.; Guo, H. Tetrahedron 2012, 68, 2349-2356.

https://doi.org/10.1016/j.tet.2012.01.029

90. Hori, M.; Akira Sakakura, A.; Ishihara, K. J. Am. Chem. Soc. 2014, 136, $13198-13201$. https://doi.org/10.1021/ja508441t

91. Vishwanath, M.; Sivamuthuraman, K.; Kesavan, V. Chem. Commun. 2016, 52, $12314-12317$. https://doi.org/10.1039/c6cc05304a

92. Yang, Zh.-W.; Wang, J.-F.; Peng, L.-J.; You, X.-L.; Cui, H.-L. Tetrahedron Lett. 2016, 57, $5219-5222$. https://doi.org/10.1016/i.tetlet.2016.10.030

93. Suárez, A.; Downey, C. W.; Fu, G. C. J. Am. Chem. Soc. 2005, 127, 11244-11245. https://doi.org/10.1021/ja052876h

94. Luo, N.; Zheng, Zh.; Yu, Zh. Org. Lett. 2011, 13, 3384-3387. 
https://doi.org/10.1021/ol201139w

95. Kirar, E. P.; Grošelj, U.; Golobič, A.; Požgan, F.; Pusch, S.; Weber, C.; Andernach, L.; Štefane, B.; Opatz, T.; Svete, J. J. Org. Chem. 2016, 81, 11802-11812.

https://doi.org/10.1021/acs.joc.6b02270

96. Li, F.; Chen, J.; Hou, Y.; Li, Y.; Wu, X.-Y.; Tong, X. Org. Lett. 2015, $17,5376-5379$. https://doi.org/10.1021/acs.orglett.5b02724

97. Mirnik, J.; Kirar, E. P.; Ricko, S.; Grošelj, U.; Golobič, A.; Požgan, F.; Štefane, B.; .; Svete, J. Tetrahedron 2017, 67, 3329-3337.

http://dx.doi.org/10.1016/j.tet.2017.04.050

98. Zhang, M.; Wu, F.; Wang, H.; Wu, J.; Chen. W. Adv. Synth. Catal. 2017, 359, $2768-2772$. https://doi.org/10.1002/adsc.201700387

99. Nelina-Nemtseva, J. I.; Gulevskaya, A. V.; Suslonov, V. V.; Misharev, A. D. Tetrahedron 2018, 74, 11011109.

https://doi.org/10.1016/j.tet.2018.01.046

100. Shi, Y.; Wang, G.; Chen, Zh.; Wu, M.; Wang, J.; Trigoura, L.; Guo, H.; Xing, Y.; Sun, Sh. J. Heterocycl. Chem. 2020, 57, 2044-2047.

https://doi.org/10.1002/jhet.3908

101. Li, Z.; Yu, H.; Zhang, L.; Liu, H.; Na, R.; Bian, Q.; Wang, M.; Guo, H. Lett. Org. Chem. 2014, 11, $220-224$. https://doi.org/10.2174/1570178610666131120003018

102. Liu, J.; Liu, H.; Na, R.; Wang, G.; Li, Z.; Yu, H.; Wang, M.; Zhong, J.; Guo, H. Chem. Lett. 2012, 41, $218-220$. https://doi.org/10.1246/cl.2012.218

103. Na, R.; Jing, C.; Xu, Q.; Jiang, H.; Wu, X.; Shi, J.; Zhong, J.; Wang, M.; Benitez, D.; Tkatchouk, E.; Goddard, W. A.; Guo, H.; Kwon, O. J. Am. Chem. Soc. 2011, 133, 13337-11348.

https://doi.org/10.1021/ja200231v

104. Gallardo-Fuentes, S.; Ormazábal-Toledo, R.; Fernández, I. J. Org. Chem. 2020, 85, 9272-9280. https://doi.org/10.1021/acs.joc.0c01272

105. Morrison, D. C. J. Org. Chem. 1958, 23, 1072-1074.

https://doi.org/10.1021/jo01101a619

106. Brunn, E.; Huisgen, R. Angew. Chem. Int. Ed. 1969, 8, 513-515.

https://doi.org/10.1002/anie.196905131

107. Camp, D.; von Itzstein, M.; Jenkins, I. D. Tetrahedron 2015, 71, 4946-4948.

https://doi.org/10.1016/i.tet.2015.05.099

108. Nair, V.; Mathew, S. C.; Biju, A. T.; Suresh, E. Angew. Chem. Int. Ed. 2007, 46, $2070-2073$. https://doi.org/10.1002/anie.200604025

109. Liu, W.; Khedkar, V.; Baskar, B.; Schürmann, M.; Kumar, K. Angew. Chem. Int. Ed. 2011, 50, 6900-6905. https://doi.org/10.1002/anie.201102440

110. Wang, C.; Chen, Y.; Li, J.; Zhou, L.; Wang, B.; Xiao, Y.; Guo, H. Org. Lett. 2019, $21,7519-7523$. https://doi.org/10.1021/acs.orglett.9b02800

111. Yamazaki, S.; Maenaka, Y.; Fujinami, K.; Mikata, Y. RSC Adv. 2012, 2, 8095-8103. https://doi.org/10.1039/c2ra21249h

112. Huisgen, R.; Gotthardt, H. Chem. Ber. 1968, 101, 839-846.

https://doi.org/10.1002/cber.19681010313

113. Karle, I. L.; Flippen-Anderson, J. L.; Huisgen, R. Acta Crystallogr. Sect. C 1985, 41, $1095-1100$. http://dx.doi.org/10.1107/S0108270185006722 
114. Durst, T.; Finke, J. A.; Huisgen, R.; Temme, R. Helv. Chim. Acta 2000, 83, $2363-2382$. https://doi.org/10.1002/1522-2675(20000906)83:9<2363::AID-HLCA2363>3.0.CO;2-4

115. Finke, J. A.; Huisgen, R.; Temme, R. Helv. Chim. Acta 2000, 83, 3333-3343. http://dx.doi.org/ 10.1002/1522-2675(20001220)83:12<3333::AID-HLCA3333>3.0.CO;2-J

116. Van Beek, W. E.; Weemaes, K.; Herrebout, W. A.; Vande Velde, C. M. L.; Tehrani, K. A. Synlett 2018, 29, 2643-2647.

https://doi.org/10.1055/s-0037-1611041; Art ID: st-2018-k0544-I

117. Basabavaiah, D.; Roy, S. Org. Lett. 2008, 10, 1819-1822. http://dx.doi.org/ 10.1021/ol800424v

118. Selvakumar, K.; Vaithiyanathan, V.; Shanmugam, P. Chem. Commun. 2010, 46, $2826-2828$. https://doi.org/10.1039/b924066g

119. Dürr, H.; Thome, A.; Steiner, U.; Ulrich, T.; Krüger, C.; Raabe, E. J. Chem. Soc. Chem. Commun. 1988, 339340.

https://doi.org/10.1039/C39880000338

120. Elguero, J.; Jacquier, R.; Tizané, D. Bull. Soc. Chim. Fr. 1970, 1121-1129.

121. Wittig, G.; Hutchison, J. J. Liebigs Ann. Chem. 1970, 741, 79-88.

https://doi.org/ 10.1002/jlac.19707410109

122. Baumes, R.; Elguero, J.; Jacquier, R.; Tarrago, G. J. Heterocycl. Chem. 1973, 10, $763-767$. https://doi.org/10.1002/jhet.5570100514

123. Bowman, R. E.; Franklin, C. S. J. Chem. Soc. 1957, 1583-1588.

https://doi.org/ 10.1039/JR9570001583

124. Wagner-Jauregg, T.; Zirngibl, L. Liebigs Ann. Chem. 1963, 668, 30-50.

https://doi.or/10.1002/ jlsc.19636680105

125. Bouchet, P.; Elguero, J.; Jacquier, R. Tetrahedron 1966, 22, 2461-2474.

https://doi.org/ 10.1016/S0040-4020(01)99035-0

126. Wagner-Jauregg, T.; Zirngibl, L. Liebigs Ann. Chem. 1970, 735, 196-197.

https://doi.org/ 10.1002/jlac.19707350123

127. Bird, C. W. Tetrahedron 1965, 21, 2179-2182.

https://doi.org/10.1016/S0040-4020(01)98354-1

128. Bouchet, P.; Elguero, J.; Jacquier, R. Tetrahedron Lett. 1966, 7, 6409-6412. https://doi.org/10.1016/S0040-4039(00)76117-X

129. El'tsov, A. V.; Omar, N. M. Zh. Org. Khim. 1968, 4, 711-716.

130. Timofeeva, Z. N.; Omar, N. M.; Tikhonova, L. S.; El'tsov, A. V. Zh. Obsh. Khim. 1970, 40, 2072-2078.

131. Aubagnac, J. L.; Elguero, J.; Jacquier, R.; Tizané, D. Tetrahedron Lett. 1967, 8, 3705-3708. https://doi.org/10.1016/S0040-4039(01)89777-X

132. Aubagnac, J. L.; Elguero, J.; Gilles, J.-L.. Bull. Soc. Chim. Fr. 1973, 288-291.

133. Alberola, A.; Bañuelos, L. A.; Cuadrado, P.; González, A. M.; Pulido, F. J. Org. Prep. Proc. Int. 1989, 21, 237240.

http://dx.doi.org/10.1080/00304948909356372

134. Cuadrado, P.; González-Nogal, A. M.; Martínez, S. Tetrahedron 1997, 53, 8585-8598.

http://dx.doi.org/10.1016/S0040-4020(97)00514-0

135. Cuadrado, P.; González-Nogal, A. M. Tetrahedron Lett. 1998, 39, 1449-1452.

http://dx.doi.org/ 10.1016/S0040-4039(97)10825-5

136. González-Nogal, A. M.; Calle, M.; Calvo, L. A.; Cuadrado, P.; González-Ortega, A. Eur. J. Org. Chem. 2005, 4663-4669. 
http://dx.doi.org/10.1002/ejoc.200500438

137. González-Nogal, A. M.; Calle, M. Tetrahedron 2009, 65, 5472-5483.

http://dx.doi.org/10.1016/j.tet.2009.01.114

138. Jursic, B. S. J. Heterocycl. Chem. 1998, 35, 811-817.

http://dx.doi.org/10.1002/ jhet.5570350406

139. Bartczak, T. J.; Hodder, O. J. R. Acta Crystallogr. Sect. B 1977, 33, 955-958.

https://doi.org/10.1107/S0567740877005160

140. Veale, Ch. A.; Rheingold, A. L.; Moore, J. A. J. Org. Chem. 1985, 50, $2141-2145$. https://doi.org/10.1021/jo00212a028

141. Largani, T. H.; Imanzadeh, G.; Pesyan, N. N.; Sahin, E.; Shamkhali, A. M.; Notash, B. Mol. Divers. 2018, 22, 37-46.

http://dx.doi.org/10.1007/s11030-017-9784-1

142. Alkorta, I.; Elguero, J. J. Heterocycl. Chem. 2021, 58, 1015-1028.

https://doi.org/10.1002/jhet.4235

143. F. Blanco, D. G. Lloyd, L. M. Azofra, I. Alkorta, J. Elguero, Struct. Chem. 2013, $24,421-432$. http://dx.doi.org/10.1007/s11224-012-0091-2

144. de la Hoz, A.; Alkorta, I.; Elguero, J. submitted to Tetrahedron.

145. Woodward, R. B.; Hoffmann, R. The Conservation of Orbital Symmetry, Verlag Chemie, Academic Press, Weinheim, 1970.

146. Anh, N. T. Les Règles de Woodward-Hoffmann, Ediscience, Paris, 1970.

147. Alkorta, I.; Elguero, J. J. Chem. Soc. Perkin Trans. 2 1998, 2497-2503.

http://dx.doi.org/10.1039/A804086I

148. Elguero, J.; Marzin, C.; Katritzky, A. R.; Linda, P. The Tautomerism of Heterocycles, Academic Press, New York, 1976.

149. Jacquier, R.; Pellier, C.; Petrus, C.; Petrus, F. Bull. Soc. Chim. Fr. 1971, 4078-4084.

150. Elguero, J.; Jacquier, R.; Tarrago, G. Tetrahedron Lett. 1965, 6, 4719-4725. http://dx.doi.org/10.1016/S0040-4039(01)84041-7

151. Teysseyre, J.; Arriau, J.; Dargelos, A.; Elguero, J. J. Chim. Phys. 1975, 72, 303-308.

152. Aubagnac, J. L.; Elguero, J.; Jacquier, R.; Tizané, D. Tetrahedron Lett. 1967, 8, $3709-3712$. https://doi.org/10.1016/S0040-4039(01)89778-1

153. Elguero, J.; Jacquier, R.; Tizané, D. Bull. Soc. Chim. Fr. 1970, 1129-1139.

154. Aubagnac, J. L.; Elguero, J.; Jacquier, R. Bull. Soc. Chim. Fr. 1969, 3316-3326.

155. Elguero, J.; Jacquier, R.; Tizané, D. Tetrahedron 1971, 27, 123-132.

https://doi.org/10.1016/S0040-4020(01)92403-2

156. Chong, J. A.; Wiseman, J. R. J. Am. Chem. Soc. 1972, 94, 8627-8629.

http://dx.doi.org/10.1021/ja00779a081

157. Roach, P.; Warmuth, R. Angew. Chem. Int Ed. 2003, 42, 3039-3042.

http://dx.doi.org/10.1002/anie.200351120

158. Bouchet, P.; Elguero, J.; Jacquier, R. Tetrahedron Lett. 1966, 7, 6409-6412.

http://dx.doi.org/10.1016/S0040-4039(00)76117-X

159. Aspisi, C.; Petrus, C.; Petrus, F. Bull. Soc. Chim. Fr. 1974, 1479-1483.

160. Aulombard, A.; Petrus, C. Bull. Soc. Chim. Fr. 1976, 2059-2062

161. Alkorta, I.; Goya, P.; Elguero, J.; Singh, S. P. Natl. Acad. Sci. Lett. 2007, 30, 139-159.

162. Gibert, J. P.; Petrus, C.; Petrus, F. J. Heterocycl. Chem. 1977, 14, 253-256. 
https://doi.org/10.1002/ihet.5570140218

163. Aubagnac, J.-L.; Elguero, J.; Jacquier, R. Tetrahedron Lett. 1965, 6, 1171-1174.

https://doi.org/10.1016/S0040-4039(01)83992-7

164. Dulou, R.; Elkik, E.; Veillard, A. Bull. Soc. Chim. Fr. 1960, 967-971.

165. Elguero, J.; Marzin, C.; Tizané, D. Org. Magn. Reson. 1969, 1, 249-275.

http://dx.doi.org/10.1002/mrc.1270010310

166. Matter, U. E.; Pascual, C.; Pretsch, E.; Pross, A.; Simon, W.; Sternhell, S. Tetrahedron 1969, $25.2023-2034$. https://doi.org/10.1016/S0040-4020(01)82823-4

167. Allen, F. H. Acta Crystallogr. Sect. B 2002, 58, 380-388.

http://dx.doi.org/10.1107/S0108768102003890

168. Wang, L.; Wang, H. J.; Dong, W. B.; Ge, Q. Y.; Lin, L. Struct. Chem. 2007, 18, 25-31. http://dx.doi.org/10.1007/s11224-006-9114-1

169. Freindorf, M.; Sexton, T.; Kraka, E.; Cremer, D. Theor. Chem. Acc. 2014, $133,1423$. http://dx.doi.org/10.1007/s00214-013-1423-z

170. Alkorta, I.; Elguero, J. J. Chil. Chem. Soc. 2015, 60, 2966-2970.

171. Dadiboyena, S.; Valente, E. J.; Hamme II, A. T. Tetrahedron Lett. 2009, 50, $291-294$. http://dx.doi.org/10.1016/j.tetlet.2008.10.145

172. Dadiboyena, S.; Valente, E. J.; Hamme II, A. T. Tetrahedron Lett. 2014, 55, $2208-2211$. http://dx.doi.org/10.1016/i.tetlet.2014.02.052

173. Begtrup, M. Acta Chem. Scand. 1973, 27, 3101-3110.

http://dx.doi.org/10.3891/acta.chem.scand.27-3101

174. Fong, C. W. Aust. J. Chem. 1980, 33, 1763-1770.

http://doi.org/10.1071/CH9801763

175. Begtrup, M.; Veds $\varnothing$, P.; Cabildo, P.; Claramunt, R. M.; Elguero, J.; Meutermans, W. Magn. Reson. Chem. 1992, 30, 455-459.

http://doi.org/10.1002/mrc.1260300518

176. Begtrup, M.; Boyer, G.; Cabildo, P.; Cativiela, C.; Claramunt, R. M.; García, J. I.; Toiron, C.; Veds $\emptyset$, P. Magn. Reson. Chem. 1993, 31, 107-168.

http://doi.org/10.1002/mrc.1260310202

177. Carrillo, J. R.; Cossío, F. P.; Díaz-Ortíz, A.; Gómez-Escalonilla, M. J.; de la Hoz, A.; Lecea, B.; Moreno, A.; Prieto, P. Tetrahedron 2001, 57, 4179-4187.

http://doi.org/10.1016/S0040-4020(01)00291-5

178. Pérez, P.; Toro-Labbé, A. Theor. Chem. Acc. 2001, 105, 422-430.

http://dx.doi.org/10.1007/s002140000223

179. Kereselidze, J. A.; Zarqua, T. S.; Kikalishvili, T. J.; Churgulia, E. J.; Makaridze, M. C. Russ. Chem. Rev. 2002, 71, 993-1003.

http://dx.doi.org/10.1070/RC2002v071n12ABEH000727

180. Jie, X.; Shang, Y.; Chen, Z. N.; Zhang, X.; Zhuang, W.; Su, W. Nat. Commun. 2018, 9, 5002.

http://dx.doi.org/10.1038/s41467-018-07534-X

181. Semenov, V. A.; Samultsev, D. O.; Rulev, A. Y.; Krivdin, L. B. Magn. Reson. Chem. 2015, 53, 1031-1034. http://dx.doi.org/10.1002/mrc.4296

182. Chapelle, J. P.; Elguero, J.; Jacquier, R.; Tarrago, G. Bull. Soc. Chim. Fr. 1970, 3145-3146.

183. Chapelle, J. P.; Elguero, J.; Jacquier, R.; Tarrago, G. Bull. Soc. Chim. Fr. 1970, 3147-3155.

184. Chapelle, J. P.; Elguero, J.; Jacquier, R.; G Tarrago,. Bull. Soc. Chim. Fr. 1971, 283-286. 
185. Kereselidze, J. A. Chem. Heterocycl. Comp. 1999, 35, 666-670. https://doi.org/10.1007/BF02251623

186. Elguero, J. Claramunt, R. Shindo, M. Y. Mukai, M. Roussel, C. Chemlal, A. Djafri, A. Chem. Scripta 1987, 27, 283-288.

187. Chan, A. W. E.; Laskowski, R. A.; Selwood, D. L. J. Med. Chem. 2010, 53, 3086-3094. http://dx.doi.org/10.1021/jm901696w

188. Mamedova, G.; Mahmudova, A.; Mamedov, S.; Erden, Y.; Taslimi, P.; Tüzün, B.; Tas, R.; Farzaliyev, A.; Aleasel, S. H.; Gulçin, I. Bioorg. Chem. 2019, 93, 103313.

http://dx.doi.org/10.1016/j.bioorg.2019.103313

189. El-Metwally, S. A.; Khalil, A. K.; El-Sayed, W. M. Bioorg. Chem. 2019, 93, 103492. http://dx.doi.org/10.1016/i.bioorg.2019.103492

190. Matiadis, D.; Sagnou, M. Int. J. Mol. Sci. 2020, 21, 5507.

http://dx.doi.org/10.3390/ijms21155507

191. Indelicato, J. M.; Pasini, C. E. J. Med. Chem. 1988, 31, 1227-1230.

https://doi.org/10.1021/jm00401a026

192. Ternansky, R. J.; Draheim, S. E. Tetrahedron Lett. 1990, 20, 2805-2808.

http://dx.doi.org/10.1016/0040-4039(90)80153-D

193. Jungheim, L. N.; Ternansky, R. J. The Chemistry of B-Lactams, Chapter "Non- $\beta$-lactam mimics $\beta$-lactam antibiotics" 1992, 306-324.

194. Svete, J.; Preseren, A.; Stanovnik, B.; Golic, L.; Golic-Grdadolnik, S. J. Heterocycl. Chem. 1997, 34, 13231328.

http://dx.doi.org/10.1002/jhet.5570340438

195. Turk, C.; Golic, L.; Svete, J.; Stanovnik, B. Arkivoc 2001, v, 87-97.

http://dx.doi.org/10.3998/ark.5550190.0002.511

196. Pezdirc, L.; Stanovnik, B.; Svete, J. Z. Naturforsch. 2008, 63b, 375-383.

http://dx.doi.org/10.1515/znb-2008-0404

197. Stanfel, U.; Slapsak, D.; Groselj, U.; Pozgan, F.; Stefane, B.; Svete, J. Molecules 2021, 26, 400.

\section{Authors' Biographies}

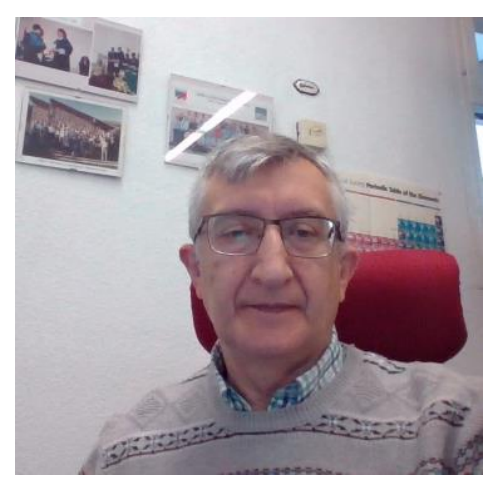

Antonio de la Hoz is Professor of Organic Chemistry in the Universidad de Castilla-La Mancha. His research is focused in microwaves, green chemistry, heterocyclic and materials chemistry 


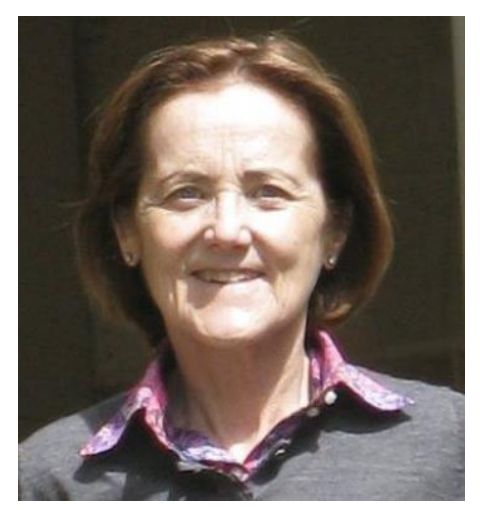

Rosa M. Claramunt is Professor at the Organic and Bio-Organic Chemistry Department of UNED, Madrid. Her main research deals on heterocyclic compounds: synthesis, multifunctional properties and metal complexes, medicinal and supramolecular chemistry, hydrogen bonding and non-covalent interactions, and NMR in solution and solid state.

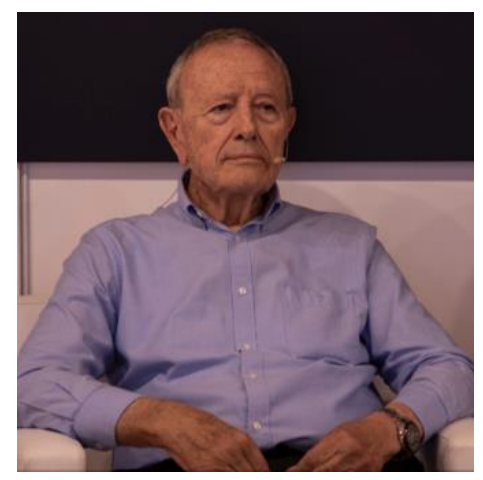

José Elguero is ad honorem Research Professor at the CSIC. His research is focused in structural chemistry, heterocyclic chemistry and NMR spectroscopy

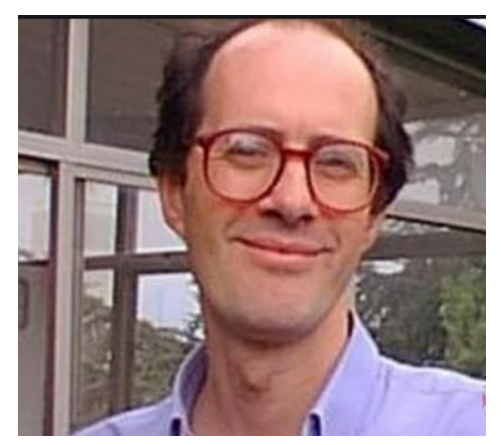

Ibon Alkorta is Research Professor at the Institute of Medicinal Chemistry of the CSIC. His main topics of research is theoretical chemistry and non-covalent interactions. 